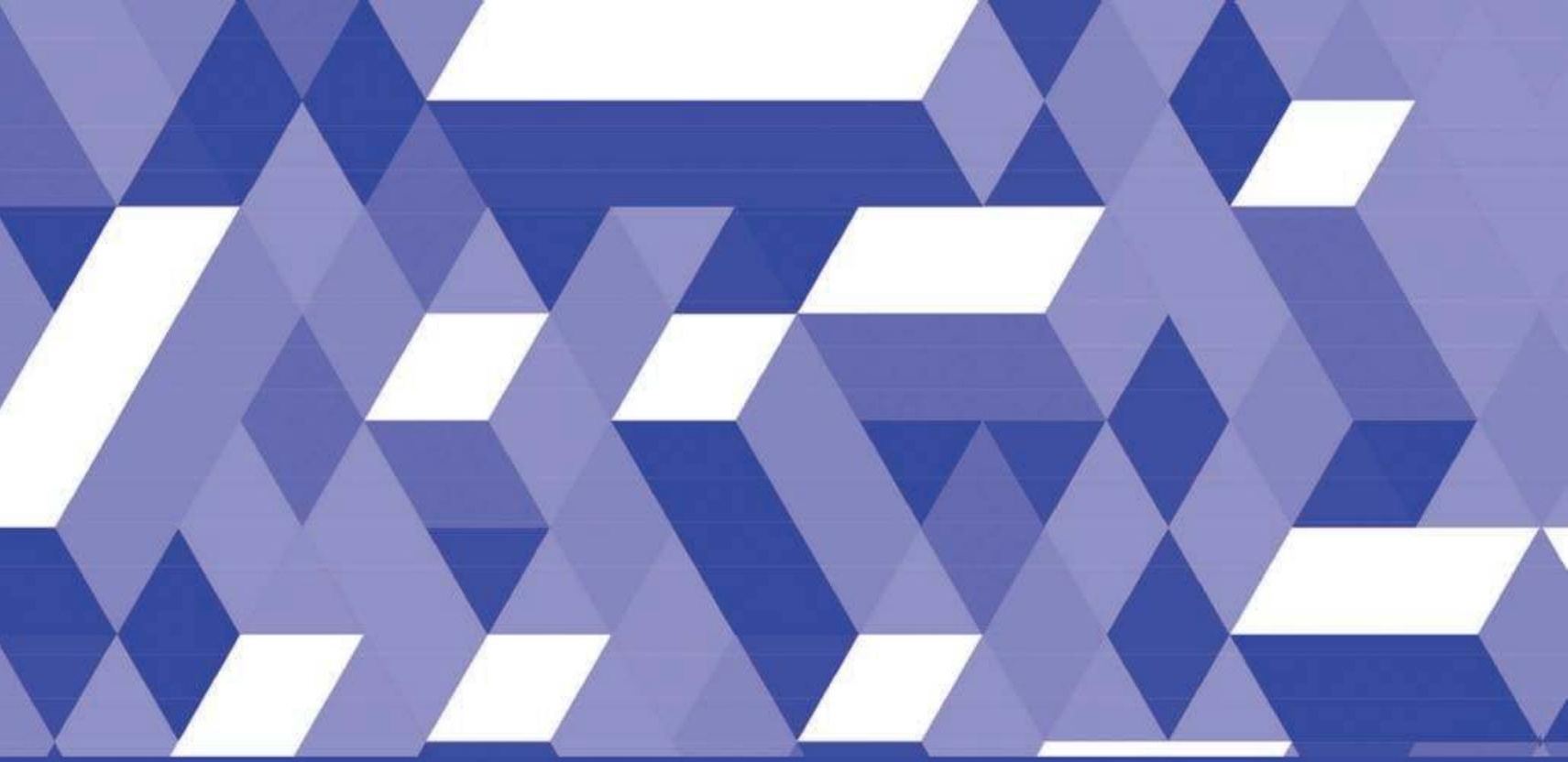

\title{
POLICING ACROSS ORGANISATIONAL BOUNDARIES
} DEVELOPMENTS IN THEORY AND PRACTICE

Edited by

Benoît Dupont, Chad Whelan and Peter K. Manning

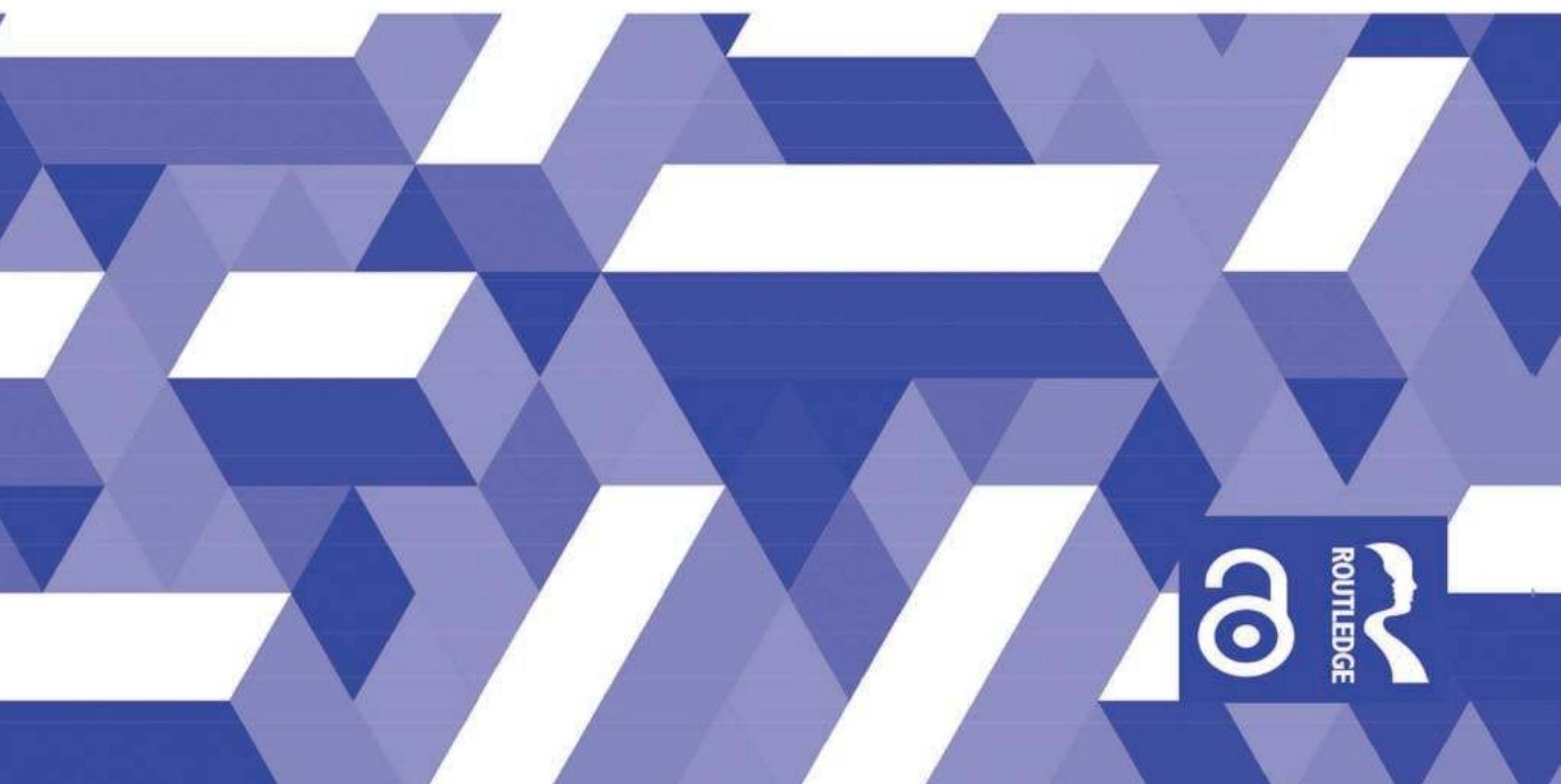




\section{Policing Across Organisational Boundaries}

This book promotes new theoretical frameworks and research questions that seek to advance knowledge of policing across internal and external organisational boundaries, specifically at the structural level of analysis. It addresses police theory, policy and practice, and also provides new directions for future research on intra- and inter-organisational policing.

Analysing boundaries is of increasing global importance for policing policy and practice. Boundaries reflect the division-of-labour inherent to complex organisations and their specialist units. In order to operate effectively, however, these boundaries must be crossed, and strong and reliable linkages must be built. Intra-organisationally, it is vital to understand how specialist units form and function and interact with other units. Inter-organisationally, it is fundamental to recognise the place of boundaries in contexts such as international police cooperation.

This book was originally published as a special issue of Policing and Society. Chapters 3 and 4 are available Open Access at https://www.routledge.com/products/9780367182915.

Benoît Dupont is Professor of Criminology at the Université de Montréal, Canada, where he also holds the Canada Research Chair in Cybersecurity and the Research Chair in the Prevention of Cybercrime.

Chad Whelan is Associate Professor of Criminology at Deakin University, Australia.

Peter K. Manning is Elmer V.H. and Eileen M. Brooks Professor of Criminology and Criminal Justice at Northeastern University, USA. 
$\Leftrightarrow$ Taylor \& Francis Taylor \& Francis Group http://taylorandfrancis.com 


\section{Policing Across Organisational Boundaries \\ Developments in Theory and Practice}

Edited by

Benoît Dupont, Chad Whelan and

Peter K. Manning 
First published 2019

by Routledge

2 Park Square, Milton Park, Abingdon, Oxon, OX14 4RN

and by Routledge

52 Vanderbilt Avenue, New York, NY 10017

Routledge is an imprint of the Taylor \& Francis Group, an informa business

Introduction, Chapters 1-2, 5-6 ๔ 2019 Taylor \& Francis

Chapter 3 @ 2017 James Sheptycki. Originally published as Open Access.

Chapter 4 @ 2017 Adam Crawford and Xavier L'Hoiry. Originally published as Open Access.

With the exception of Chapters 3 and 4, no part of this book may be reprinted or reproduced or utilised in any form or by any electronic, mechanical, or other means, now known or hereafter invented, including photocopying and recording, or in any information storage or retrieval system, without permission in writing from the publishers.

For details on the rights for Chapters 3 and 4, please see the chapters' Open Access footnotes.

Chapters 3 and 4 of this book are available for free in PDF format as Open Access from the individual product page at www.routledge.com. Chapter 3 has been made available under a Creative Commons Attribution-Non Commercial-No Derivatives 4.0 license. Chapter 4 has been made available under a Creative Commons Attribution 4.0 license.

Trademark notice: Product or corporate names may be trademarks or registered trademarks, and are used only for identification and explanation without intent to infringe.

British Library Cataloguing in Publication Data

A catalogue record for this book is available from the British Library

ISBN 13: 978-0-367-18291-5

Typeset in Myriad Pro

by RefineCatch Limited, Bungay, Suffolk

\section{Publisher's Note}

The publisher accepts responsibility for any inconsistencies that may have arisen during the conversion of this book from journal articles to book chapters, namely the inclusion of journal terminology.

\section{Disclaimer}

Every effort has been made to contact copyright holders for their permission to reprint material in this book. The publishers would be grateful to hear from any copyright holder who is not here acknowledged and will undertake to rectify any errors or omissions in future editions of this book. 


\section{Contents}

Citation Information

vii

Notes on Contributors

ix

Introduction - Policing across organisational boundaries: developments in theory and practice

Benoît Dupont, Chad Whelan and Peter K. Manning

1. Implementation fidelity in a loosely coupled system: the challenges of maintaining consistent 'problem theory' and 'programme theory' in a multi-force training pilot

Chris Giacomantonio and Yael Litmanovitz

2. Funnelling through foundations and crime stoppers: how public police create and span inter-organisational boundaries

Randy K. Lippert and Kevin Walby

3. The police intelligence division-of-labour James Sheptycki

4. Boundary crossing: networked policing and emergent 'communities of practice' in safeguarding children Adam Crawford and Xavier L'Hoiry

5. 'It's about using the full sanction catalogue': on boundary negotiations in a multi-agency organised crime investigation

Heidi Fischer Bjelland and Annette Vestby

6. Taking stock of networks across the security field: a review, typology and research agenda

Chad Whelan and Benoît Dupont

Index 
$\Leftrightarrow$ Taylor \& Francis Taylor \& Francis Group http://taylorandfrancis.com 


\section{Citation Information}

The following chapters were originally published in Policing and Society, volume 27, issue 6 (August 2017). When citing this material, please use the original page numbering for each article, as follows:

\section{Chapter 1}

Implementation fidelity in a loosely coupled system: the challenges of maintaining consistent 'problem theory' and 'programme theory' in a multi-force training pilot

Chris Giacomantonio and Yael Litmanovitz

Policing and Society, volume 27, issue 6 (August 2017), pp. 586-601

\section{Chapter 2}

Funnelling through foundations and crime stoppers: how public police create and span inter-organisational boundaries Randy K. Lippert and Kevin Walby

Policing and Society, volume 27, issue 6 (August 2017), pp. 602-619

\section{Chapter 3}

The police intelligence division-of-labour

James Sheptycki

Policing and Society, volume 27, issue 6 (August 2017), pp. 620-635

\section{Chapter 4}

Boundary crossing: networked policing and emergent 'communities of practice' in safeguarding children

Adam Crawford and Xavier L'Hoiry

Policing and Society, volume 27, issue 6 (August 2017), pp. 636-654

\section{Chapter 5}

'It's about using the full sanction catalogue': on boundary negotiations in a multi-agency organised crime investigation Heidi Fischer Bjelland and Annette Vestby Policing and Society, volume 27, issue 6 (August 2017), pp. 655-670 


\section{Chapter 6}

Taking stock of networks across the security field: a review, typology and research agenda Chad Whelan and Benoît Dupont

Policing and Society, volume 27, issue 6 (August 2017), pp. 671-687

For any permission-related enquiries please visit:

http://www.tandfonline.com/page/help/permissions 


\section{Notes on Contributors}

Heidi Fischer Bjelland is a PhD student at the Norwegian Police University College, Norway.

Adam Crawford is Professor of Criminology and Criminal Justice at the Centre for Criminal Justice Studies in the School of Law at the University of Leeds, UK.

Benoît Dupont is Professor of Criminology at the Université de Montréal, Canada, where he also holds the Canada Research Chair in Cybersecurity and the Research Chair in the Prevention of Cybercrime.

Chris Giacomantonio is a Research Coordinator at Halifax Regional Police, Canada.

Xavier L'Hoiry is Lecturer in Criminology and Social Policy in the Department of Sociological Studies at the University of Sheffield, UK.

Randy K. Lippert is a Professor in the Department of Sociology, Anthropology and Criminology at the University of Windsor, Canada.

Yael Litmanovitz is a Postdoctoral Research Fellow at the Institute of Criminology at the Hebrew University of Jerusalem, Israel.

Peter K. Manning is Elmer V.H. and Eileen M. Brooks Professor of Criminology and Criminal Justice at Northeastern University, USA.

James Sheptycki is Professor of Criminology in the Department of Social Science at McLaughlin College at York University, Canada.

Annette Vestby is a Doctoral Researcher at the Norwegian Police University College, Norway.

Kevin Walby is an Associate Professor in the Department of Criminal Justice at the University of Winnipeg, Canada.

Chad Whelan is Associate Professor of Criminology at Deakin University, Australia. 
$\Leftrightarrow$ Taylor \& Francis Taylor \& Francis Group http://taylorandfrancis.com 


\title{
INTRODUCTION
}

\section{Policing across organisational boundaries: developments in theory and practice}

\author{
Benoît Dupont, Chad Whelan and Peter K. Manning
}

This edited collection was originally derived from a special issue of the journal Policing and Society: An International Journal of Research and Policy. The call for papers for that special issue argued that global influences are now at work in modern research and both policy and practice are being shaped by the possibility of exploring intra- and inter-organisational processes as well as the boundaries that frame them. Put simply, a boundary refers to a set of relations that define one group from another (Giacomantonio 2014). Boundaries demarcate one group or organisation from its environment and influence its efficiency, the power it wields, the competence it can claim and its identity (Santos and Eisenhardt 2005). Approaching boundaries at the level of groups or work units, the term is used here to refer to organisational units (intra-organisational policing) and organisations (inter-organisational policing). Intra-organisationally, it means understanding how independent units form and function and, more particularly, interact with other units within police organisations. Inter-organisational policing has been subject of much important research and scholarship in recent years, particularly in the context of international police cooperation (for a recent review, see Schafer 2014). However, much of this work has adopted a higher-level perspective to examine legal and policy questions rather than the dynamics and challenges of police cooperation at the organisational level, which is pursued through direct or indirect organisational ties and/or structures such as multi-agency networks. Policing is now unquestionably shaped and differentiated by processes and forces that are both national and international, local and global. As such, these developments cry out for new perspectives on organisation, theory and practice. The papers presented here meet the challenge of developing new ideas and illuminating them with rich and nuanced data.

Implicit in the call for papers were several ideas that are reflected in the special issue. They raise questions about organisations, about what holds them together, aspects of change and the role of police organisations in larger social networks. Organisations are at once material, symbolic and interactional arenas (Manning 1992). They occupy space, have employees, structures and technologies, establish boundaries and carry out transactions with many other organisations in larger networks of interdependence. These networks provide opportunities for, and impose constraints on, organisations; they may facilitate access to information and knowledge while also restricting the autonomy of individual actors (Kilduff and Tsai 2003). Networks, of course, are also shaped by varying degrees of cooperation and competition as these interdependent actors seek to make sense of and enforce their organisational boundaries. A boundary can be symbolic, or physical but in both occasions, they can generate significant constraints for cooperation (Giacomantonio 2014). In police organisations, there are several internal barriers to communication, including rank, specialisation of units and ecological limits on interaction created by physical distance (including local settings and ecology) (Manning 2010). These barriers are only exacerbated when the focus shifts to external barriers, which may include legal, cultural and technical considerations, as studies of such networks have shown (Brewer 2014; Sheptycki 2004; Whelan 2017; Whelan and Molnar 2018).

The papers here are concerned with symbolic or tacit boundaries, particularly insofar as they shape intra- and inter-organisational cooperation. In the papers, questions are asked about the nature of 'organisation' and 'organisations' and how they operate within and in concert with other organisations. Defining an organisation in both material and symbolic aspects requires, as the papers by Giacomantonio and Litmanovitz, and Lippert and Walby dramatically show, an understanding of what an organisation is and how it constructs its boundaries. Where do specific boundaries lie when police training in several 
organisations is shaped by governmental policy? If police organisations are differentiated internally, as Sheptycki shows in striking detail, what 'holds them together?' He suggests it is a cluster of assumed ideas about 'police work', abstractly described as the 'police métier' (Manning 2010, p. 217). Sheptycki convincingly argues that the loose coupling (Weick 1995) within and among units within the organisation requires tacit assumptions about what is processed and why. Unpacking the internal division-oflabour in relation to police intelligence, Sheptycki puts forward a framework for approaching police organisations based on different types or focal points of intelligence and where they sit within contemporary police organisations. His approach, we suggest, has the potential to influence studies of police organisations for many years to come.

These features of the 'organisational culture' (Ingram et al. 2013; Manning 2007; Whelan 2016) are reflected in the papers by Crawford and L'Hoiry, and Giacomantonio and Litmanovitz, as police at times pursue and other times resist cooperation and collaboration. What holds police together, it seems, also creates or at least reinforces boundaries against information sharing. The paper by Crawford and L'Hoiry suggests that tacit knowledge and assumptions drive interactions and lead to misunderstandings. 'Why do you not see what I assume' is a question that may come to mind from reading their paper. What is described is a dance of misunderstanding about what is the issue and what is being examined. In their paper, the police and the social workers accounted for why they differed, but continued their traditional practices. Crawford and L'Hoiry demonstrate that working across organisational boundaries can and does challenge introspective organisational cultures and foster organisational learning, even if in rather haphazard ways. Interestingly, Giacomantonio and Litmanovitz take as their starting point the position that the police occupational culture, particularly with regard to resistance to change, is perhaps given too much prominence as a reason why police reforms often fail at the expense of not enough attention directed toward the organisational processes essential for designing, implementing and managing change.

Assuming organisations are a coherent idea requires that members have a sense of their role in the organisation and a sense of the purpose of that organisation. Lippert and Walby's analysis of Crime Stoppers and police foundations raises major questions: what is an organisation when it is penetrated by external forces it cannot co-opt (Selznick 1949) yet claims to be free and devoted to the collective will? The authors raise the spectre of 'privatisation' from an entirely new perspective - the embedding of non-public forces and interests within 'public organisations.' It is TVA and the Grassroots (Selznick 1949) yet again. To gain strength of a mandate, the police organisations are attempting to co-opt private organisations that in fact undermine their mandate. In the context of Canada at least, Lippert and Walby's work suggests that Crime Stoppers and police foundations are now deeply embedded in police organisations and use boundary-spanning strategies to obfuscate growing interdependencies.

Giacomantonio and Litmanovitz's review of attempts to revise police training as guided by the United Kingdom's Police College, shows, as have many studies (e.g., Mastrofski and Willis 2010; Willis et al. 2007), that behavioural change does not occur; that the role and character of training is not agreed upon and remains dominated by traditional views about 'the job'; and that sustained change is often unlikely. It also suggests that the occupational culture was not the barrier in the attempt to change training, but that this was instead caused by a failure of implementation. This may be true, but the power of the traditional uniformed segment of policing clearly dominates and may be a significant source of the resistance among officers who delivered and received the training. It may be that the métier (Sheptycki 2017), the assumptions of the job and what it means, and the idea rooted in the claim that the constable's authority is 'original' indicates that efforts to constrain and guide stop and searches (in this research) strike a dagger at the heart of the police role in Anglo-American societies as it is understood.

Fischer Bjelland and Vestby's study of multi-agency action in Norway provides a refreshing insight into collaboration and information-sharing, but also raises questions about the reach of the state and its use of diverse powers to investigate and prosecute certain offences. The paper shows that organisational boundaries are negotiable and can be bridged pragmatically, as mutual benefits can be identified and leveraged across the 'full sanction catalogue', even though it seems these negotiations may lean more in certain directions than others. In their case study, as has been found elsewhere (Bayer 2010; Bigo 2000; Cotter 2017), informal pockets of information sharing developed to connect intelligence systems that were not designed to communicate with each other. In their very perceptive closing remarks, the authors note how this 'ad hoc instrumentalism' challenges existing accountability 
mechanisms and remind us that boundaries have often been designed and implemented on purpose, to prevent governmental overreach.

Finally, Whelan and Dupont's paper seeks to explore the value of the idea of networks and moves away from the idea of police as exceptional and insulated from organisational analysis. In a similar manner to organisational theorists (Salancik 1995), they emphasise the benefits of network research lies in correcting a tendency in police research to focus on the trees rather than the forest, on the activities of individual organisations rather than on the organisation of their activities. On the basis of a comprehensive literature review, Whelan and Dupont assess the current state of the security network literature and argue strongly for the more rigorous use of the network concept. They seek to update an earlier typology designed by one of them (Dupont 2004), arguing that it may be more productive to consider security networks across four functional dimensions: information exchange, knowledgegenerating, problem-solving and coordination. This formulation provides a basis for a future research agenda on security networks that, they argue, would benefit from engaging more systematically with the methodological and theoretical advances found in the broader organisational and public administration literature (e.g., Brass et al. 2004; Provan and Kenis 2008; Provan and Lemaire 2012). In particular, they argue research should move beyond using the network concept as a metaphor to explore the precise ways in which security actors are networked (Brewer 2014; Dupont 2006), the internal properties of security networks, and how they form and function.

Although police organisations are at the centre of this special issue, these six articles situate them as an organisation, not necessarily a unique organisation, but one element in an institutional and social web of actors (Brodeur 2010), working to cooperate with other organisations in ways such as seeking to change training, practices and the delivery of services generally associated with the governance of security (e.g., Johnston and Shearing 2003; Shearing and Johnston 2010; Wood and Dupont 2006; Wood and Shearing 2007). In addition, the shape and boundaries of police organisations are being changed, reshaped and restructured in North America, the United Kingdom and many other jurisdictions beyond. Among the many sources of change are market-based, technological, political factors as well as those internal to police organisations. It is these changes, shaped by global shifts in modern politics as well as routine operations, that the papers bring to our attention.

\section{References}

Bayer, M., 2010. The blue planet: informal international police networks and national intelligence. Washington DC: National Defense Intelligence College.

Bigo, D., 2000. Liaison officers in Europe: new officers in the European security field. In: J. Sheptycki, ed. Issues in transnational policing. London: Routledge, 67-99.

Brass, D., et al., 2004. Taking stock of networks and organizations: a multilevel perspective. Academy of Management Journal, 47 (6), 795-817.

Brewer, R., 2014. Policing the waterfront: networks, partnerships and the governance of port security. Oxford: Oxford University Press.

Brodeur, J.-P., 2010. The policing web. Oxford: Oxford University Press.

Cotter, R. S., 2017. Police intelligence: connecting-the-dots in a network society. Policing and Society, 27 (2), $173-187$.

Dupont, B., 2004. Security in the age of networks. Policing and Society, 14 (1), 76-91.

Dupont, B., 2006. Delivering security through networks: surveying the relational landscape of security managers in an urban setting. Crime, Law and Social Change, 45 (2), 165-84.

Giacomantonio, C., 2014. A typology of police organizational boundaries. Policing and Society, 24 (5), 545-565.

Ingram, J., Paoline, E. A., and Terrill, W., 2013. A multilevel framework for understanding police culture: the role of the workgroup. Criminology, 51 (2), 365-397.

Johnston, L. and Shearing, C., 2003. Governing security: explorations in policing and justice. London: Routledge.

Kilduff, M. and Tsai, W., 2003. Social networks and organizations. London: Sage Publications.

Manning, P. K., 1992. Organizational communication. Hawthorne: Aldine DeGruyter.

Manning, P. K., 2007. A dialectic of organisational and occupational culture. In: M. O'Neill, M. Marks and A. Singh, eds. Police occupational culture: new debates and directions. Amsterdam: Elsevier, 47-83.

Manning, P. K., 2010. Democratic policing in a changing world. Boulder: Paradigm Publishers.

Mastrofski, S.D. and Willis, J.J., 2010. Police organization continuity and change: into the twenty-first century. Crime and Justice, 39 (1), 55-144.

Provan, K. and Kenis, P., 2008. Modes of network governance: structure, management and effectiveness. Journal of Public Administration Research and Theory, 18 (2), 229-252. 
Provan, K. and Kenis, P., 2012. Core concepts and key ideas for understanding public sector organizational networks: using research to inform scholarship and practice. Public Administration Review, 72 (5), 638-648.

Salancik, G., 1995. WANTED: a good theory of organization. Administrative Science Quarterly, 40 (2), 345-349.

Santos, F. M. and Eisenhardt, K. M., 2005. Organizational boundaries and theories of organization. Organization Science, 16 (5), 491-508.

Schafer, J., 2014. International police cooperation. In: B. M. Huebner, ed. Oxford bibliographies in criminology. Oxford: Oxford University Press, DOI: 10.1093/OBO/9780195396607-0153.

Selznick, P., 1949. TVA and the grass roots: a study in the sociology of formal organization. Berkeley: University of California Press.

Shearing, C. and Johnston, L., 2010. Nodal wars and network fallacies: a genealogical analysis of global insecurities. Theoretical Criminology, 14 (4), 1-20.

Sheptycki, J., 2004. Organizational pathologies in police intelligence systems: some contributions to the lexicon of intelligence-led policing. The European Journal of Criminology, 1 (3), 307-332.

Sheptycki, J., 2017. Liquid modernity and the police métier: thinking about information flows in police organisation. Global Crime, 18 (3), 286-302.

Weick, K., 1995. Sensemaking in organizations. Thousand Oaks: SAGE Publications.

Whelan, C., 2016. Organisational culture and cultural change: a network perspective. Australian and New Zealand Journal of Criminology, 49 (4), 583-599.

Whelan. C., 2017. Security networks and occupational culture: understanding culture within and between organisations. Policing and Society, 17 (2), 113-135.

Whelan, C. and Molnar, A., 2018. Securing mega-events: networks, strategies and tensions. London: Palgrave Macmillan.

Willis, J.J., Mastrofski, S.D., and Weisburd, D., 2007. Making sense of COMPSTAT: a theory-based analysis of organizational change in three police departments. Law \& Society Review, 41 (1), 147-188.

Wood, J. and Dupont, B., eds., 2006. Democracy, society, and the governance of security. Cambridge: Cambridge University Press.

Wood, J. and Shearing, C., 2007. Imagining security. Cullompton, UK: Willan Publishing. 


\title{
Implementation fidelity in a loosely coupled system: the challenges of maintaining consistent 'problem theory' and 'programme theory' in a multi-force training pilot
}

\author{
Chris Giacomantonio* and Yael Litmanovitz*
}

\begin{abstract}
This paper considers the organisational and institutional structures involved in the design and delivery of a police training pilot in England in 2015. The training pilot was implemented in six English police forces, and was developed by the College of Policing to improve police use of stop and search powers. Drawing on observations of training sessions and interviews with trainers, trained officers, training designers and national stakeholders in the design process, the paper examines the differences in delivery across forces, and considers key (dis)connections within the communications processes between and within police organisations. The paper examines the institutional and organisational aspects of this attempt to reform police behaviour, and demonstrates the importance of organisational boundary navigation in reform initiatives. This approach challenges predominant conceptualisations of resistant police (sub-)cultures as the main barrier to reform. More specifically, the paper considers clarity in problem theory and programme theory as inherently complex in police training interventions and illuminates the challenges of translating high-level goals into training-room activities. This is particularly the case where multiple forces are involved, each undertaking their own process of translation and interpretation of the training goals and methods. Following an examination of the findings, the implications of these findings for the ways in which police institutions can seek to improve implementation fidelity are explored, as well as the broader challenges for maintaining consistent standards of practice across multiple organisational boundaries.
\end{abstract}

\section{Introduction}

This paper examines institutional pathways relevant to police reform, through evidence from an evaluation of a multi-force training pilot in England (Giacomantonio et al. 2016). This provides an example through which issues of navigating both intra- and inter-organisational boundaries can be illuminated, particularly in relation to the problem of police reform through training and education.

The pilot was intended to change the way in which police officers use their 'stop and search' powers, under which police in England and Wales are able to detain and search citizens whom they suspect are carrying stolen or prohibited articles. Stop and search powers have come under

\footnotetext{
*The authors are equal contributors listed alphabetically. This research was undertaken while Chris Giacomantonio was a senior analyst at RAND Europe.
} 
increasing scrutiny in England and Wales due to disproportionate use against minority communities as well as broader impacts on relationships between police and communities. To improve police practice, the College of Policing, working with the Equality and Human Rights Commission (EHRC), developed a training package to be delivered to randomly selected officers in 5 of the 43 territorial police forces in England and Wales as well as the British Transport Police.

Through this case study of the stop and search reform, the paper seeks to problematise the common conception in literature on policing that the main obstacle to changing police behaviour is a resistant police 'culture' (or sub-cultures) that is inherently closed to change. Instead, working within the wider organisational and institutional literature on policing and reform, the paper puts forth the argument that the institutional configurations in which police reform initiatives occur have substantial explanatory value in understanding why these initiatives face challenges. Understanding the consequences of a specific institutional configuration is therefore essential to overcoming many of the challenges of police reform.

In order to develop this argument, the paper first sets out an alternative three-tiered typology of the problematics inherent in police reform processes. From different levels of analysis, reform may be seen as: (a) a problem of behavioural change: identifying problem behaviours in officers and finding ways to modify those; (b) a problem of navigating internal and external organisational boundaries in a loosely coupled system, particularly the boundaries between those actors who are trying to affect change, and those on whom change is effected; and (c) a problem of institutional change, which requires working within isomorphic constraints on acceptable and expected types of police behaviours and activities. The paper uses these problematics to illustrate the complexities involved in achieving clarity in problem theory and programme theory in police training interventions, and illuminates the challenges of translating high-level goals into training-room activities. Maintaining implementation fidelity (the extent to which a programme is delivered as intended, see for example, Dane and Schneider 1998) is particularly challenging where multiple organisations are involved, each undertaking their own process of translation and interpretation of the training goals and methods.

After setting out these problematics, the paper substantiates these ideas using the findings of the stop and search pilot process evaluation. While this evaluation asked and answered other, focused questions (concerning mostly implementation fidelity), it presented many insights which go past the specific case study. This paper therefore draws on the data which examines the delivery of the training across forces, including observations of training sessions and interviews with trainers, trained officers, training designers and national stakeholders in the design process.

The paper considers key (dis)connections within the communications processes - and the institutional structures that create these (dis)connections - between and within police organisations. The paper examines three levels at which boundaries emerged - between stakeholders at the national level, between the national level designers and the force-level trainers, and between the trainers and the officers receiving the training. It discusses the results of the process evaluation, through which the interconnectedness of the problematics can be better understood - particularly, how behaviour change (the end goal of the intervention) would likely have required better alignment of messages across organisational boundaries and coherence with institutional structures.

Following an examination of the evaluation findings, the implications for the ways in which police institutions can seek to improve implementation fidelity are explored, as well as the broader challenges for maintaining consistent standards of practice across multiple organisational boundaries. The limits of resorting to a 'police culture' explanation when behaviour change interventions fail to achieve the desired results is discussed, as well as the socio-political environment that encourages a cultural over organisational explanation for resistance to change.

\section{The multiple problematics of police reform}

Police organisations today are almost constantly in a state of reform. By most measures, this is a good thing. As police officers and organisations seek an increasingly professional identity, they are 
inherently bound to examine their routine practices, organisational hierarchies and institutional structures to determine how these might be improved. This process of internal examination and enhancement of professional standards is not unique to policing, of course, and is a large part of what allows a body of labourers to call themselves 'professionals' (Walker 1977, Chan et al. 2003).

However, the process of reform in policing is by no means straightforward. Academic literature on policing is full of examples of individual police forces undertaking reform initiatives that experience substantial divergence between intentions and results. Recent UK examples where intentions did not entirely match outcomes include the introduction of body-worn video cameras (Grossmith et al. 2015, Ariel et al. 2016) and the introduction of new 'procedural justice'-based interventions (MacQueen and Bradford 2016) for traffic officers in Scotland.

Part of this is a problem of expectations - as Skogan and Frydll note, 'Police organisations change slowly, even under the best of circumstances' (Skogan and Frydll 2004). It may be inappropriate to expect rapid change in policing practice even where the importance of the reform is widely agreed at all levels of the police organisations involved. Moreover, institutional change is a slow process in all institutionalised organisations (Mastrofski and Willis 2010, Giacomantonio 2015), so the police should not be expected to be an exception to this rule.

In this paper, we consider three types of challenges that are intricately bound up with one another in any effort to change an aspect of the way police conduct their work. From this perspective, a reform may not 'work' where it does not take all (or even some) of these challenges into account in design and implementation efforts.

First, the challenge of police reform is one of behaviour change. While most police reform initiatives actually require changes to individual behaviour, organisational behaviour or often a combination of both, there is little recognition by policy-makers and police chiefs of the immense challenge such endeavours pose. 'More training' is often suggested as a simple solution to what is in reality a complex problem of the interplay between individual officer behaviours and institutional structures, without adequate attention to either the specific organisational context (Mastrofski and Ritti 1996) or the wider needs for institutional change (Reiner 2010). As Mastrofski and Ritti (1996, p. 292) point out, 'regardless of its capacity to achieve any technical objective... a [training] program displays commitment to a goal, and thus legitimates the agency or enterprise', whether or not behaviour change is achieved.

In turn, often there is no coherent programme or logic-model guiding training-based reforms. In their review of effective policing interventions, Skogan and Frydll (2004) highlight the need to meaningfully study successful paths to behaviour change, considering the rather limited available evidence. Training interventions in particular were singled out in their review as an area requiring extensive research, as it was not clear what strategies would support behaviour change. A more recent review also found no evidence-base in the field, demonstrating that a police force's training is usually based on what has been done, or what is believed to work (Neyroud 2011; see also Wheller and Morris 2010), rather than being evidence-led.

Second, the challenge of police reform is a problem of navigating organisational boundaries. The will to change a police organisation rarely arises from within the same group that is the subject of reform efforts. Reform tends to be a top-down affair, with senior management or superordinate political structures deciding that reform needs to take place, and then tasking a group in the middle of the organisation to find ways to get those at the front lines to change in some way. ${ }^{1}$ One way of viewing these boundaries is that each of these groups has a unique and often different (if not necessarily contradictory) 'theory' on the nature of the problem and the best way to solve it (Weiss 1995). This emphasises the need to articulate and define the problem being addressed (the problem theory), and to detail the appropriate steps for addressing that problem (the programme theory) (Fraser et al. 2009). In the context of a training intervention like the one under examination in this paper, the problem theory refers to the sets of individual and collective behaviours police need to change, while the programme theory identifies the components of the training intervention that may bring about that change. ${ }^{2}$ For example, a 'problem' in the field of policing might be victims' 
unwillingness to cooperate with the police (Rosenbaum 1987). One possible 'problem theory' is that officers are insensitive to victims of crime, causing added trauma and resulting in victims 'withdrawing' from future interactions. The adjunct 'programme theory' could be a training intervention that raises officers awareness to the issue, provides knowledge about post-traumatic stress and provides the skills for better, more sensitive interaction with individuals at risk.

The information used to define the problem, design and implement the solution, and measure the results of the reform is unavoidably gathered and communicated between the different levels within the organisation. Such information not only determines whether the reform could succeed - whether the appropriate processes, procedures and structures exist to implement new practice - but also whether and to what degree the reform is seen as legitimate and coherent by the rank and file officers who are being asked to do something differently. This information - which may include 'objective' data such as administrative data on levels or frequencies of certain activities, as well as 'subjective' data such as opinions, perceptions and priorities amongst different levels and stakeholders - will also determine if a reform effort's results are viewed as a success, and by whom.

Third, the challenge of police reform is one of institutional change. Police organisations are not normally, through training or otherwise, able to effect substantial changes to what Manning (2010) refers to as the police metier, that is, the day-to-day ways of working within policing. Organisational leaders have limited ability to change practice not only because of their own organisational limitations (for example related to resources, time and funding pressures, and existing bureaucratic, command and political structures), but also and perhaps more importantly because of the wider institution of which they are part. The institution is not only the organisation, but also the collection of organisations and the accepted norms that go along with those organisations about what police should do and how they should do it.

The organisations of police - from their rank structure and tactical decisions to their attitudes towards the public (and the public's attitude to them) - are all conditioned by wider institutional norms and practices that individual organisations have limited ability to affect. As Crank (2003, pp. 187-188) suggests, police organisations operate on the underlying 'values' of the police 'institutional environment' - a set of 'good faith' assumptions about how policing should be done that are rarely identified or discussed, much less challenged or changed. Radical departures from standard practices - even promising or evidence-based approaches to dealing with a particular criminal or social problem - are treated with suspicion by those within and outside of the profession, and may risk bringing the wider legitimacy of the organisation into question. For example, as Willis et al. (2007) demonstrated in relation to the advent of COMPSTAT, police organisations may push attempts at reform into existing ways of working to minimise organisational disruption, rather than actually change established patterns as reformers intend. Thus, police reform needs to navigate the 'isomorphic' and 'iron cage' (DiMaggio and Powell 1983) aspects of the ways police are expected to act, not only reinforced by their own internal expectations and beliefs but also those of the public and political institutions that rely on police doing business in a certain way (see also Giacomantonio 2015). The problem of police reform is often approached as a problem of overcoming police culture a culture that has developed an 'us-versus-them' mentality towards the public externally and a 'street' versus 'management' cultural divide internally; and a culture that is inter alia 'an obstacle to police accountability ... a reason why police reforms fail.... and a cause of police abuse of authority' (Ingram et al. 2013: 366). As Whelan (2016, p. 587) has argued, police culture is often treated as an 'inherently negative variable' in the analysis of police organisations, and academics often 'overstate the relationship between organisational culture and behaviour'. The concept of police culture as a unitary phenomenon with specific, linear, consistent and predictable effects on police organisations and initiatives has been challenged by a number of authors in the past two decades (Whelan 2016, p. 587; see also Bradford and Quinton 2014). Nonetheless, there remains a general view that many efforts to reform police practice land on a cultural terrain that must be contended with as an obstacle in and of itself. The central positioning of police culture remains evident in the recent US President's 
Task Force on Policing in the twenty-first century (2015, p. 11); it emphasises as its first and foremost recommendation the need for a change in the 'cultural mentality' of police.

In the following sections, we wish to challenge this view. Particularly, we want to examine police reform as a process taking place in a system where multiple factors continuously interact with one another, and relationships between actors and units within and between organisations define the relevant boundaries and barriers to be addressed. While it is possible to see police culture as inherently related to the problem of police reform, we find the term somewhat unhelpful in explaining most of the problems of police reform once the behavioural, organisational and institutional factors are considered.

Theoretically, this builds on the combination of two strands. First, previous work by one of the authors (Giacomantonio 2015) and others (e.g. Mastrofski and Ritti 1996, Maguire 2003, Mastrofski and Willis 2010, Ingram et al. 2013) has sought to examine police activity through an organisational lens, and in particular the consequences and implications of organising police work in certain ways. The second strand is one that positions police training - as a sub-type of police reform - as a complex intervention $^{3}$ in a complex context (Litmanovitz 2016). Once training is not conceptualised as a simple intervention, and the focus shifts away from 'only' the content of a de-contextualised programme, the mediating and moderating factors within the societal and organisational ecology are brought to the fore.

Our approach does not reject the importance of charting the contours of contemporary police (sub-)culture(s) that are capable of impacting police institutional reform efforts (e.g. Loftus 2009), nor does it reject the proposal that culture is an important 'relational' variable in explaining interactions within and between police organisations (Whelan 2016, pp. 584585). Rather, it reorients the gaze of the researcher towards the institutional and organisational structures that inhibit or facilitate reform, independent of the cultural context, and the structural and institutional conditions in which certain aspects of these (sub-)culture(s) are either reinforced or discouraged.

\section{The stop and search training experiment}

In 2014, the College of Policing began developing a pilot training programme to improve practice around the use of stop and search powers by police in England and Wales. The training was developed in collaboration with the EHRC, in response to direction from the Home Office and as part of a wider programme of reform aimed at reducing the negative social impact of stop and search practice. The reforms were aimed largely at reducing the disproportionate effect of stop and search on black and minority ethnic (BME) communities, and the consequent tensions this created between police and those communities.

The training package was developed from 2014 until July 2015, and then implemented in six pilot forces in England from August to October 2015. The training was implemented as a randomised controlled trial (RCT), meaning that in each pilot force a group of 220 'regular' users of stop and search were randomly selected and then subsequently randomly allocated into treatment (receiving training) and control (not receiving training) arms. The training was delivered by force-level trainers. The 'lead' trainers from each force attended a national train-the-trainers event organised by the College of Policing to expose them to the training package. These trainers would then subsequently cascade the training to other trainers in their organisation.

Each treatment group officer attended a one-day training session at their own force. The intended delivery format was of an 8-hour course, with 12 trainees and 2 trainers per session. The exact content of each training session was allowed to vary between forces - the training package was based on a 'guidance' model rather than a 'manual', meaning that while trainers were provided with a suggested approach to the training, an editable slide pack, and a set of optional exercises they could use, trainers were free to modify the training as they felt appropriate and did not have to cover specific material in a set order or for a specified amount of time. 
The guidance indicated training should address 14 related learning objectives through in-class and pre-read activities. These covered the history, purpose, and appropriate and effective uses of stop and search, with an in-class focus on areas including the identification and recording of grounds for a search, the role of conscious and unconscious bias in the decision to conduct a search, and the potential adverse impact a search can have on the individuals involved in the search as well as to wider relations between the police and the public. The guidance also indicated a participatory approach should be used to a great extent, involving substantial discussion and interactive exercises between trainers and trainees. Alongside suggested in-class activities, the training package included a pre-reading booklet and 'knowledge check' test on officers' pre-existing understanding of the law, history and practice surrounding stop and search.

The experiment was designed to measure three areas of police activity: officers' self-reported attitudes and practices relating to stop and search; their 'hit rates' (the proportion of searches resulting in an arrest), and; the quality of recorded grounds (the written justification for search). While these outcomes were not explicitly articulated as the formal 'goals' of the training, improvements in these areas would, presumably, result in fairer and more effective searches, reducing the negative impact of stop and search practice.

To this end, immediately before the training began, in August 2015 the College published guidance for police on how they should define a 'fair and effective' search, as follows:

A stop and search is most likely to be fair and effective when: the search was a justified and lawful use of the power that stands up to public scrutiny; the officer genuinely believes the person has an item in their possession; the member of the public understands why they have been searched and feels that they have been treated with respect; the search was necessary and was the least intrusive method a police officer could use to establish whether a member of the public has a prohibited article or an item for use in crime with them and; more often than not the item is found.

The definition is significant insofar as it states that: an officer should 'genuinely believe' that they will find an item, which is a higher level of certainty than the legal threshold of 'genuine suspicion' as the basis for a search; and that it requires that 'more often than not' an item is found, despite consistent data that even in the highest-performing forces (in terms of hit rate) an item is normally found in fewer than one in five searches (Eastwood et al. 2013). These aspects of the definition created conflict with institutional norms, an issue to which we return below.

The training was evaluated through separate process and impact evaluations commissioned by the College, to inform the subsequent modification and national roll-out of the training package. The process evaluation combined in-class and field observations alongside interviews with officers, trainers and training designers to examine implementation issues and perceptions of the training and provide recommendations for the planned national roll-out of the training to all police forces in England and Wales in late 2016 (see Giacomantonio et al. 2016). The results of the process evaluation are the primary basis for the analysis presented in this paper.

The impact evaluation measured a series of 'primary' outcomes through surveys of treatment and control officers as well as 'secondary' outcomes through analysis of police stop and search data for treatment and control groups (see Miller and Alexandrou 2016). A brief review of the findings will provide useful background for the paper, however a fuller review is outside of the scope of the paper. In summary, the survey results indicate that officers in the treatment group did report some moderate positive changes in knowledge and attitudes, although there were areas where null or negative effects were also reported. However, the training did not appear to have a statistically significant impact on officer behaviour in the field. The quality of grounds recorded, disproportionality of searches and 'hit rate' were not significantly different between treatment and control in the post-treatment phase.

\section{The process evaluation methods}

The process evaluation involved, first, observations of 2 training sessions in each of the 6 pilot forces (12 sessions in total), which employed a structured implementation assessment tool - a matrix for 
recording and coding data from the observations - modified from a previous study conducted by one of the authors on police training in Israel (Litmanovitz and Montgomery 2015). This approach was intended to assess, first, how and how well the training components were delivered and, second, the range of difference between sessions and between forces in terms of content and quality of delivery.

Following the observations, three types of semi-structured interviews were conducted by members of the research team. Eighteen of the trainers were interviewed: 3 from each force, of a total possible sample of 32 across all forces. Of the three in each force, one was the training coordinator or leader and there was an attempt for the others to have been involved in the force-level design process. Thirty treatment group officers were interviewed, 5 from each force, out of a total possible sample of approximately 660 across all forces. Interviews were coordinated by an identified single point of contact in each force, who were asked to identify available officers from neighbourhood, response and specialist roles. Since officers did not have to participate in interviews, this may have introduced a selection bias, as officers who may have felt very negative (or indifferent) about the training might have chosen not to take part. The research team also interviewed six national level stakeholders involved in the conceptualisation and design of the training. We attempted to include stakeholders from the different organisations involved, who played a substantial role at one or more stages of the pilot development process. Interviews were on average 50 minutes each. Audio recordings from interviews were transcribed professionally and divided for thematic coding among the research team.

Alongside the interviews, all trainers and treatment group officers were asked to complete surveys relating to their experiences and perceptions of the training process and content. In the months following the training delivery, the research team also accompanied treatment group officers on-shift, and during these shifts completed 'field' interviews during down-times in the shifts, alongside collecting systematic observational data. This paper focuses primarily on the data collected through the 12 training observations and the 54 total interviews, particularly relating to the stakeholders, trainers and officers' perceptions and experiences of the training.

\section{A loosely coupled system: making sense of the institutional chain}

Maguire (2003, p. 216) argues that police organisations are 'loosely coupled', which among other things means that organisational components are not always rationally or functionally aligned with one another. Similarly, as Crank (2003) notes, loose coupling in policing means that formal structures may not always reflect or predict front-line or unit-level behaviours, and leaves space where officers may be able to behave in contradiction to established policy. This can create efficiencies by allowing individual components adequate autonomy to respond to local conditions without affecting the whole police organisation or wider policing institution. However, this form of coupling can also lead to disconnections across organisational boundaries.

To better understand the kinds of boundaries that need to be navigated to undertake police reform through a training intervention, we will briefly review the institutional components involved in policing in England and Wales that were involved in taking this training package from the conceptual stage to delivery and implementation. As noted above, this training package was developed as a result of direction from the Home Office, funded by the EHRC and developed by the College of Policing with support from the National Police Chiefs Council and the EHRC as well as force-level stakeholders who provided feedback on the draft training package. Following the train-the-trainers session, force leads and trainers were encouraged to tailor the course content to local circumstances and/or cross-reference to other kinds of force-level training or related initiatives (for example, some but not all of the forces had parallel initiatives in place to improve stop and search practice or make improvements in related areas such as addressing unconscious bias). Forces provided data on officers suitable for the pilot, and the randomisation to treatment and control was undertaken by the College at the national level. The College then provided treatment group lists to each force along with 
explanatory text to be sent to each officer who had been selected to participate, and the forces then informed the relevant officers through their internal communication channels that they would be required to attend the training.

Each of these processes required navigating multiple boundaries between organisations, and between units within organisations. Coordination between and within public organisations is an inherently complex process, and not only in police organisations. Different units and sub-units within and between organisations may be able to work coherently together but coherence is not assured in organisational coordination processes, and units are regularly in tension with one another due to partially overlapping, or partially competing, mandates (see e.g. Christensen et al. 2007). Maintaining implementation fidelity throughout this chain therefore faces many opportunities for miscommunication, misinterpretation or complication at each link between components.

\section{Defining a national vision}

In the context of this pilot, the first relevant boundary to be navigated was between the stakeholders at the national level - those multiple organisations involved with the conceptual and practical design of the training package. These stakeholders came from the College of Policing, the National Police Chiefs' Council and the EHRC. Interviews with these stakeholders revealed that, while they tended to agree on the broad goals of the package - which were, in essence, all related to 'raising the bar' on stop and search practices - they had differing perceptions regarding what this meant and how they thought this would be accomplished.

One of the issues, relating to programme theory, was an assessment of the pre-existing knowledge levels of officers on the ground, prior to the reform. For example, one interviewee felt that treatment group officers should not extensively review areas, such as the existing law regarding stop and search powers, which could be assumed knowledge or light-touch 'refresher' content:

Officers [attending the training] generally knew the law and so they didn't need a huge refresh on what their powers were, they pretty much had that. So that was something that could be just simply re-stated. The issues that we know do cause concern and it's disproportionality, so the unconscious bias plays out in many, many areas of policing and policing concern. I think it was right to have a significant focus on [unconscious bias] and that's something that takes a lot of thinking, a lot of self-reflection and as I mentioned, there's perhaps not a great deal of opportunity for officers to do that.

In contrast, another national stakeholder felt that there had been a knowledge- or skills-fade in stop and search practice, as most officers only received training on stop and search powers during their induction as police recruits. For some officers, recruit training was over 20 years earlier, since which time the expectations of practice had changed substantially, as had important components of the law. In this stakeholder's view, this issue warranted devoting some of the course to more in-depth refresher content, to be repeated into the future:

[T] he subject is so important it needs to standalone and that's maybe why we've ended up in a bit of a mess and under so much scrutiny because it's gone off the radar... We've been saying there should be refresher training, it mustn't just be another one-off and then we do nothing for another 10 years because we'll end up in the same position.

A second issue, which could lead to even wider gaps in interpretation, concerns the different theories held by stakeholders as to the nature of the problem. This gap is not simply about how much officers already know, but what is causing the problem situation which has triggered the reform process. The problem theory could be seen to differ between the different stakeholders at the national level and later between them and the training leaders at the force level. Of course, as indicated above, the national stakeholders were by no means a unified body, composed of diverse organisational representatives. While some stakeholders spoke of focused problems another saw an encompassing problem: 
Actually you need to step right back and looking around the whole way at which police are trained.... So unless you are looking at something in the round, it's very hard to tackle an individual issue that pops up. It [stop and search] could be a massive problem which is systemic, and needs more systemic issues to be addressed.

\section{From a national vision to force-level reality?}

The issue of diverging problem theories was also prominent when examining the central disconnects in translation to the force level. While two of the national stakeholders spoke extensively of implicit bias and discrimination as the 'real' problem the reform was meant to address, this very rarely was brought up in interviews by training leaders and trainers at the force level. It is interesting to note that this 'mistranslation' occurred prior to delivery and is evident in the make-up of the training guidance. As one stakeholder who felt that conscious and unconscious bias was a central issue noted, as the training was being developed, the concept of bias became increasingly peripheral:

I don't think it [bias] was well enough embedded, I think it was bolted on where it was evident, and I don't think it was embedded. You see these are the kind of conversations that we had at meetings, in that I would have to be to a degree led by the practitioners that would say 'the way in which officers will understand this is this,' and of course from my perspective I would want to say 'well unless you embed it they're not going to change attitudes, if you bolt it on it will be an add on, and it will be something like a tick box and they won't be able to get it.'

Another aspect of the reform process which brings to light the importance of a unified problem and programme theory is the 'fair and effective search' definition, which was meant to be communicated as part of the training package. The precise role of this definition in augmenting police behaviour was never clearly articulated at the national level, and its proper interpretation raised issues throughout the training process. Additionally, since two of six forces chose not to use the definition as an element of their training package, this represented an issue for intervention fidelity across all pilot forces - and acts as a reminder of the loose coupling in the national policing institution. The possible repercussions of the differential application of the definition were discussed by one of the stakeholders:

Unless you've got a common definition throughout ... to then take out the bits of the package, the guidance, the training that they wish, and leave the bits that they don't want to do, inevitably people will leave out the bits that are hard to do, whether they're costly, or whether they will take a lot of time, or whether they don't get them, or whether they don't think they apply there. That's the risk, that's a big risk.

In trying to explain the reasons behind the limited application of the definition, another stakeholder suggested that the problem was the definition created a standard that was higher than what is found in relevant legislation (in this instance, Code A of the Police and Criminal Evidence Act), which could create confusion:

Again, there is a feeling from some Chief Officers that [the new definition] will confuse officers, they'll be two standards. [For example] the grounds [for a search] will be reasonable in Code A but the guidance will be telling officers you should have genuine belief. Some Chief Officers have said, 'I don't mind having a higher standard than the Guidance.'

A different type of disconnect between the national and force-level is in how the training package was 'handed over' by the national implementation team to the force-level trainers. This relates primarily to the train-the-trainers sessions and the delivery of course content in the form of the guidance-for-trainers documentation. Again, here we find breaks in the chain of activity, where both the initial train-the-trainers session and the content of the guidance did not match expectations with content. It should be noted that this was not the result of a top-down process. In fact, the design process included structures and a time frame to provide advance communication to, and allow feedback from, the force-level trainers and project leads before and after the train-the-trainers session. Despite this, very few trainers understood prior to attending the train-the-trainers session that they were not being given a manual. Most expected that the course was already designed end-to-end, rather than requiring them to interpret and modify a loosely structured book of guidance. This was stated clearly by one force's lead trainer: 
I have to say I was really disappointed with the College of Policing's way of delivering the package. We made sure that we had people available to attend the train-the-trainer event, but that turned out not to be a train-the-trainer event, at all.

This is echoed in the disappointment expressed by a trainer from a different force upon attending the train-the-trainer event:

I went down thinking I was going to a train-the-trainer [event, where I would be told] this is what the package is, this is what the College wants and this is the way you need to deliver it ... I thought we would come out with a ready-made package because that's what the train-the-trainers I have attended in the past have been ...I left there not having learnt anything, it wasn't beneficial at all I felt.

Notably, this disappointment was also experienced by one of the training designers, who connected the issues with the train-the-trainer event with the issues related to the new fair and effective search definition:

To my mind the whole idea of the train-the-trainer event should have been how to deliver this six-hours' worth of classroom learning but it wasn't. It was basically, it was around discussions, there was an awful lot of time taken up discussing the draft definition of a fair and effective stop and search, too much time. In the first event, I think it was nearly an hour spent discussing that and it should have been more about the methodology which you're going to use to deliver this learning, but it wasn't.

This highlights the compounding effect that can occur when multiple communication issues arise within a training intervention - and it is worth keeping in mind that all of the issues identified above have yet to include the actual delivery of the training.

\section{Trying to deliver behaviour change: from trainers to front-line officers}

The next and perhaps most crucial boundary to navigate in this chain was between force project leads and trainers, and the officers receiving the training. As noted above, there were important explicit differences in implementation between forces, for example, some forces included the 'fair and effective' definition while others did not. The balance of time spent on the main learning objectives also differed between sessions. For illustration, Figure 1 is drawn from data collected in the implementation assessment tool during training observations. This figure identifies five key inclass learning objectives, and the amount of time spent on each of these across the 12 observed sessions. The data demonstrate that some activities (particularly those that had a practical-legal dimension, such as understanding reasonable grounds for a search) received substantial in-class attention and discussion, with normally over 15 minutes and often nearly an hour committed to grounds-based exercises and discussion. However, other activities (particularly those relating to recognising and

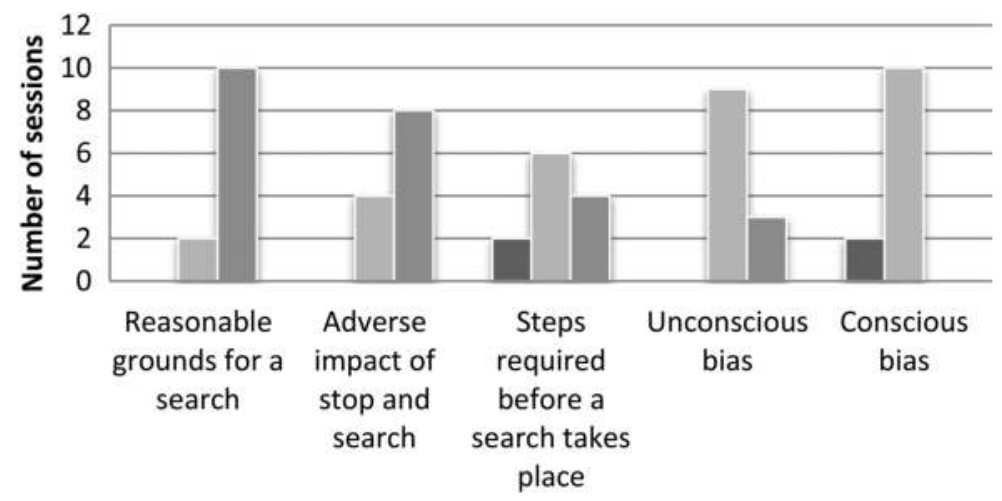

- Not covered

= Less than 15 minutes

- More than 15 minutes

Figure 1. Coverage of selected learning objectives across training sessions $(n=12)$. 
overcoming conscious and unconscious bias) tended to receive more limited attention, and certain learning objectives identified in the guidance were entirely left out of some training sessions.

As well, some forces made much more in-depth use of the preliminary knowledge check to support in-class discussions, while others left the knowledge check as a strictly outside-class activity. To further complicate the intervention, certain forces already had training in place that covered similar ground as the stop and search package - for example, around unconscious bias or communication skills - and others reported having training that was in some ways contradictory to the messaging in the stop and search package. Taken in sum, this means that between different forces officers will have received different training packages. This is not necessarily problematic, and indeed it was desired by designers that each force make necessary adjustments to local needs. However, in this case the differences may have been sufficiently substantial as to damage the 'active ingredients' (Fraser et al. 2009) of the training package - the core issues that training was meant to deal with and change.

Qualitative observations of the training sessions also revealed that even when time was dedicated to core issues such as bias, it is not clear that the delivery methods chosen at a local level were oriented towards behaviour change. As was discussed earlier in the paper, while the evidence regarding 'what works' in training is inconclusive, it is unlikely that the kinds of activities observed would lead to lasting changes in knowledge, attitudes or skills. In particular, in the observed training sessions, there was little if any time dedicated to active learning methods such as simulation or indepth, personalised debriefing of participants to their own responses to exercises. Active, engaging methods are considered an important ingredient in enabling lasting retention of these kinds of skills and competencies (Cook et al. 2011, Davis et al. 1999).

The observational data and interviews with trainers also reveal gaps in the framing of the training between national and local level. While at the 'top' we see a complex view of the problem the training sets out to achieve - despite differences between stakeholders, at the national level there was at least consensus that there was a real problem that led to disproportionate targeting of BME communities and low hit rates - this articulation of the problem theory was often lost at the local level.

While trainers presented the problem theory of the training relatively consistently across forces, it was inconsistent with the message one would have expected based on the national stakeholders' intentions. During training, most of the trainers framed the training as addressing a 'problem' with stop and search that in some way did not apply to those in the room - for example, that it was other forces that were the main problem users of the power; that other officers or officers in the past may have misused it, but that those in the room were not part of that group. In some cases, trainers went so far as to argue that the problem as a whole was overblown and necessary improvements had already been made, making the training essentially moot. ${ }^{4}$

Such messaging was misaligned with the intentions of the training designers (and potentially counterproductive for efforts at behavioural change), and while some trainers (perhaps rightly) suggested that the messaging needed to be somewhat cynical and officer-friendly to avoid raising trainees' defences and shutting down discussion, there is certainly a disconnect between this messaging and the belief at the core of the training that misuse of stop and search remains a real and persistent problem across England and Wales.

The link between trainers, force leads and officers was not only an important link in the classroom - where the main messages of the training were delivered - but also in the force's communications around the training before and after the training sessions. As part of communication prior to the sessions, officers had been sent standard text that had been drafted by the College regarding how they had been selected onto the pilot (which was based on them being a 'regular' user of stop and search powers) and that their assignment to treatment or control groups was done randomly. This messaging, while accurate, was greeted with some scepticism both in interviews and during observations. As one officer stated during an interview: 
In the seven years nearly I've been in the cops, it's surprising how many times l've been selected for these random studies. I wondered whether or not I was selected more based on they've probably accessed stop-searches and because I've searched more, I've been selected. When I was on division, when I was doing the drugs side, yeah I searched a hell of a lot of people. But ... . I don't think it's been random.

Training observations verified that many officers were unclear prior to attending regarding the selection procedure; in an extreme case, one trainer recounted an officer who literally wept with relief upon discovering he was not singled out for being 'problematic'. While the College's communications on this provided accurate information, the findings suggest at minimum that the College's approach did not adequately account for officers' past experiences and recent activities, which resulted in mistrust of the process.

This further highlights the lack of alignment between force-level trainers and national stakeholders regarding the competing problem theories underpinning the training, and the consequent effects of this disconnect on the training that was delivered in class:

\footnotetext{
I have to say I am not quite convinced that the College of Policing is in touch with how police officers are out there. They [police officers] are desperately trying to do the right thing, and do it right, and the problem is that the blurb that came out from the College of Policing already put barriers up to the training. It was about us having to remove those barriers to actually get to the point of the training, which was to look at the fair and effective search.
}

This passage helpfully sums up the communication challenge involved in the training. The national level did not establish a clear and unambiguous purpose of the training in advance of the training commencing. In turn, trainers delivered competing or equivocal messages about the problem theory underpinning the training, and this was compounded by the 'fair and effective' definition, which was out of step with institutional norms and distracted from the goals of reducing bias and improving practice. Trainers resultantly felt they were unable to implement a programme theory to match the problem theory.

This paper has focused on some of the key issues involved with the training delivery. Nonetheless, post-course surveys as well as interviews indicate that despite variability in delivery, the trainers and officers taking the training in all six forces felt generally positive about the training that was delivered. This 'positive-ness' in itself might be said to go against the grain of the 'police cynicism' narrative of 'why reforms fail'. However, as other studies of police training have suggested (e.g. Litmanovitz 2016), positive post-course assessments are not strong predictors of successful outcomes - in this case, actual behavioural or attitudinal changes (see also Webster-Stratton 1990, Bates 2004).

\section{Discussion - implications for police reform across organisational boundaries}

The paper began by setting out three problematics of police reform - at individual/behavioural, organisational and institutional levels. The findings from the process evaluation of the training pilot demonstrate the complexities of establishing and maintaining problem theory and programme theory across these levels, and identify the kinds of boundaries between and within police organisations that need to be navigated to translate from a high-level vision to actual or at least potential behavioural change. The impact evaluation of the pilot (Miller and Alexandrou 2016) suggests that certain attitudes and disposition towards the law around stop and search has had lasting improvement within the treatment group, but there has been no significant difference between the treatment and control groups in terms of officer behaviour in the field. While we need to be careful about attributing causality between the communication disconnections identified in this paper and the limited and null effects identified in the impact evaluation - since in particular we cannot be certain that the establishment of clearer or more consistent programme theory or problem theory would have resulted in actual behaviour change - it seems to us highly likely that more consistent messaging between the organisations involved would have removed friction, mistrust and misalignment where these occurred. ${ }^{5}$ 
Moreover, the findings of the evaluation point to a configuration of organisations and institutions that places boundaries between those tasked with perceiving a problem at the system level, and those tasked with the application of a solution at the front-line level. These boundaries exist outside of, though may also condition, what some have historically seen as a resistant police (sub)culture(s). In particular, within this study, where we encountered resistance to the intention to reform, this was more often than not due to a lack of clarity surrounding the programme or problem theories underpinning the reform than to a belief that the reform itself was unwarranted. We certainly encountered resistance to the idea that stop and search practice needed to be improved, and this training was undertaken in a politically charged context where police use of stop and search was being challenged by a range of reforms, inspections and political statements. This specific context may have also negatively impacted officers' receptivity to engage with the training and reinforced protective (sub-)cultural norms. Nonetheless, from our perspective, the more salient problem was that trainers and front-line officers were often unclear regarding what they were being asked to achieve, and this stemmed from ambiguities throughout all levels of the training design and implementation chain.

This certainly does not discount or disprove the existence of resistance to change in the occupational (sub-)culture(s) of public policing. Particularly, it seems to us that (sub-)cultural explanations may help us understand, for example, why police organisations in different times and places, faced with similar institutional and organisational constraints, are more or less successful with implementing reform or changing behaviour. Certainly, in the context of this pilot, we encountered police services that were more or less inclined to take the need for reform seriously, and a cultural explanation may help us understand why. Nonetheless, an institutional perspective is an essential tool in understanding the slow pace of reform within police organisations, and the institutional challenges that would remain even where (sub-)cultural norms may support reform efforts. What may often masquerade as a resistant police (sub-)culture(s) may in many cases be a resistant police institutional structure. This paper's perspective therefore seems to amplify Reiner's argument that the persistent focus on training as a central mechanism of reform efforts is a way of focusing on individuals, rather than recognising the need for wide (or at least wider) organisational and social transformation (Reiner 2010). This outlook recognises that it is easier to 'problematise' the police officer rather than reform the police institution.

The stop and search training experiment highlighted the complicated terrain through which any attempt at large-scale police reform in England and Wales must pass. Certainly, other countries have different institutional arrangements with different mechanisms to encourage behavioural change and police reform. Nonetheless, the underlying challenges presented by the experiment - maintaining problem theory and programme theory through a loosely coupled institutional system - are relevant to any attempt to implement reform, especially but not limited to multi-organisational reform initiatives. Indeed, large individual police organisations - with substantial institutional distance between the training, administrative and operational arms - may face similar complications along the institutional chain to those faced in multi-organisational activities such as the training pilot under examination here. Moreover, problems relating to specification and realisation of programme goals have been regularly found in studies on piloting in the public sector more generally (Ettelt et al. 2015), so these challenges here are not unique to police and can likely be found in many public organisations.

These findings strengthen the position that piloting of police reform initiatives should be accompanied by rigorous process evaluations which employ a variety of research methods. One

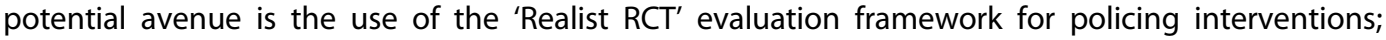
this new synthesis of methodologies has been developed to capture the importance of the ecological and organisational setting and their interactions with an intervention (Bonell et al. 2012). This might be of particular use when working in a multiple context system such as policing. Utilising this methodology to study police reform interventions would help substantiate the arguments of this paper. It 
would enable researchers to examine the role of cultural as opposed to institutional perspectives, and the interplay between them.

More broadly, process evaluations are crucial for allowing the organisation to understand the boundaries that will have to be crossed for the ship of reform to be steered to safety. A predefined role of the process evaluation should be to identify disconnects that did or may occur, as well as the bridges that may be used to overcome them. Looking through the particular disconnects that were uncovered, this case study also serves as a reminder that knowledge transfer - the 'interactive process involving the interchange of knowledge between research users and researcher producers' (Mitton et al. 2007, p. 729) - needs to occur not only between academia and police, but also through the different levels of the organisation. This paper highlights the need to invest in multiple translation processes across systems.

\section{Notes}

1. But see, for example, van Zyl Smit and van der Spuy (2004) for discussion of societal-led reform of the police in South Africa.

2. This was clearly demonstrated in the 'Teens and Toddlers programme' process evaluation, see Jessiman et al. (2012) for a fuller description.

3. An intervention is 'complex' where it has many component parts that are intended to collectively create an effect, and where these parts cannot be easily separated to explain or predict their independent effects (see e.g. Hawe 2015).

4. The opposite of this was also observed, although decidedly less frequently. For example, one of the trainers, who was an experienced officer seconded to the pilot, described situations in which he or colleagues were biased, and stated this was a problem 'for everyone'. An interesting route of future research is to explore if trainers who are in active service are more able to put forward difficult assertions.

5. Incidentally, there are good indications that the lessons learned from the evaluation related to communication are being taken into account for the national roll-out of a modified training package.

\section{Acknowledgements}

This research involved a large team from RAND Europe, the Hebrew University of Jerusalem, the University of Oxford and the College of Policing, including the authors as well as Ben Bradford, Matthew Davies, Tal Jonathan-Zamir, Rory McKenna, Daniel Packham, Paul Quinton, Lucy Strang and Alex Sutherland. The authors are grateful for the contributions of the anonymous peer reviewers and the editors for the special edition. The views expressed in this paper are those of the authors alone and do not necessarily represent the views of the College of Policing or RAND Europe.

\section{Disclosure statement}

No potential conflict of interest was reported by the authors.

\section{Funding}

The research described in this paper was commissioned by, and completed in partnership with, the College of Policing.

\section{References}

Ariel, B. et al., 2016. Wearing body cameras increases assaults against officers and does not reduce police use of force: results from a global multi-site experiment. European journal of criminology, 13 (6), 744-755.

Bates, R., 2004. A critical analysis of evaluation practice: the Kirkpatrick model and the principle of beneficence. Evaluation and program planning, 27 (3), 341-347.

Bonell, C., et al., 2012. Realist randomised controlled trials: a new approach to evaluating complex public health interventions. Social science \& medicine, 75 (12), 2299-2306.

Bradford, B. and Quinton, P., 2014. Self-legitimacy, police culture and support for democratic policing in an English constabulary. British journal of criminology, 54 (6), 1023-1046.

Chan, J.B., et al., 2003. Fair cop: learning the art of policing. Toronto: University of Toronto Press. 
Christensen, T., et al., 2007. Organization theory and the public sector: instrument, culture and myth. New York: Routledge. Cook, D. A., et al., 2011. Technology-enhanced simulation for health professions education: a systematic review and metaanalysis. JAMA, 306 (9), 978-988.

Crank, J.P., 2003. Institutional theory of police: a review of the state of the art. Policing: an international journal of police strategies \& management, 26 (2), 186-207.

Dane, A.V. and Schneider, B.H., 1998. Program integrity in primary and early secondary prevention: are implementation effects out of control? Clinical psychology review, 18 (1), 23-45.

Davis, D., et al., 1999. Impact of formal continuing medical education: do conferences, workshops, rounds, and other traditional continuing education activities change physician behavior or health care outcomes. JAMA, 282 (9), 867-874.

DiMaggio, P. and Powell, W. W., 1983. The iron cage revisited: collective rationality and institutional isomorphism in organizational fields. American sociological review, 48 (2), 147-160.

Eastwood, N., et al., 2013. The numbers in black and white: ethnic disparities in the policing and prosecution of drug offences in England and Wales. London: Release. Available from: http://www.Ise.ac.uk/businessAndConsultancy/LSEConsulting/ pdf/ReleaseReport.pdf [Last accessed on 20 June 2017].

Ettelt, S., Mays, N., and Allen, P., 2015. Policy experiments: investigating effectiveness or confirming direction? Evaluation, 21 (3), 292-307.

Fraser, M.W., et al., 2009. Intervention research: developing social programs. Oxford: Oxford University Press.

Giacomantonio, C., 2015. Policing integration: the sociology of police coordination work. London: Palgrave Macmillan.

Giacomantonio, C., et al., 2016. College of policing stop and search training experiment: process evaluation. Ryton-onDunsmore: College of Policing. Available from: http://whatworks.college.police.uk/Research/Documents/SS_ training_PROCESS_EVALUATION_Final_report.pdf [Last accessed 20 June 2016].

Grossmith, L., et al., 2015. Police, camera, evidence: London's cluster randomised controlled trial of body worn video. London: MOPAC/College of Policing. Available from: http://www.college.police.uk/News/College-news/Documents/ BWV20report20Nov\%202015.pdf [Last accessed 25 October 2016].

Hawe, P., 2015. Lessons from complex interventions to improve health. Annual review of public health, 36, $307-323$.

Ingram, J.R., Paoline, E.A. III, and Terrill, W., 2013. A multilevel framework for understanding police culture: the role of the workgroup. Criminology 51 (2), 365-397.

Jessiman, T., et al., 2012. Teens and Toddlers integrated process evaluation. NatCen Social Research for DfE Research Report DFE-RR212 [online]. Available from: http://lx.iriss.org.uk/sites/default/files/resources/dfe-rr212.pdf [Last accessed 20 June 2017].

Litmanovitz, Y.D., 2016. Moving towards an evidence-base of democratic police training: the development and evaluation of a complex social intervention in the Israeli border police. Unpublished doctoral thesis. University of Oxford, Oxford, UK.

Litmanovitz, Y.D. and Montgomery, P., 2015. On the borders of legitimacy: procedural justice training in the Israeli Border Police. European journal of policing studies, 3 (2), 184-203.

Loftus, B., 2009. Police culture in a changing world. Oxford: Oxford University Press.

MacQueen, S. and Bradford, B., 2016. Where did it all go wrong? Implementation failure - and more - in a field experiment of procedural justice policing. Journal of experimental criminology, 1-25. doi:10.1007/s11292-016-9278-7.

Maguire, E.R., 2003. Organizational structure in American police agencies: Context, complexity and control. Albany, NY: SUNY Press.

Manning, P., 2010. Democratic policing in a changing world. Boulder, CO: Paradigm.

Mastrofski, S.D. and Ritti, R.R., 1996. Police training and the effects of organization on drunk driving enforcement. Justice quarterly, 13(2), 291-320.

Mastrofski, S.D. and Willis, J.J., 2010. Police organization continuity and change: into the twenty-first century. Crime and justice, 39 (1), 55-144.

Mastrofski, S.D., et al., 2007. The challenges of implementing community policing in the United States. Policing: a journal of policy and practice, 1 (2), 223-234.

Miller, J. and Alexandrou, B. 2016. College of policing stop and search training experiment: Impact evaluation. Final report [online]. Ryton-on-Dunsmore: College of Policing. http://whatworks.college.police.uk/Research/Documents/SS_ training_IMPACT_EVALUATION_Final_report.pdf [Last accessed 20 June 2016].

Mitton, C., et al., 2007. Knowledge transfer and exchange: review and synthesis of the literature. Milbank quarterly, 85 (4), 729-768.

Neyroud, P., 2011. Review of police leadership and training. Home Office. Available from: http://www.homeoffice.gov.uk/ publications/consultations/rev-police-leadership-training/ [Last accessed 20 June 2016].

President's Task Force on 21st Century Policing, 2015. The final report of the president's task force on 21st century policing. Washington: Office of Community Oriented Policing Services. Available from: https://cops.usdoj.gov/pdf/taskforce/ TaskForce_FinalReport.pdf [Last accessed 20 June 2016].

Reiner, R., 2010. The politics of the police. 4th ed. Oxford: Oxford University Press.

Rosenbaum, D.P., 1987. Coping with victimization: the effects of police intervention on victims' psychological readjustment. NPPA journal, 33 (4), 502-519.

Skogan, W. and Frydll, K., 2004. Fairness and effectiveness in policing: the evidence. Washington, DC: National Academies Press. 
van Zyl Smit, D. and van der Spuy, E., 2004. Importing criminological ideas in a new democracy: recent South African experiences. Criminal justice and political cultures: national and international dimensions of crime control, 184.

Walker, S., 1977. A critical history of police reform. Lexington, MA: Lexington Books.

Webster-Stratton, C., 1990. Enhancing the effectiveness of self-administered videotape parent training for families with conduct-problem children. Journal of abnormal child psychology, 18 (5), 479-492.

Weiss, C.H., 1995. Nothing as practical as good theory: exploring theory-based evaluation for comprehensive community initiatives for children and families. New approaches to evaluating community initiatives: concepts, methods, and contexts, 1, 65-92.

Whelan, C., 2016. Organisational culture and cultural change: A network perspective. Australian \& New Zealand journal of criminology, 49 (4), 583-599.

Wheller, L. and Morris, J., 2010. Evidence reviews: what works in training, behaviour change and implementing guidance? Bramshill: National Policing Improvement Agency. Available from: http://whatworks.college.police.uk/Research/ Documents/What_Works_in_Training_and_Behaviour_change_REA.pdf [Last accessed 20 June 2016].

Willis, J.J., Mastrofski, S.D. and Weisburd, D., 2007. Making sense of COMPSTAT: a theory-based analysis of organizational change in three police departments. Law \& society review, 41 (1), 147-188. 


\title{
Funnelling through foundations and crime stoppers: how public police create and span inter-organisational boundaries
}

\author{
Randy K. Lippert and Kevin Walby
}

\begin{abstract}
Public police require a reliable supply of resources to operate effectively, and police increasingly seek resources from private organisations and individuals. Since police departments are public bodies, they encounter boundaries in doing so. The key challenge for public police is how to access private resources for initiatives while seeming to avoid real or alleged influence from private entities providing them. This article examines policing across inter-organisational boundaries and boundary negotiation by investigating two kinds of private organisations - police foundations and Crime Stoppers organisations - operating in Canadian jurisdictions, and which reflect significant trends in public police practices. Both organisational models were established by public police in the United States in 1970s, have proliferated, and now commonly operate adjacent to - but not within - North American police departments. Both models, and especially how they connect, create distance from, and otherwise relate to public police, lend insight into how boundaries are maintained, negotiated, and spanned. Implications of these arrangements for future research and the public good are discussed.
\end{abstract}

\section{Introduction}

Public police require a reliable supply of resources to operate effectively. Despite the fact that public police departments in Canada are not facing cut-backs and budget restrictions at levels similar to their counterparts in other Western countries or evident in other government sectors, public police increasingly seek resources from private organisations and individuals (Luscombe et al. forthcoming; Grabosky 2007, Ayling et al. 2009, Ayling 2014). Yet, as public entities, police in Canada encounter and must overcome these organisational boundaries that are shaped by the traditional, legally enshrined distinction between public and private domains assumed in liberal democracies (Lippert and Walby 2016) to do so. The key challenge for public police is to access these privately provided resources to fill identified gaps and for new initiatives while appearing to avoid influence from or 'embeddedness' (Kilduff and Brass 2010) with these donors and sponsors across organisational boundaries. Our interest here is with how public police relate to resource-providing private sponsors, donors, and others. While encountering similar boundary issues, how public police engage with private security firms and agents to achieve their operational goals (Gill 2013; Lippert and O'Connor 2006; Sleiman and Lippert 2010) is not our focus, although such firms are sometimes sponsors, and both sponsorships and public-police-private security relations tend to adopt the similar language of 'partnerships' (Fleming 2005, Prenzler and Sarre 2012). 
What is the level and character of such private resources, and how do police maintain public legitimacy while permitting their flow into operations, thus spanning organisational boundaries? Drawing from empirical research about public police and two types of organisations prevalent in North America - police foundations and Crime Stoppers (CS) - we explore this question in this article. We first elaborate the public-private boundary and its rules before discussing the origins and boundary-related features of these two organisational models. We then empirically document the extent of and shifts in resources provided to Canadian public police; identify differences within these two models as well as the character of their organisational sponsors (or 'partners') and the benefits they receive; and what public police derive from these arrangements. We assess how public police have maintained, negotiated, and spanned boundaries between these entities and themselves while simultaneously managing transgressions of these boundaries. The article concludes by discussing implications of this analysis for the public good as well as prospects for further illuminating enigmatic private funding of public police to ensure better oversight of exchanges across these organisational boundaries.

The public-private boundary is a defining feature and long-standing tradition of liberal democracies. In Canada it is legally established by the Charter of Rights and Freedoms, Canada's constitution, and specifically rights to be free of arbitrary state (i.e. public government) arrest, detention, and search of (private) citizens. More pertinent is the Charter's Section 15, however, that establishes the rule of law: 'Every individual is equal before and under the law and has the right to the equal protection and equal benefit of the law...'. It is the possibility of the rule of law's violation that creates public concern and informs opposition ${ }^{1}$ to crossing the public-private boundary. In the police service context specifically this boundary is further buttressed via enabling legislation (e.g. Ontario's Police Services Act 1990) in each of Canada's provinces that prescribe municipal (public) government responsibilities to fund and oversee public police services including establishment of police boards. These Acts grant authority to municipal police boards to form policies to govern the police service. For example, Section 31(1) (c) of Ontario's Police Services Act states 'a board shall establish policies for the effective management of the police force'. These laws prevent police services from becoming business enterprises or altering their organisational structure too. Such provincial legislation is consistently silent ${ }^{2}$ on private sponsorships, donations, and gifts, but it serves as the legal authority used by police boards to create detailed rules about theses transfers for the police services they oversee. Typical is the Ottawa Police Services Board's (2013) policy that stipulates: 'The Chief shall ensure that any donation, loan or sponsorship accepted by the Police Service is beneficial to the community as a whole and is handled in a transparent manner.' This policy defines sponsorships, donations, and gifts and prescribes how they are to be reported. In addition, '[in] the third year of the business cycle, the Chief shall provide a report on the effectiveness of this Policy by outlining the funds received, scope and nature of them, benefit to the community and public perception' (Ottawa Police Services Board 2013). Thus, rules regarding sponsorships, donations, and gifts from the private realm are created and enforced at the police board or service level drawing on legislative authority. The Canadian police services we studied all have similar rules in place.

Police foundations and CS were established or facilitated by major public police departments in the United States in the 1970s and since the 1980s have spread to Canada. They now commonly operate adjacent to - but not within - many North American police departments. These two organisational models generate resources for police, and can be conceptualised as a move toward corporate forms of police resource generation and management (O'Malley and Hutchinson 2007). The latter arrived as the new managerialism or 'new public management' that insists on more efficient use of police resources (Hoque et al. 2004). This has happened at the same time as the onset of neo-liberal forms of governance that emphasise moving away from state control and resources toward austerity and private market solutions (Lippert and Walby 2016) as well as the rise of community policing (Brogden and Nijhar 2005) with its emphasis on engaging the community in policing through partnerships, though that sometimes simply meant engaging the for-profit private sector rather than 
authentic communities or their representatives. As a result, in Western countries sponsorship of public police by private firms is increasing (Ayling et al. 2009, Ayling 2014, p. 948). While these arrangements are variable they tend to result in increased police attention to or readiness for types of crime or patrols in areas mostly to sponsors' benefit or symbolical benefit by appropriating the legitimacy of the public police (Ayling et al. 2009).

Foundations primarily though not exclusively provide police funding for technology, while CS programs provide police with a constant flow of information about crime. Thus, police foundations fund items such as 'night vision devices' to help police engage in or enhance non-traditional activities 'above and beyond' (VPF 2016a) regular funding and CS provides monies for the cultivation and transfer of actionable information to local police investigators to identify criminal actors and initiate and clear criminal cases. We contend the resources provided by both types of organisations over time have been substantial, with foundations promising to become more significant in the future. We then identify organisational private donors (or 'partners') as primarily private corporations in relation to these two models. In at least two instances in Canada a police foundation has provided funding to a CS program too, and in some CS programs new flows of public funding can be discerned (including grants generated from legal gambling revenues or from provincial or municipal governments in the same jurisdiction), both suggesting an increasingly complex picture of these organisational boundaries in relation to public police and how these are strategically maintained and overcome. Foundations and CS act as 'boundary organisations' (O'Mahony and Bechky 2008, p. 426) that 'can accommodate the varying interests of parties by providing a mechanism that reinforces convergent interests while allowing divergent ones to persists'. Police variably span and transgress these boundaries between these private entities and themselves. This is accomplished in both organisations by permitting current or ex-public police personnel to serve on boards to act as 'boundary spanners' (Williams 2002), and for CS specifically, permitting public police to second CS coordinators from their rolls and to provide virtually free office space in the police department too (arrangements that almost no other private organisations enjoy). Thus these significant personnel and rental expenses normally borne by a private organisation are often covered for CS by police departments. Regarding CS programs, and the affiliation of board members of both foundations and CS programs, we suggest these special arrangements create opportunities for regular police influence on the private organisation's operational priorities that is not severed at the public-private boundary to the benefit of public police, and vice versa. Yet, we argue sometimes this influence, as with 'funnelling' in CS, adopts an undesirable, unruly form that might in the long run be detrimental to public police if it erases or pokes large holes in this boundary.

These findings contribute to theories of organisational boundaries (Giacomantonio 2014, Giacomantonio and Gundhus 2015, Whelan 2016) and of police legitimacy by revealing two established but neglected ways police systematically gain resources in times of public restraint, budget cuts, and calls for greater accountability. These 'strategic alliances' (Gulati and Gargiulo 1999) between police and the corporate world also raise questions about these arrangements in relation to policing for the public good and transparency (Loader and Walker 2007). Finally, this article also makes an empirical contribution to the policing and security literature that has neglected both these organisational models.

\section{Police foundations}

In Canada, police foundations are a new form of organisation. Public police in Canada are traditionally funded by tax dollars, but recently they have established private, seemingly arms-length foundations that can receive large donations and in turn spend the acquired monies on police initiatives. Foundations allow private funds to be channelled indirectly, circumventing established rules described above. Police foundations operate similar to what Jancsics (2017) terms 'domestic shell corporations'. Donations and sponsorships can be filtered through these shell corporations where similar funds passed directly to police would raise questions about corruption, bribery, or biased relations 
(Graycar and Jancsics 2016). Although as official independent charities these entities must disclose some financial information to Canada Revenue Agency (CRA) (the Canadian federal government's tax agency), they are neither treated as public bodies subject to freedom of information (FOI) legislation that would render their operations transparent, nor (depending on the jurisdiction) subject to much public oversight (beyond reporting rudimentary publicly available numbers to CRA). Indeed, in our research we tried to obtain information from police foundations via friendly requests but also through formal FOI requests for disclosures. These foundations either refused to provide the requested information with no explanation or indicated they are private and not subject to FOI requests. When we complained to provincial officials overseeing FOI legislation that the close proximity of police foundations to police departments renders them subject to FOI legislation, our complaints were dismissed. This immunity and private dimension of foundations allows them to act as a go-between for private donors and public police.

Not all police foundations in Canada operate in the same way. There is a bifurcation (Walters 2004) between more philanthropic and corporate models. Some police foundations operate on a model of charity or philanthropy, such as those in London, Winnipeg, Montreal, Waterloo, Hamilton, and to a lesser extent the RCMP Foundation. ${ }^{3}$ These foundations relay funds raised to other charities or social services and rarely seem to benefit police practices directly. They appear to leverage their legitimacy as public police agencies to raise funds mostly for under-funded organisations. Although they function to span boundaries between police and other organisations, we do not examine these more philanthropic police foundations here. There are, however, other police foundations that have adopted a corporate model that raise private funds primarily for public police benefit by procuring equipment or by funding police programs. These are located in Vancouver, Delta, Abbotsford, Edmonton, and Calgary. Whether primarily philanthropic or corporate in character (these categories are not watertight), police departments in Canada desire and are endeavouring to create foundations. For example, at a recent police conference, one author overheard several police conference goers speaking about the desire to establish a police foundation. Saskatoon Police Service, for example, eagerly reported on efforts to create a corporate-style police foundation and are waiting for approval from the provincial-level Saskatchewan Police Commission chair (Tank 2016). Foundations operate as 'convenors' evidenced by their 'attempt to build networks among organizational actors' (Brass et al. 2004, p. 804). To invoke Giacomantonio's (2014, p. 551) research, foundations span the boundary as a bridge between private donors and public police, thus buffering public police from accusations of collusion, bribery, or corruption.

\section{Crime stoppers}

CS is a ubiquitous, long-standing organisation and program operated locally but linked to regional, national, and international umbrella organisations. As a local program CS purports to be 'a partnership of the public, police and media that provides the community with a proactive program for people to assist the police anonymously to solve crimes, thereby contributing to an improved quality of life' (Toronto CS 2016). As with charitable foundations in North America CS programs are overseen by boards. One CS program reports: 'A group of concerned citizen volunteers serve on the Board of Directors' (Toronto CS 2016). Police-supported, media-based, and privately sponsored, CS attempts to mobilise the citizenry to seek out and submit information about crime in the form of a 'tip' in exchange for anonymity and variable cash rewards (Toronto CS 2016). If this information leads to an arrest or seizure of property or illegal drugs, the informant, or 'tipster', is offered this cash reward. Since its inception in the US in 1976 (see below), and fostered by widely touted (e.g. CS International 2016) but somewhat dubious (Lippert 2002; Carriere and Ericson 1989) claims of success, CS has also garnered public legitimacy (Pfuhl 1992). CS is now undoubtedly the most popular crime reduction program in North America and has expanded to at least 30 other countries, including the United Kingdom, Australia, India, the Netherlands, and South Africa. So in addition to the 100 programs in Canada, CS presently claims no less than 
1800 programs globally (Metro Vancouver CS 2016), thus suggesting our findings from Canada have wider relevance.

Central to CS programs is the effort to generate reliable, actionable information about crime for public police investigators. At present CS programs use everything from billboards, to bumper stickers, to You Tube advertisements to promote themselves and distribute contact information. Many CS advertisements appear as the 'Crime of the Week', once deemed the program's promotional heart, entailing rich portrayal across media of an 'unsolved' criminal act for which police investigators require information (Carriere and Ericson 1989; Lippert 2002; Lippert and Wilkinson 2010). CS programs typically advertise a toll free telephone number or 'tip line' to encourage anonymous submission of information to CS where it is then screened and passed to local police investigators for consideration. E-mail, texts, or internet submission are also available. In Ontario, British Columbia, and other Canadian provinces CS programs are now linked to a Canada-wide CS call centre that receives and processes these 'tips' (Toronto CS 2016). Unlike foundations (e.g. VPF 2016a) and because of their promise of anonymity, CS programs actively promote a clear separation from public police.

\section{Previous police foundations and CS research}

Given their proliferation across the US and then into Canada, and their growing significance, it is surprising how rarely police foundations and CS programs have been studied. Previous research on police foundations is especially scant. While there are comparable literatures on charitable foundations (Adloff 2015) and granting foundations (Fernandez and Hager 2014), and while other public bodies such as universities are establishing private foundations, no research considers these arrangements specific to public police; boundaries established between these organisations and police; and broader implications of these arrangements. In Canada, this neglect might be due to fewer foundations of the corporate kind relative to the US. What literature exists on police foundations tends to be practitioner-oriented (Wasserman 2005, Delaney and Carey 2007), as in instructing police management on their merits. Walters (2004) compared 10 police foundations across the US to more conventional philanthropic foundations. Walters argued ethical guidelines and standards should be established to ensure police foundations engage in honest solicitation and application of funds. There is also community, activist oriented literature (e.g. Minnesotans for a Fair Economy 2016) drawing attention to the potential for trading in influence, given that police foundation board members also often hold prominent positions in major corporations that happen to be a foundation's largest corporate donors.

While a US-based national evaluation of CS effectiveness was conducted in the 1980s (Rosenbaum et al. 1989), 40 years after its inception and near global spread, only a few critical, theoretically engaged studies of CS exist (Carriere and Ericson 1989, Pfuhl 1992; Lippert 2002; Lippert and Wilkinson 2010). These draw on concepts ranging from ideology to risk to governance and have surfaced the prevailing neo-liberal logic and symbolic and practical functions of CS consistent with its location at a convergence of police, mass media, and (other) private organisations. Primarily focusing on the type of crime in advertisements, Carriere and Ericson (1989) revealed the narrow range of behaviour that CS defined as criminal (i.e. 'street crime') and argued that it symbolically supported 'law and order' policies of deterrence and incapacitation. Pfuhl (1992) argued that CS encouraged 'snitching' among the public, a practice with a 'prior negative moral meaning' (p. 514) that he claimed was overcome in CS by appealing to localism and self-reliance (Pfuhl 1992, p. 515) among 'tipsters'.

In another study a similar emphasis on 'street crimes' with a property element in CS advertisements was found to respond to needs of mostly private 'partners' such as private insurance and trucking industries in promising to reduce property loss by garnering 'tips' about insurance fraud and cargo theft respectively (Lippert 2002; see also Ontario Association of CS 2016c). Finally, another study of CS advertisements (Lippert and Wilkinson 2010) found issues concerning identification and the 'ratcheting effect' (Harcourt 2007) as it concerned visible minorities when more resources 
(i.e. advertisements) were devoted to this 'higher offending' depicted group. These studies also collectively suggested resources gained through CS are used to respond to a narrow range of crime while neglecting other serious harms. This implies any complete consideration of acquiring resources across these organisational boundaries should also consider to what purposes they are put. We return to this point in the conclusion. More generally, previous work has not explicitly identified the importance of police foundations and CS for the provision of resources for public police much less explored the maintenance and spanning of the public-private boundary separating them.

\section{Research procedures}

Qualitative methods were used for this study. First, charitable status information from the CRA from the last three years were systematically collected and analysed. For this we selected 10 of the largest CS programs and the five corporate police foundations associated with metropolitan areas greater than 100,000 population and with the adjacent police services in those areas. These CS programs are located in Metro Vancouver (including Delta and Abbotsford), Edmonton, Calgary, Winnipeg, Saskatoon, Hamilton, Quebec (called 'Info-Crime'), Toronto, Windsor, and Ottawa and the five police foundations are in Vancouver, Delta, Abbotsford, Calgary, and Edmonton. They were selected based on population and geographical coverage as well as data availability. This charitable information reveals board directors' names only, so to obtain a sense of organisational affiliation of directors in a feasible manner, we searched Internet websites regarding the directors of each of the 15 organisations. Current Canadian CS program and police foundation websites were examined. Newspaper indices were searched for accounts of development of police foundations and CS programs in Canadian cities. We also drew from interviews with two CS coordinators and a foundation board director and sponsor to supplement our findings. ${ }^{4}$ Newsletters and other promotional information about funding initiatives and developments related to foundations and CS programs were also collected and examined.

\section{Police foundations and crime stoppers}

\section{Origins and boundaries}

Both foundations and CS are private, non-profit, registered charitable organisations in Canada, thus establishing clear boundaries between private and public spheres. As registered charitable organisations, these two models are legally required to be institutionally separate from public police. There is no formal link between them. CS programs in particular consistently claim, such as on the Metro Vancouver CS (2016) website in large bold letters: 'We Are Not the Police'. Foundations, in contrast, play up their connection to police to generate donations. For example, the Abbotsford police foundation website prominently reads:

Growing communities like ours face enormous pressures on available resources at the very time they're needed most. The APD cannot directly receive financial contributions; however the Abbotsford Police Foundation is a trusted, practical way for you to support the work of our dedicated officers and enhance public safety in Abbotsford. (Abbotsford Police Foundation 2016)

Both clearly trumpet crime control over other established public police functions such as order-maintenance or community service. For example, one dinner event organised by Abbotsford Police Foundation is called 'Crime is Toast' (APF 2016, VPF 2016a), suggesting that when donors come on board crime is not merely stopped, as in CS, but burned up or obliterated.

While the location of the first police foundation established in the US is difficult to ascertain, the New York City Police Foundation is among the first and seems, based on the claim of a 40-year history (NYCPF 2016), to have commenced in 1976 (the same year as CS). Like CS, the idea of a police foundation of the kind still very active in New York City (NYCPF 2016) spread to Canada in subsequent decades. Based on CRA information the first police foundation was established as a charitable 
organisation in Vancouver in 1995 (though Vancouver Police Foundation claims to have commenced operations in 1976, like the NYCPF noted at the outset). Edmonton Police Foundation was formed in 2000, Delta Police Foundation in 2002, and Abbotsford Police Foundation in 2005. The Calgary Police Foundation was formed in 2010, and received charitable status in 2011. Typical of other police foundations, the Calgary Police Foundation Board of Directors comprises persons from major corporations including Cenovus, Nexen, Shaw, and PricewaterhouseCoopers. Police foundations continue to grow in number and in annual budget, but they are a more recent trend and are much fewer in number compared to CS programs in Canada.

The first Canadian CS program emerged only six years after CS introduction in the US. CS appeared in Calgary, Alberta in 1982 and a few months later in Edmonton, Alberta and it then proliferated across Canada. The well-rehearsed 'company history' of CS locates the organisation's origins in the ingenuity of one police officer in the US:

\footnotetext{
Crime Stoppers was the brainchild of Canadian-born Greg MacAleese, a Detective with the Albuquerque Police Department in New Mexico. In 1976, Greg had run out of leads in a homicide investigation and out of frustration had appealed to the public for assistance. He went so far as to produce the first crime re-enactment, which was aired on local television, and also made available for radio and the press. Anyone providing information regarding this murder was to be eligible for a cash reward. Within hours of the broadcast, an individual called in valuable information that resulted in the arrest and conviction of two suspects who were sentenced to life in prison with no chance of parole. (Toronto CS 2016)
}

This narrative, repeated thousands of times across North America and by CS umbrella organisations (e.g. CS International 2016, Ontario Association of CS 2016a) since 1976 via various media, has remained largely the same over the decades. ${ }^{5}$ The anonymity of 'tipsters' and charitable status of the CS model were established shortly after 1976, and these strategies assist CS operations in generating 'tips' or actionable information for police investigators.

\section{Donations and expenditures}

Below we examine police foundations and CS program donations and expenditures. Our findings suggest the level of resources provided to public police via these two models over time has been substantial. For foundations sometimes this has been in the hundreds of thousands of dollars annually to purchase technology and for CS programs this has led to thousands of actionable 'tips'. Based on current trends, with more coming on board in the 2000s, and if the massive multimillion dollar annual donations to the pioneering Vancouver Police Foundation is exemplary, the foundation model is likely to become a more significant resource provider in the future in Canada and elsewhere (see Tables 1 and 2).

For police foundations we examined charitable donations and expenditures from the five organisations based upon the corporate model for the last three years as reported to the CRA. In 2015, total fundraising revenue for Vancouver Police Foundation was $\$ 8,198,426$, with over $\$ 7$ million in donations, with total expenses of $\$ 1,147,417$. A primary Vancouver Police Foundation donee was the Vancouver Police Department, which received $\$ 258,725$. What happens with excess revenue is not explained. These figures were up from total revenue of $\$ 3$ million in 2014, a year in which total expenses were $\$ 1,574,498$ and total donations were just over $\$ 1$ million. The total amount of gifts to Vancouver Police Department (the primary donee) in 2014 was $\$ 290,668$. In 2013, total revenue was $\$ 1,085,733$, with $\$ 816,151$ in donations, and $\$ 647,902$ in expenses. Vancouver Police Department (VPD) (the primary donee) received $\$ 226,841$. In 2012, the foundation bestowed $\$ 593,255$ to VPD, and in 2011 the figure VPD received from the foundation was $\$ 435,898$. What these figures demonstrate is an upward trend in the number and amount of donations foundations receive, and that the public police are often the primary donee. The trend is similar with other foundations. In 2014, total fundraising revenue for Calgary Police Foundation was $\$ 2,502,442$, with over $\$ 2$ million in donations, with total expenses sitting at $\$ 1,788,385$. Calgary Police Service received $\$ 400,000$. Compare this to 2012 , when total fundraising revenue for Calgary Police Foundation 
Table 1. Selected Crime Stoppers programs in Canada.

\begin{tabular}{|c|c|c|c|}
\hline Crime Stoppers program & $\begin{array}{c}\text { Year } \\
\text { established }\end{array}$ & $\begin{array}{l}\text { Total directors } \\
\text { (Avg.10.4) }\end{array}$ & $\begin{array}{c}\text { Total } \\
\text { expenditures }\end{array}$ \\
\hline Metro Vancouver Crime Stoppers Association & 1989-03-04 & 8 & $\begin{array}{l}\$ 440,510 \\
\$ 481,929 \\
\$ 356,960\end{array}$ \\
\hline Calgary Crime Stoppers Association & $1982-05-13$ & 10 & $\begin{array}{l}\$ 231,310 \\
\$ 173,513 \\
\$ 180,097\end{array}$ \\
\hline Crime Stoppers Association of Edmonton and Northern Alberta & $1983-02-02$ & 8 & $\begin{array}{l}\$ 176,570 \\
\$ 229,231 \\
\$ 288,806\end{array}$ \\
\hline Crime Stoppers of Hamilton INC & 1983-05-17 & 10 & $\begin{array}{c}\$ 97,779 \\
\$ 102,240 \\
\$ 122,455\end{array}$ \\
\hline Crime Stoppers Saskatoon INC & $1986-11-20$ & 12 & $\begin{array}{l}\$ 86,938 \\
\$ 71,009 \\
\$ 67,977\end{array}$ \\
\hline Ottawa Crime Stoppers & 1985-04-01 & 13 & $\begin{array}{l}\$ 49,429 \\
\$ 65,478 \\
\$ 82,129\end{array}$ \\
\hline Toronto and Regional Crime Stoppers INC & 1984-07-17 & 11 & $\begin{array}{l}\$ 153,493 \\
\$ 191,543 \\
\$ 220,382\end{array}$ \\
\hline Windsor and Essex County Crime Stoppers INC & 1985-05-02 & 15 & $\begin{array}{l}\$ 151,117 \\
\$ 141,197 \\
\$ 139,686\end{array}$ \\
\hline Winnipeg Crime Stoppers INC & 1984-09-01 & 9 & $\begin{array}{l}\$ 82,826 \\
\$ 66,114 \\
\$ 94,122\end{array}$ \\
\hline Info Crime Quebec & 1997-01-01 & 8 & $\begin{array}{l}\$ 125,174 \\
\$ 167,570 \\
\$ 153,623\end{array}$ \\
\hline
\end{tabular}

${ }^{\mathrm{a}}$ Expenditures represent the last three reporting periods (2012-2014 or 2013-2015) that were provided on the CRA website. Reporting periods differ for each Crime Stoppers Program.

Table 2. Police foundations using corporate model in Canada.

\begin{tabular}{|c|c|c|c|c|c|c|c|}
\hline Foundation & Year & $\begin{array}{c}\text { Total } \\
\text { directors } \\
\text { (Avg.16) }\end{array}$ & $\begin{array}{c}\text { Total } \\
\text { expend }^{\mathrm{a}}\end{array}$ & $\begin{array}{l}\text { Police } \\
\text { budget } \\
\text { including } \\
\text { salaries }^{\mathrm{b}}\end{array}$ & $\begin{array}{l}\text { Police budget } \\
\text { excluding } \\
\text { salaries }^{\mathrm{b}}\end{array}$ & $\begin{array}{l}\text { Foundation } \\
\text { contributions } \\
\text { to Police } \\
\text { Department }^{\mathrm{b}}\end{array}$ & $\begin{array}{c}\text { Budget/ } \\
\text { Contribution } \\
\text { ratios }^{c}\end{array}$ \\
\hline $\begin{array}{l}\text { Vancouver } \\
\text { Police } \\
\text { Foundation }\end{array}$ & $\begin{array}{l}1995- \\
11-16\end{array}$ & 27 & $\begin{array}{c}\$ 1,147,417 \\
\$ 1,574,498 \\
\$ 647,902\end{array}$ & $\$ 259$ million & $\$ 49$ million & $\$ 648,045$ & $\begin{array}{l}0.25 \% \\
1.33 \%\end{array}$ \\
\hline $\begin{array}{c}\text { Calgary Police } \\
\text { Foundation }\end{array}$ & $\begin{array}{l}2011- \\
06-07\end{array}$ & 15 & $\begin{array}{c}\$ 1,788,385 \\
\$ 1,727,435 \\
\$ 220,397\end{array}$ & $\$ 454$ million & \$76 million & $\$ 435,760$ & $\begin{array}{l}0.09 \% \\
0.57 \%\end{array}$ \\
\hline $\begin{array}{l}\text { Edmonton } \\
\text { Police } \\
\text { Foundation }\end{array}$ & $\begin{array}{l}2000- \\
07-25\end{array}$ & 18 & $\begin{array}{l}\$ 549,442 \\
\$ 599,946 \\
\$ 524,230\end{array}$ & $\$ 362$ million & $\$ 68$ million & $\$ 222,883$ & $\begin{array}{l}0.06 \% \\
0.32 \%\end{array}$ \\
\hline $\begin{array}{l}\text { Abbotsford } \\
\text { Police } \\
\text { Foundation }\end{array}$ & $\begin{array}{l}2006- \\
01-01\end{array}$ & 11 & $\begin{array}{c}\$ 28,606 \\
\$ 783 \\
\$ 9,724\end{array}$ & $\$ 42$ million & $\$ 6$ million & $\$ 10,400$ & $\begin{array}{l}0.024 \% \\
0.17 \%\end{array}$ \\
\hline $\begin{array}{l}\text { Delta Police } \\
\text { Foundation }\end{array}$ & $\begin{array}{l}2004- \\
01-01\end{array}$ & 9 & $\begin{array}{l}\$ 40,064 \\
\$ 36,047 \\
\$ 68,159\end{array}$ & $\$ 31$ million & $\mathrm{N} / \mathrm{A}$ & $\$ 120,000^{d}$ & $\begin{array}{c}0.38 \% \\
\text { N/A }\end{array}$ \\
\hline
\end{tabular}

\footnotetext{
${ }^{a}$ Expenditures represent the last three reporting periods (2012-2014 or 2013-2015) provided on the CRA website. Reporting periods differ for each Foundation.

${ }^{b}$ Budget and Foundation information is from the most recent year available.

'Top ratio includes police salaries while the bottom ratio excludes police salaries.

${ }^{\mathrm{d}}$ This total represents a donation towards the purchase of a $\$ 400,000$ mobile command unit for the Delta Police Department. Delta Police Foundation did not report donee information on the CRA website but see www.bclocalnews.com/community/202587981. html.
} 
was $\$ 3,283,157$, with over $\$ 3$ million in donations, with total expenses of $\$ 1,727,435$. Calgary Police Service received $\$ 220,907$. Edmonton Police Foundation raised $\$ 615,050$ in 2014, and Edmonton Police Service was the primary donee receiving $\$ 287,992$. Edmonton Police Service is the primary donee in each year for which there are records.

Donations to police foundations can be sizeable in ways that direct donations to or sponsorship of public police cannot. For example, in one year the Edmonton Police Foundation accepted donations from Enbridge $(\$ 25,000)$, Northlands $(\$ 10,000)$, and several other $\$ 10,000$ donations from provincially based companies. In 2014, Calgary Police Foundation embarked on a funding drive and secured several large donations from energy companies headquartered in Calgary totalling more than $\$ 1$ million. Foundations also need to spend money to raise money. In 2016, Vancouver Police Foundation spent $\$ 60,231$ on advertising and $\$ 133,782$ on fundraising. Calgary Police Foundation spent $\$ 139,512$ on advertising and $\$ 88,262$ on fundraising. Edmonton Police Foundation spent $\$ 240,983$ on fundraising. Galas in particular cost money to host. Each year the Edmonton Police Foundation hosts the 'True Blue Gala'. For a table of eight persons, the cost is $\$ 2200-2700$. At these galas not only do donors contribute but they have privileged access to key public police decision-makers at their tables or the event (Luscombe, et al. forthcoming). Other forms of fundraising include the selling of police calendars, such as in Calgary in 2014 when all sales of the Police Service Canine Unit charity calendar went to the Calgary Police Foundation. Sales of the calendar had raised more than $\$ 30,000$ for the Calgary Police Foundation the year earlier. Like other police foundations, Vancouver Police Foundation raises funds through print and radio advertisements, fundraising dinners, galas, and concerts, targeted corporate donations and sponsorships, and targeted personal contacts.

Some expenditures of police foundations seem philanthropic, though criminal justice oriented. For example, in 2016 the Vancouver Police Foundation funded VPD Women's Safety Fair $(\$ 4,480)$, Lunch with the Chief $(\$ 3,600)$, the Fentanyl Awareness Campaign $(\$ 20,000)$, and athletics and youth programs including a Youth Police Academy $(\$ 20,000)$. Other items catered more to public police members, such as the Vulnerable Person Registry $(\$ 10,000)$, the VPD Member Appreciation and Promotion Event $(\$ 21,000)$, and the VPD Family Day $(\$ 9,000)$. The Calgary Police Foundation funded the Calgary Police Cadet Corp, and YouthLink, a police museum collection of exhibits and mock forensics labs for kids. Abbotsford Police Foundation funded the Abbotsford Police Camp, operated in conjunction with Abbotsford Police Department and Central Abbotsford Community School. The Abbotsford Police Foundation website allows donors to give to the Foundation specifically or to specific projects.

However, with corporate police foundations that operate as domestic shell corporations, much funding is used for police equipment or initiatives. The Vancouver Police Foundation has been behind several major recent procurements of the VPD. In 2016, this foundation allocated $\$ 12,950$ for special medical kits and $\$ 30,000$ for binocular night vision devices for VPD. In 2015, the Vancouver Police Foundation allocated $\$ 47,000$ for a boat, engine and trailer for the Marine Unit, $\$ 40,797$ for a canine-mounted video camera system, and $\$ 75,000$ for enhanced video surveillance for the Mobile Command Vehicle for VPD. In 2014, the Vancouver Police Foundation allocated $\$ 24,000$ for an aiming laser for the Emergency Response Team. In 2013, this Foundation allocated $\$ 7,000$ to a VPD Crime Alerts system that would update subscribers on crimes in specific neighbourhoods. In 2013 the Vancouver Police Foundation provided $\$ 15,000$ for the VPD Ceremonial Unit, which sends delegations to public events and police funerals. The foundation contributed funds toward the Mobile Command Vehicle for VPD as well. In 2013 Vancouver Police Foundation also spent \$25,725 to an arm for a robot that the Vancouver Police Foundation had purchased for the VPD's Emergency Response Team the year prior. Vancouver Police Foundation raised $\$ 250,000$ for a bullet-proof, armoured rescue vehicle in 2008-2009 (Paperny 2008). Vancouver Police Foundation also raised funds for infra-red cameras for the Marine Unit in 2009, and drug dogs and dog bullet-proof vests in 1999. The Delta Police Foundation raised $\$ 120,000$ for a mobile command unit (see Table 2), a satellite police station complete with computer workstations and toilets that coordinates video surveillance 
at public events (Mangelsdorf 2013). The Delta Police Foundation also raised funds for three motor vehicles for community policing initiatives and special events in the city. In 2013, the Edmonton Police Foundation raised $\$ 85,000$ toward purchase of police helicopters. In 2015-2016, Abbotsford Police Foundation helped to raise funds for an all-terrain vehicle for Abbotsford Police Department.

There was crossover between police foundations and CS in our data. ${ }^{6}$ As the Vancouver Police Foundation website proclaims, 'In 1984, the Vancouver Police Foundation provided $\$ 10,000$ in seed money to start a new program in Canada called "Crime Stoppers"' (VPF 2016b), a practice that mirrors arrangements pioneered in New York City in the same decade between the New York City Police Foundation and the corresponding New York CS program (NYCPF 2016). Indeed, presently one can donate to CS through this Foundation's website (NYCPF 2016). Traversing these organisational boundaries in multiple ways, in this case private money is given to a private entity associated with police, then transferred to another private entity to produce information that is then sent to public police to act upon.

For CS programs we examined charitable donations and expenditures from 10 programs for the last three years reported to the CRA. All programs were created as charitable organisations from 1983 to 1989 and have remained in place since, thus showing a long-standing and for most programs in Canada a 30 year arrangement with police services. The levels of expenditures (drawing primarily private and public donations) for the CS programs to generate 'tips' for police is significant for the past three years. Thus, for example, for 2014, the expenditures were significant for each of Metro Vancouver $(\$ 440,510))^{7}$ Calgary $(\$ 173,513)$, Edmonton $(\$ 176,570)$, Hamilton $(\$ 102,240)$, Quebec $(\$ 125,124)$, Saskatoon $(\$ 86,938)$, Ottawa $(\$ 49,429)$, Toronto $(\$ 153,493)$, Windsor $(\$ 141,197)$, and Winnipeg $(\$ 66,114)$ CS programs. Four of 10 CS programs had increasing levels of expenditures, whereas, surprisingly, the other 6 programs showed slightly decreasing levels over the past three years. These decreases may be due to increased efficiencies in the CS organisation in providing information to police, thus requiring fewer resources or because police or other organisations, including foundations, are increasingly providing police resources. Even with these decreases, none of the 10 CS programs we studied had insignificant or near zero levels of expenditure (see Table 1). As significant is the level of information flowing to public police through CS as a consequence of these expenditures. For example, Toronto CS reported a remarkable 8790 'tips' (Ontario Association of CS 2016b), Edmonton and Northern Alberta CS had 5061 'tips' and Ottawa CS had 3900 during 2015.

As with board members' affiliations discussed below, sponsors of CS tend to be private corporations. For example, the Metro Vancouver CS program displays 23 private sponsors on its website, at least 14 of which are Canadian or transnational private corporations, including banks like Toronto Dominion and retail chains like Mac's Milk and London Drugs. These corporations benefit from an affiliation with the crime-fighting aspect of police practices in particular, effectively supporting police in exchange for greater public legitimacy (see Walby et al. 20142014).

Other funding comes from CS efforts themselves. A CS coordinator explained, besides 'corporate donations':

Our funding comes from fundraising, we do a 'bail and jail'. We do a golf tournament. We do a curling tournament. We have a Western Rodeo and an old car show and we do Bingos and Nevada's [instant win ticket sales]. (CS coordinator)

Examining donations for the last three years for which information is available ${ }^{8}$ reveals the appearance and growth of public funding in 3 of the 10 CS programs. Thus, programs in Vancouver, Edmonton, and Winnipeg are receiving public funding in addition to private donations and, moreover, these former amounts in two of these three programs ${ }^{9}$ are increasing in value, and in all three increasing as a percentage of all donations over the past three years for which information was reported (see Table 3). Thus, for Metro Vancouver CS, public funding of this private organisation is significant (most funding is now public) and has increased from an already remarkable almost $\$ 326$ thousand (76\% of all funding) to $\$ 423$ thousand (94\% of all funding). Our research reveals the source of this public funding tends to be mostly municipal government and legalised gambling funds via grants 
Table 3. Public funding of three CS programs as percentage of all funding.

\begin{tabular}{lll}
\hline Metro Vancouver CS & \multicolumn{1}{c}{ Edmonton CS } & \multicolumn{1}{c}{ Winnipeg CS } \\
\hline$\$ 422,625(94 \%)(2015)$ & $\$ 38,120(20 \%)(2015)$ & $\$ 17,000(34 \%)(2014)$ \\
$\$ 341,000(83 \%)(2014)$ & $\$ 12,925(4 \%)(2014)$ & $\$ 17,000(31 \%)(2013)$ \\
$\$ 325,700(76 \%)(2013)$ & $\$ 7,728(3 \%)(2013)$ & $\$ 0(2012)$ \\
\hline
\end{tabular}

(for example, British Columbia 2016, Metro News 2016). There is a sense in which, as with corporate sponsorship, this arrangement grants legitimacy to the donating body or related practices, in this case legalised gambling, by permitting a positive association with the noble fight against crime alongside police.

This also means funding is received as public, transformed into private, and then used to support public police via CS, effectively privatising public funds (see also Pfuhl 1992). Then the funds are used to transfer information to public police. Note that this avoids an obvious alternative, which is to simply transfer these same public funds directly to public police to enhance existing informant programs or for proven crime prevention initiatives operated in the public domain. Though beyond the scope of this paper, this may mean there is benefit accrued or symbol capital (Lippert et al2016) created through these additional points of transfer. Regardless, this is a noteworthy shift since avoiding public funding since 1976 has been a prominent selling point of CS arrangements to private donors. One CS coordinator reiterated this long-standing claim: 'We don't receive any government money or any money from the police departments other than the two officers that are seconded' (CS coordinator; emphasis added). To the extent that private sponsors benefit from increased legitimacy for their own practices this means that public funding is helping to make this a reality.

\section{Maintaining and transgressing boundaries}

Maintaining as well as negotiating (Giacomantonio 2014, p. 562) or transgressing the public-private boundary occurs with both CS and police foundations. This takes both symbolic and physical forms. Symbolically, one prevalent signifier the two models share about the nature of associations with police as private organisations and regarding their own donors and sponsors is 'partnership'; ultimately but not exclusively a partnership with police. The promotional websites and other materials of both foundations and CS display the language of 'partnership' widely (see Toronto CS 2016, VPF 2016a). As the Corporate Partner tab on the Vancouver Police Foundation website notes, 'If you belong to an organization that wants to make a real difference in the fight against crime, we invite you to partner with us'. This notion of 'partner' permits a discursive spanning of this otherwise firm public-private boundary established via rules and doing so has acquired moral overtones as the proper way to relate among rational, bold, future-oriented organisational actors. Partners plainly prosper and thrive rather than subsist and survive. To partner is to morally and not merely financially invest in the police. All partners win through such 'strategic alliances' (Gulati and Gargiulo 1999). There are no firm bureaucratic requirements, civic duties, or intimate community bonds related to 'partnership' arrangements, much less any hint of coercion by one partner of another. 'Partnerships' are to be absent of such notions; they are omitted from the pretty partnership pictures that are increasingly framed across the public-private boundary, faintly out of reach in time, and if continuous advertising for ever more donors and sponsors in both models is any measure, never quite completed.

Fundraising is one aspect of the work of police foundations where the public-private boundary is transgressed. Vancouver Police Foundation has been pushing the boundaries of police fundraising. In 2011, this Foundation established a relationship with the large drugstore chain London Drugs, whose customers could donate to the Vancouver Police Foundation or purchase a \$20 'I Love Vancouver' tshirt, with proceeds to the Foundation (Marketwire Canada 2011). More recently, London Drugs and Vancouver Police Foundation partnered on the Kops Shades for Kids Campaign. Aviator sunglasses - 
'a signature look inherently tied to police' (Canadian Government News 2014b) - were also sold for $\$ 20$, with proceeds to the Foundation. The marketing and advertising personnel in police foundations are thus 'boundary spanners' (Williams 2002) who fill holes or gaps between public police and the corporate world. In 2016, Calgary Police Foundation copied the Aviator fundraising strategy, according to their foundation website. Enrolling a corporation to collect funds for a police foundation in a commercial context shows both how foundations broker police legitimacy to arrange this and the long reach of foundations into the private realm.

Donations are another aspect of the work of police foundations where the public-private boundary is transgressed. The Calgary Police Foundation literally framed the names and faces of its biggest donors on a wall at the Calgary Police Headquarters. The donor wall included framed these acknowledgements for Cenovus, Enbridge, Encana, MEG Energy, Talisman Energy, and more (Canadian Government News 2014a). Together these corporate entities donated over $\$ 1$ million to this Foundation in one year. Their donations must be funnelled through the foundation, due to rules for private sponsorship of public police. However, it is clear that the Calgary Police deem themselves the chief benefactor, although the display must tip-toe around the public-private boundary since the wall does not indicate these corporate entities donated directly to police. Government officials and police strive to depict the foundation as independent. For example, when in May 2016 the City of Calgary designated May 30-June 4 Calgary Police Foundation Week, Mayor Naheed Nenshi referred to the foundation as an 'independent charity' several times.

Board composition is another aspect of the work of police foundations where the public-private boundary is transgressed. Occasionally a member of a police foundation will be appointed an honorary chief constable for a day as a way of expressing appreciation. However, seemingly transgressing the boundary between public police and private interests, some police foundation boards comprise police officers or administrators. The Edmonton Police Service Chief sits on the Edmonton Police Foundation board. A chief constable and police sergeant sit on the board of the Abbotsford Police Foundation. With corporate type police foundations that fundraise to provide monies for police gear and operations, the presence of sworn officers on the foundation boards would seem to transgress the very boundary the foundation seeks to establish. In this sense, board members of police foundations act as 'boundary spanners' (Williams 2002) that make links between corporations and public police. Not only is this a reason that Walters (2004) argues police foundations should be subject to ethical guidelines and standards, but it renders less plausible the claim that foundations are independent charities. Transgressing the boundary from the private side, the presence of corporate CEOs and private businesspersons on foundation boards is a crucial aspect of fund solicitation. As described by one foundation board member and police sponsor we interviewed, the private connections of board members are invaluable to the foundation's fundraising, allowing a deep reach into bulging private pockets:

[We are] 18 trustees, and we're all in many, many different businesses. We all have contacts in many different businesses so ... you can often make things happen. The police department itself, would have no ability to do that ... They're busy policing, we have all these contacts with people. I've used my contacts a lot to get money for the foundation ... like my business is dealing with rich people*laughs* Hey, I need 25 grand for something, giving it to the police. Okay.

When different levels of government are asked to provide an opinion on establishment of police foundations, public-private boundary transgression is often identified as a problem. For example, when the Saskatoon Police Service attempted to create a corporate-style foundation, the provincial-level Saskatchewan Police Commission chair admonished the Saskatoon Board of Police Commissioners for proposing the idea. As the Saskatchewan Police Commission chair noted, 'policing isn't a charity. It's an essential public service' (Tank 2016). The Saskatchewan Police Commission chair removed a paragraph from its core policy that allowed police foundations to be established, adding a paragraph prohibiting police from receiving private monies. Yet, another section of the policy still allows police chiefs to apply for exemptions. Saskatoon Police Service thus continues to 
advocate for establishment of a corporate-style foundation. This example shows how police foundations in Canada are understood to fly right through the public-private boundary but that public police pursue these golden geese anyway.

Regarding CS, it is vital to understand who the 'concerned citizen volunteers' are on CS boards, that is, who controls these private organisations if we are to discern whether and how the boundary between CS and police is breached in some manner. Our research using directors' names described earlier revealed patterns of affiliation. Most directors were from private corporations or other businesses including private security firms, law firms, or government agencies rather than representing a much wider 'citizenry'. Most significant was that 6 of the 10 CS programs had at least one director who was either a current or former police officer (Metro Vancouver CS had two). ${ }^{10}$ While there may be practical reasons for this arrangement, such as a board knowing how to liaise with public police or to determine reward levels for tipsters using police knowledge of risks likely taken to provide it (the riskier, the greater the reward - see Lippert 2002), it nonetheless suggests another way public police span the public-private boundary that the private CS program establishes. This is because directors directly affiliated with and with more intimate knowledge of the adjacent police service make key decisions about how the program will be operated as well as its expenditure priorities. As well, CS programs typically receive coordinators to run the program from the local police service(s) of the geographical area covered by the program (e.g. Furminger 2015):

I'm not a professional, I'm a policeman ... I have a very difficult job because we have to try and liaison with the board. We got to have respect from our fellow police officers, that when we give them something [information] that they know that and I think that's why we've been successful. We were both street cops. So when you give them something they understand it. Our primary objective number one is just to catch bad guys. And so you have to liaise with the media and so, wear a lot of hats it's a very difficult position to be in. (CS coordinator)

This means that some of the cost is actually covered by the local police service but also that it is typically run by police officers.

CS program office space is also typically provided by public police to CS for a nominal fee but not necessarily at a separate address. Thus CS program operations are often housed within the same structural confines of the police service it serves. All five of the CS programs (100\%) for which we could identify street addresses rather than mere postal box numbers, shared the same address and physical office space as the local police service. These are Windsor, Hamilton, Toronto, London, and Metro Vancouver. This fact is not advertised by CS or police and this office space is not necessarily frequented by outsiders since this is where promotions are designed and information is processed for transfer to police investigators. However, the spatial relationship alone begins to suggest that the public-private boundary is transgressed in this less than subtle way too.

The problem of 'funnelling' emerged early in CS's development (Carriere and Ericson 1989, pp. 27-28; Pfuhl 1992, pp. 508n, 509n). This is when police investigators encourage regular and/or registered police informants to send actionable information to CS as tips to collect a monetary reward rather than informants being paid by the police service via an informant fund. But because police already know the informant's identity, when their information is 'funnelled' to CS their anonymity is potentially compromised (Carriere 1987), which contradicts CS protocol. The police informant is funnelled into the CS system to become a CS informant but is tainted since his or her identity is already known, thus potentially destroying CS legitimacy among would-be tipsters since anonymity - the lynchpin of CS (see Lippert 2002) then becomes doubtful. This 'funnelling' became the subject of an article by the 'father' of CS MacLeese in 1988 (Wisconsin CS 2013, p. 5) and then a standard topic in the CS Manual, training videos, and other CS training (e.g. CS International 2001, 3.7). However, this practice has since continued in the US (see Wisconsin CS 2013, p. 5) as well as in Canada (Bruist et al. 2016). Thus in a recent infamous Canadian case involving Hamilton police investigator Matthews who was later arrested and charged for several offences: 
Matthews told Jane Doe by text he would contact Crime Stoppers to help her get some money. The following day, Matthews texted her that he spoke with Crime Stoppers and that he lied about their connection to help facilitate a reward. (Bruist et al. 2016)

Noting funnelling's significance is to underscore the effort to maintain the boundary between CS and the public police. One CS coordinator explained the problem with funnelling:

\begin{abstract}
It could be a problem; it very much depends on the coordinator. [For] one of the programs ... a new coordinator went in there and he was reading tips that were like ... 'Joe Smith's dealing drugs'. Well, that's not a tip. So you know something smells because they paid this guy two hundred dollars on it right? So you know something is wrong and what that police department was doing was ... they had their ... coordinator in there and they would just come in on Monday and say 'pay these people'. The danger with funneling is that we're not a police program. So ... we're not here to ... fund raise money to help the drug unit pay their people, that's their business, they have to pay their own people. Now I have no doubt there's ... people that are smart enough to play both ends against the middle that they're telling the drug unit stuff [and] they're telling us stuff but if we find out they're doing that they're not with us anymore. (CS coordinator)
\end{abstract}

The following exchange about 'funnelling' in a newsletter from a US CS program effectively captures several foregoing themes about the public-private public boundary. A local police officer and apparent board member asks: 'We have had a couple cases where some crimes were solved but the tipster did not report the information to Crime Stoppers but went directly to an officer. What should we do as a Crime Stoppers board ... ?' The CS president responds:

\footnotetext{
This question comes up from time to time and we refer to it as 'funneling'. As the term suggests, information is funneled to the Crime Stoppers coordinator from another law enforcement officer and not through the Crime Stoppers tip line. This poses numerous issues ... the Crime Stoppers program may not be able to protect the anonymity of the informant, which is the primary premise of Crime Stoppers. Take away the anonymity of the informant and the ability for future tips from anonymous sources may be jeopardized. Secondly, the integrity of the program that is administered by the board of directors, a separate and distinct community non-profit organization from the law enforcement officials is seriously compromised. The board promotes the program of anonymity and generates the reward fund from fundraising events identifying rewards paid to anonymous informants. Crime Stoppers does not hold fundraisers to supplement a 'snitch fund' for law enforcement officers. Sometimes due to budgetary restraints in law enforcement departments, some police chiefs or law enforcement officials come to Crime Stoppers programs because they believe Crime Stoppers may have some funds available for the 'snitch fund' or other needs within the law enforcement department. This is to be avoided at all costs. I know you are a police sergeant within your unit, but it is the integrity of the Crime Stoppers Police Coordinator liaison and the relationship he/she has with the Crime Stoppers board of directors that is also important. (Wisconsin CS 2013; emphasis added)
}

When 'funnelling' of information occurs it becomes a dilemma between short term exploitation of information flow via CS when public police have limited resources to gain such information and longer term clogging of an informational artery if it jeopardises the anonymity and integrity of the boundary between CS and public police.

\title{
Conclusions
}

Contributing to literature on boundary management and transgression in public policing networks (Giacomantonio 2014, Whelan 2016; also see Kilduff and Brass 2010), this article has examined policing across inter-organisational boundaries by investigating two neglected private organisations police foundations and CS organisations - operating mostly in Canadian jurisdictions. The establishment of these organisations reflects significant trends in public police practices and raise some issues similar to those stemming from 'partnering' with for-profit private security firms also others. Most fundamental is the question of the rule of law and whether certain private entities will be given preferential treatment by police in some way, even via unwitting neglect of certain forms of illegal conduct with more attention paid to others to their benefit. There are several related implications of our analysis regarding the public good (Loader and Walker 2007) as well as prospects of further illuminating these enigmatic funding sources for the broader public. Public police relations with foundations and CS programs were found to be more multifaceted and the resources generated more significant than 
implied by their neglect in the policing and security literature. To date, police foundations and CS have been successful in obfuscating (Rossman 2014) the flow of private funds into public police operations.

Foundations in particular allow police to receive funds from private, corporate entities while mitigating the association with private interests. The board members and staff of foundations act as 'boundary spanners' (Williams 2002) filling structural holes between previous disconnected organisations. If the flow of private resources continues to grow the extent to which public police are using these resources for the public good will become even less clear. Police maintain public legitimacy while permitting the flow of resources into their operations via several strategies, both physical and symbolic. In a sense, police foundations operate to obfuscate private funding of public police in ways that render the disreputable exchange (Rossman 2014) more palatable by mitigating any perceived collusion created by public-private boundary transgressions. Canada's public police are not facing scarcity or austerity as in the United Kingdom or elsewhere. Public police budgets take up one third or more of most municipal budgets in Canada's largest cities (CCPA 2008) and these are expanding, not shrinking (although municipalities are at least contemplating some reductions to municipal police services in Canada's largest jurisdiction of Ontario under the rubric of 'modernisation' (Association of Municipalities Ontario 2015)). The piece of the private pie that public police want is growing as well, but police are barred from direct, unfettered access. They need a gobetween. In this sense it is apt to conceptualise police foundations as 'cash cows' (Jancsics and Javor 2012, p. 70) or points in a network where the prohibition of trading resources is overcome via secrecy or a legal loophole. Given that sworn officers often serve on the boards, and given that police departments tend to be primary donees of the larger, corporate foundations, the characterisation of police foundations as independent charities is misleading. ${ }^{11}$

Yet, because of their private, charitable status, information about donations to police foundations and CS are not subject to FOI requests, thus rendering transparency and accountability opaque in a way that public police practices, in principle at least, are not. If foundations grow in number and influence and CS programs continue this means the transfer of resources and what is transferred back in return will remain significant but unknown. Nor is it clear that public legitimacy ought to be cheaply handed over to private sponsors (or 'partners') for a cash handout. An alternative would be to properly tax those organisations apparently so capable of making hefty donations to police foundations and CS programs, and using those funds, or other funds apparently available from public sources like municipalities that are increasingly handed to CS (see Table 1) for existing police operations and initiatives. These could be used for non-traditional initiatives beyond narrow street crime and the usual suspects (that are played up by CS and foundations to the neglect of other serious harms) under proper citizen oversight.

This transparency matters because any complete consideration of acquiring resources across public-private boundaries should consider to what purposes they are put by both sides of the line since it is doubtful the sources of those resources is independent of their uses. Thus, many private partners of CS come with strings attached in permitting the prioritising of 'tips' about particular kinds of conduct (Lippert 2002) and otherwise absorb some police legitimacy. Rather than marine boats and night vision devices, foundations could provide technology or other targeted resources to improve police efforts to combat domestic violence, crimes by police, or corporate malfeasance, while CS programs could provide resources to garner information about these types of offences. They do not.

The public-private boundary is long held, and is the source of much tension and conflict in the field of policing and security (perhaps most especially in Canada). Yet, as O'Mahony and Bechky (2008, p. 455) note, 'boundary organizations do not resolve all conflict', in our case conflict over the perception of private interests being mixed with public police departments in Canada charged with being impartial, non-biased, and fully public entities. The fact that spanning the publicprivate boundary may shape public police priorities, if sometimes unwittingly or in broad strokes, is troubling and requires deeper empirical investigation. 


\section{Notes}

1. In response to the sponsorship of Hamilton Police by a large pipeline company, Enbridge, the rule of law was central to the complaint about this arrangement signed by 350 citizens who also protested on the street (CBC 2013).

2. Nova Scotia's police act provides legal authority specifically to account for 'other money that comes into the hands of members of police departments'.

3. The RCMP Foundation also manages the RCMP Licensing Program that reviews products manufactured using the RCMP name or logo. Royalties collected are then redirected to the foundation and used to support community initiatives as well as youth and community policing projects.

4. These three representatives had been contacted by letter explaining the purpose of the research and indicating their confidentiality would be guaranteed. These interviews were not intended as a major data source for this paper.

5. One recent noteworthy modification to this narrative, compared to earlier versions displayed on a few Canadian CS websites, is addition of the claim that Greg MacAleese was 'Canadian-born', suggesting this program had Canadian and not exclusively US roots, presumably rendering it more acceptable to Canadians and helping its spread in this country among citizens whom would otherwise seek to distinguish the two crime control cultures.

6. London Police Association Charity Fund does not follow the corporate model of foundations and appears to be more philanthropic, giving most funds raised to agencies such as the Salvation Army and United Way. Interestingly, however, London Police Association Charity Fund gave London Crime Stoppers $\$ 1,000$ in 2015, $\$ 1,500$ in 2014, and \$750 in 2013.

7. All values are CDN dollars.

8. For some programs this was 2012-2014 and for others it was 2013-2015.

9. Ottawa National Capital CS in 2010 approached Ottawa municipal government for the first time to request public funding, claiming that otherwise the program would 'whither and die' (Devoy 2010, p. 5). This request that came after the annual budget deliberations was ultimately rejected, but interestingly CS had suggested the requested '\$100,000 be given to Crime Prevention Ottawa (CPO), to give to Crime Stoppers' (Devoy 2010, p. 5) showing an effort to obfuscate funding arrangements, perhaps to mask the public source of the requested funds later on.

10. A variation on this arrangement which obfuscates funding of CS on behalf of public police was evident in relation to the RCMP in Northern Alberta in the infamous case of serious vandalism of oil company field operations and the subsequent investigation of suspects Wiebo Ludwig and Richard Boonstra in the late 1990s. The head of the local RCMP detachment formed the 'South Peace Crime Prevention Association' for which he became a board member to raise funds from oil companies to transfer to the local CS program to encourage tips about these specific acts, rather than crime in general (Alaska Highway News 2000, p. 3).

11. Elsewhere we have argued (see Walby et al.2017) that police foundations and similar entities should be added to the schedule of FOI laws to promote greater transparency and accountability.

\section{Disclosure statement}

No potential conflict of interest was reported by the authors.

\section{Funding}

This work was supported by the Social Sciences and Humanities Research Council of Canada [grant number 2015-86].

\section{References}

Abbotsford Police Foundation (APF), 2016. Available from: http://www.abbypd.ca/abbotsford-police-foundation.

Adloff, F., 2015. Foundations and the Charisma of giving: a historical sociology of philanthropy in Germany and the United States. Voluntas, 26 (5), 2002-2022.

Alaska Highway News, 2000. Oil money never affected Ludwig case. Officer Says. 7 Mar, p. 3.

Association of Municipalities Ontario, 2015. Building a new public safety model in Ontario: AMO's Policing Modernization Report. AMO. 27 April.

Ayling, J., 2014. Trading in security: issues in the commodification of public security. In: M. Gill, ed. Handbook of security. 2nd ed. London: Palgrave, 936-958.

Ayling, J., Grabosky, P., and Shearing, C., 2009. Lengthening the arm of the law: enhancing police resources in the 21st century. Cambridge: Cambridge University Press.

Brass, D., et al., 2004. Taking stock of networks and organizations: a multilevel perspective. Academy of management journal, 47 (6), 795-817. 
British Columbia, 2016. Available from: https://news.gov.bc.ca/stories/local-crime-prevention-efforts-share-in-gaminggrants\#.

Brogden, M., and Nijhar, P., 2005. Community policing: national and international models and approaches. Portland, OR: Willan.

Bruist, S., Hayes, M., and Dunphy, B., 2016. Sex, drugs, money behind Cop's suicide. Toronto Star. 28 May. Available from: https://www.thestar.com/news/gta/2016/05/28/cops-drug-fuelled-sexual-relationship-with-key-informant-led-tosuicide.html.

Canada Centre for Policy Alternatives (CCPA), 2008. Two visions, two cities: a citizen's guide to understanding Winnipeg's city budget. Winnipeg: Public Services for Public Good. Manitoba branch.

Canadian Government News, 2014a. Calgary police foundation surpasses fundraising goal. 10 Oct.

Canadian Government News, 2014b. Police sunglasses raise funds for community outreach programs. 19 June.

Carriere, K., 1987. Crime stoppers critically considered. Canadian criminology forum, 8, 104-115.

Carriere, K., and Ericson, R., 1989. Crime stoppers: a study in the organization of community policing.Toronto: Centre of Criminology, University of Toronto.

CBC, 2013. Enbridge donations to Hamilton police draw street protest: Enbridge pipelines Inc. has donated $\$ 44,410$ to Hamilton police. 6 June. Available from: www.cbc.ca.

CS International, 2001. Operations manual. CS International.

CS International, 2016. Available from: http://csiworld.org/about-csi/.

Delaney, P. D., and Carey, D., 2007. Police foundations: partnerships for 21st-century policing. Police chief, 74 (8), 16.

Devoy, D., 2010. Crime stoppers may 'Whither and die' without funds. Ottawa East EMC. p. 5.

Fernandez, K., and Hager, M., 2014. Public and private dimensions of Grantmaking foundations. Public administration quarterly, 38 (3), 405-439.

Fleming, J., 2005. Working together: neighbourhood watch, reassurance policing and the potential of partnerships (No. 303). Canberra: Australian Institute of Criminology.

Furminger, G., 2015. Crime doesn't pay - but crime stoppers does. Welland Tribune. 11 Jan.

Giacomantonio, C., 2014. A typology of police organizational boundaries. Policing and society, 24 (5), 545-565.

Giacomantonio, C., and Gundhus, H., 2015. Policing, boundaries and the state: the changing landscape of sovereignty and security. European journal of policing studies, 3 (2), 109-115.

Gill, M., 2013. Senior police officers' perspectives on private security: sceptics, pragmatists and embracers. Policing and society, 25 (3), 276-293.

Grabosky, P., 2007. Private sponsorship of public policing. Police practice and research, 8 (1), 5-16.

Graycar, A., and Jancsics, D., 2016. Gift giving and corruption. International journal of public administration.

Gulati, R., and Gargiulo, M., 1999. Where do interorganizational networks come from? American journal of sociology, 104 (5), 1439-1493.

Harcourt, B., 2007. Against prediction.Chicago, IL: University of Chicago Press.

Hoque, Z., Arends, S., and Alexander, R., 2004. Policing the police service: A case study of the rise of 'new public management' within an Australian police service. Accounting, auditing \& accountability journal, 17 (1), 59-84.

Jancsics, D., 2017. Offshoring at home? Domestic use of shell companies for corruption. Public integrity, 19 (1), 4-21.

Jancsics, D., and Javor, I., 2012. Corrupt governmental networks. International public management journal, 15 (1), $62-99$.

Kilduff, M., and Brass, D., 2010. Organizational social network research: core ideas and key debates. Academy of management annals, 4 (1), 317-357.

Lippert, R., 2002. Policing property and moral risk through promotions, anonymization and rewards: Revisiting crime stoppers. Social and legal studies, 11 (4), 475-502.

Lippert, R., and O'Connor, D., 2006. Security intelligence networks and the transformation of private security. Policing and society, $16(1), 49-65$.

Lippert, R., and Walby, K., 2016. Governing through privacy: Authoritarian liberalism. Culture and the humanities, 12 (2), 329-352.

Lippert, R. K., Walby, K., and Taylor, P., 2016. Capital exchanges, security networks, and 'user pays' policing. Criminology, criminal justice, law \& society, 17 (2), 18-33.

Lippert, R., and Wilkinson, B., 2010. Capturing crime, criminals and the public's imagination: Assembling crime stoppers and CCTV surveillance. Crime, media, culture, 6 (2), 131-152.

Loader, I., and Walker, N., 2007. Civilizing security. Cambridge: Cambridge University Press.

Luscombe, A., Walby, K., and Lippert, R. K., forthcoming. Police-Sponsorship Networks: Benign Ties or Webs of Private Influence?. Policing \& society.

Mangelsdorf, R., 2013. Foundation gives back to DPD. South Delta Leader. 12 April.

Marketwire Canada, 2011. London drugs pays tribute to the Vancouver police foundation. Comtex New Network. 24 June.

Metro News, 2016. Available from: http://www.metronews.ca/news/canada/2016/04/15/23m-in-funding-will-providemore-police-and-prosecutors-to-fight-gangs-premier.html.

Metro Vancouver CS, 2016. Available from: http://solvecrime.ca/ABOUT.html.

Minnesotans for a Fair Economy. 2016. Police, prison, and profits: how Minnesota's largest banks make money from misery. Minneapolis. http://www.spft.org/wp-content/uploads/2016/07/Police-Prison-and-Profits.pdf. 
New York City Police Foundation (NYCPF), 2016. 40 year history. Available from: ttp:// www.nycpolicefoundation.org/ about-us/40-year-history/.

Ontario Association of Crime Stoppers, 2016a. About us. Available from: http://ontariocrimestoppers.ca/about-us/theorigin-of-crime-stoppers.

Ontario Association of Crime Stoppers, 2016b. Captain Canuck fighting crime. Available from: http:// ontariocrimestoppers.ca/news.php?nv=29\&catid=\&id=90\&search=.

Ontario Association of Crime Stoppers. 2016c. OACS Partnerships. Available from: http://ontariocrimestoppers.ca/aboutus/oacs-partnerships.

Ontario Police Services Act, R.S.O, 1990. c. P.15.

O'Mahony, S., and Bechky, B., 2008. Boundary organizations: enabling collaboration among unexpected allies. Administrative science quarterly, 53 (3), 422-459.

O'Malley, P., and Hutchinson, S., 2007. Converging corporatization? Police management, police unionism, and the transfer of business principles. Police practice and research, 8 (2), 159-174.

Ottawa Police Services Board, 2013. CR-8 The Acceptance of Donations, Gifts, Loans and Sponsorships. Available from http://capg.ca/wp-content/uploads/2013/05/OPSB-Policy-CR-8-Donation-Sponsorship.pdf.

Paperny, A., 2008. Vancouver police to get armour on wheels. Globe \& Mail. 25 June, S1.

Pfuhl, E., 1992. Legitimation of snitching. Justice quarterly, 9 (3), 505-528.

Prenzler, T., and Sarre, R., 2012. Public-private crime prevention partnerships. In: T. Prenzler, ed. Policing and security in practice. London: Palgrave, 147-169.

Rosenbaum, D., Lurigio, A., and Lavrakas, P., 1989. Enhancing citizen participation and solving serious crime: a national evaluation of CS programs. Crime and delinquency, 35 (3), 401-420.

Rossman, G., 2014. Obfuscatory relational work and disreputable exchange. Sociological theory, 32 (1), 43-63.

Sleiman, M., and Lippert, R., 2010. Downtown ambassadors, police relations and 'clean and safe' security. Policing and society, 20 (3), 316-335.

Tank, P., 2016. Policing isn't a charity, Saskatoon board of police commissioners told. Saskatoon StarPhoenix, 23 Jan.

Toronto Crime Stoppers, 2016. About us. Available from: https://222tips.com/aboutUs.aspx.

Vancouver Police Foundation (VPF). 2016a. 2016 funded projects. Available from: http://www. vancouverpolicefoundation.org/impact/2016-funded-projects/.

Vancouver Police Foundation (VPF). 2016b. 40 years of building safer communities. Available from: http://www. vancouverpolicefoundation.org/2016/11/40- years-of-building-safer-communities/.

Walby, K., Lippert, R.K., and Luscombe, A. 2017. Federal access to information act reform is overdue. Montreal Gazette, April 7.

Walby, K., Wilkinson, B., and Lippert, R.K., 2014. Legitimacy, Professionalization and expertise in public sector corporate security. Policing and society, 16 (1), 38-54.

Walters, C., 2004. A multi-site case study involving ten police foundations: Examining integrity and ethics relative to the establishment and maintenance of best practices. Dissertation. ETD collection for University of Nebraska (1 Jan).

Wasserman, G., 2005. The role of police foundations in the United States. Policing today, 11 (4), 27.

Whelan, C., 2016. Informal social networks within and between organisations. Policing: an international journal of police strategies and management, 39 (1), 145-158.

Williams, P., 2002. The competent boundary spanner. Public administration, 80 (1), 103-124.

Wisconsin Crime Stoppers, 2013. In pursuit. Available from: www.wicrimestoppers.org/ln_Pursuit/Combined\% 20Newsletter\%20Update\%202013-03.pdf. 


\title{
Ә OPEN ACCESS
}

\section{The police intelligence division-of-labour}

\author{
James Sheptycki
}

\begin{abstract}
This article describes the police intelligence division-of-labour. It is argued that police organisation gains overall coherence in relation to the 'police métier'; a rationale that allows protagonists in the police world to make sense of an irrational workplace structure where personal loyalty, trust and honour (not formal organisational logic) form the basis of action and compliance. The concept of the police métier is defined in terms of the police professional concern with the mastery of surveillance and coercion in the reproduction of order, the making of crime and the governance of insecurity, and it is the polestar of the police mindset. The article describes the police intelligence division-of-labour paying specific attention to four different aspects of intelligence activity: the acquisition of intelligence or information; the analysis of information in the production of intelligence; tasking and co-ordination on the basis of intelligence 'product'; or being tasked on that same basis. The descriptive analysis presented here is useful in several respects. Firstly it provides a basis for the comparative study of police intelligence work and its configuration within broader processes of security governance. Secondly, it provides a prototypical organisational map useful understanding the orientation of particular units - the organisational elements of policework (e.g. of drug squads, primary response, public order and homicide investigation units) - within the broader police division-of-labour. Lastly, it provides a complex view of issues concerning democratic governance of 'the police' as they are configured as nodes within broader networks of security governance.
\end{abstract}

\section{Introduction}

In the sociology study of police organisation, the term boundary has been understood to refer to organisational units (intra-organisational policing) and institutions (inter-organisational policing) and the co-ordination work necessary for their coherent operation has emerged as an important concern (Giacomantonio 2014, 2015). Understanding how different police units form, function and interact with each other in police organisations is a vital aspect of police research. This paper describes the police intelligence division-of-labour, here understood as intra-organisational information and intelligence flows bounded within the archetypal form of the multi-functional urban police service. It is a useful if not necessary prior step in understanding how inter-organisational boundaries work in police organisation (Sanders and Henderson 2013; Delpeuch and Ross 2016).

As certain police researchers will know from experience, there is a sense of being 'inside' the police organisation and some author's use of the dramaturgical metaphor draws specific attention to both

This is an Open Access article distributed under the terms of the Creative Commons Attribution-NonCommercial-NoDerivatives License (http:// creativecommons.org/licenses/by-nc-nd/4.0/), which permits non-commercial re-use, distribution, and reproduction in any medium, provided the original work is properly cited, and is not altered, transformed, or built upon in any way. 
'front stage' and 'back stage' arenas for the performance of policing (Young 1991; Manning 1997; Moskos 2008, Fassin 2011). From such a perspective, multi-agency work has both 'open' and 'hidden' aspects for the actors participating in what amounts to co-operative organisational boundary maintenance (Giacomantonio 2014; 2015). If a particular police institution is acting as a node in a broader network of security, what goes on inside the node (Sheptycki 2017)? A general theory of police information networking is the Holly Grail of the intelligence-led policing perspective, long sought and yet to be discovered (James 2003, 2013; Ratcliffe 2016). What is presented here is more modest. It is part of an effort to make theoretical sense of a mass of data collected over a number of years in North America, Europe and the UK. ${ }^{1}$ These data include notes from field observation, focus group discussions, documentary analysis and qualitative conversational interviewing in many different police agencies. The frame of analysis is limited to English language scholarly literature on police organisation and police intelligence in North America, the UK and Europe. What is offered here is a general description concerning how a multiplicity of different types of intelligence and information, knowledge and facts, percolates within a multi-functional division-of-labour organised around the police métier.

A great deal of the literature on police organisation rests on a sometimes overt, but more often subconscious belief that it is machine-like. For example, some of the literature on intelligence and police security networks has used the metaphor of 'cybernetics', which is a form of machine-thinking (e.g. Gill 1998). According to Robert Reiner, bureaucratic rationality, the rule of law and formal accountability structures in the service of efficient and effective police service have under-pinned claims to police legitimacy (Reiner 2010). Projecting an image of formal rationality is very important to police decision-makers and police actors. The police are frequently imagined as a rank-structured, bureaucratically organised, rational, institutional machine (Maguire 2010; Jobard and de Maillard 2015). As sophisticated research on police organisation further reveals, police organisation seldom conforms to machine-like rationality (Manning 1997; Maguire and Uchida 2015) and, indeed, sometimes other more powerful motives propel police action (Hobbs 1988). The vital importance of informal information exchange to the achievement of police organisational goals is acknowledged in the literature (e.g. Bayer 2010). Nonetheless, the machine metaphor is reoccurring, especially when articulating measures for controlling police malpractice (Punch 2011) and governing the police (Jones et al. 1996; Stenning 2009). In the literature on intelligence modelling, flows, cycles and the management thereof, police organisation is continuously re-imagined as a cybernetic network of computational analysis (Ratcliffe 2016).

The following discussion develops a vocabulary of seven types or focal points of intelligence and locates them with reference to an ideal-typification of the modern multi-functional police organisation (Mouhanna 2009; Manning 2010; Jobard and de Maillard 2015; Maguire and Uchida 2015). There is a deliberate attempt to avoid depicting police organisation as a hierarchical and mechanistic set of arrangements in recognition that empirical observation has long confirmed that police organisation is idiosyncratic (e.g. Manning and van Maanen 1978; Monjardet 1985, 1996; Manning 1997; Chan 2003; Marks and Sklansky 2013). According to a report published by the US Department of Justice, 'traditional, hierarchical intelligence functions need to be reexamined and replace with cooperative, fluid structures that can collect information and move intelligence to end users more quickly (Peterson 2005, p. vii, emphasis mine)'. Since contemporary official expectations are that police intelligence systems should become more fluid, analytical descriptions ought not to smuggle mechanistic assumptions in by the back door (Sheptycki 2017). A challenge inherent when attempting to analytically describe the police intelligence division-of-labour is how to avoid machine-thinking.

Here it is argued that police organisation gains its overall coherence insofar as it is formed around what is referred to as the 'police métier', a term adopted from Manning (2010). According to the Oxford English Dictionary, the term métier is derived from ancient Latin and came to the English language via the Norman French. Originally the term was misterium, from which we get modern terms like Ministry and Mister. The word is probably also etymologically linked with the term 
mysterium, from which we get our modern word mystery. A métier is someone's profession, the implication being that membership includes some secret knowledge which is privilege of professional insiders. The police métier undergirds a specific intuitive grasp of situations peculiar to the police occupation (Bittner 1970; van Maanen 1974; Young 1991; Chan 2003). Peter K. Manning has made a persuasive case that translating occurrences from the general lifeworld into criminal 'incidents' and perhaps transforming those into a 'case' for criminal prosecution is the essential basis and the sacred centre of the police métier (Manning 2010, 2016). In this sense, the term police métier is understood to be a set of habits and assumptions focused on the trope of 'crime' that 'envisions only the need to control, deter and punish the visible and known contestants' (Manning 2010, p. 105-106). Understanding of the term is both broadened and deepened here. Following Brodeur (2007, 2010), Bittner (1970) and others, here the essence of police professionalism is understood to centre on the mastery of surveillance and coercion in the reproduction of order (Ericson 1982), the making of crime (Ericson 1981) and the governance of insecurity (Ericson and Haggerty 1997; Ericson 2007). The 'fundamental mindset' (Sklansky 2011) of 'the police' is oriented towards their métier like a sailor to the polestar.

The typical multi-functional police service found cities in North America and the UK, and some cities in Europe, assumes wide responsibilities - from traffic enforcement to policing protest. In the discussion that follows, it is understood that the police division-of-labour gains overall coherence as a set of organisational practices not because of functional command-and-control relationships. Analytically, they are to be understood in terms of positioning in the police division-of-labour and the intersecting intelligence foci. The processes undertaken within the police intelligence divisionof-labour - its routines, recipes, rituals and roles - are interpretable in terms of specific orientations to the police métier.

This article is organised in a number of sections. First is outlined the model police division-oflabour typical of the modern multi-functional urban police department. This is followed by a brief enumeration of seven foci of policing intelligence and a discussion of how these relate to various positions within the police division-of-labour. Analytically speaking, different positions within this configuration are concerned with four different aspects of intelligence activity: the acquisition of intelligence or information; the analysis of information in the production of intelligence; tasking and co-ordination on the basis of intelligence 'product'; or being tasked on that same basis. This picture of the police intelligence division-of-labour compliments the view of police organisations consisting of 'units' that police the boundaries between themselves (Giacomantonio 2015). Describing the police intelligence division-of-labour offers a useful guide for future comparative analysis of specific police institutions. It also provides an organisational map for charting the relations between different units that make up the contemporary urban police service as described in ethnographic accounts of, for example, drugs units (Bacon 2016), front-line primary response units (PRUs) (Moskos 2008), public order units (Jefferson 1990), homicide investigations (Innes 2003) and other 'units' that comprise an essential part of the policing web (Brodeur 2010). Further, describing the police intelligence division-of-labour as it is configured within the typical urban police department is essential to understanding how it fits in with security governance more generally (Johnston and Shearing 2003; Shearing and Marks 2011). A fortiori, it raises complex issues regarding the politics and governance of police (Ericson and Haggerty 2005). Ultimately this contribution helps in explaining the configuration of broader nodal relations of security governance in which police organisation is 'interpellated' (Boussard et al. 2006). ${ }^{2}$

\section{The police division-of-labour}

Police organisations are depicted in organisational diagrams which usually show the office of the chief at the apex of an organisational pyramid and array police departmental resources below it in hierarchical fashion reinforcing the image of a 'chain of command'. This common picture is modestly inaccurate. The orchestra pays only minimum heed to the conductor, or, in the words of Peter 
Moskos, 'The chain of command is a myth. A sergeant cannot be in active command of five units simultaneously' (2008, p. 112). Another reason why police organisational charts are rather fictitious is that they emphasise formal top-down relations between units leaving out the many horizontal connections and informal relations. They miss the fluidity of an organisation where individuals perform a variety of functions from patrol to office administration and frequently move between roles throughout a career lifetime. The 'hierarchical fiction' is important to keep in mind when describing the police division-of-labour in general and abstract terms because the description may blend with common conceptions of what the police do and how the organisation works which 'tend to be wrong' (Smith and Gray 1985, p. 309; Hobbs 1986, p. 198). Manning (2010), police are authoritatively co-ordinated, legitimate organisations that employ practices aimed at tracking, surveillance and arrest and remain ready to apply force, up to and including fatal force, in pursuit of the general organisational goal of maintaining social order and governing crime and insecurity. Multi-functional police agencies are also called upon to undertake a host of social service functions, for example, including responding to issues concerning homelessness, mental health and psychological distress. In Egon Bittner's wonderful turn of phrase, urban police have an emergency role in responding to myriad situations that cannot be predicted in advance and that can only be characterised as 'something that ought not to be happening about which something ought to be done now' (Bittner 1970; Brodeur 2007). According to Giacomantonio it is 'hard to imagine a public police force being organised - and considered legitimate - without at minimum a uniformed patrol division and reactive investigative services that deal with local crime and order problems' $(2015$, p. 20).

Table 1 presents an ideal-type model of the modern multi-functional police service. Manning observed that police organisations hold in reserve slack personnel resources that can be mobilised in the event of emergency (Manning 1992, p. 354-355). So, for example, resources indicated under the auspices of uniformed patrol in this diagram might be mustered under the heading of an operational public order support unit or an officer who is normally part of a community contact unit may also have a skill set (rarely put to use) in bomb disposal. Mutable and capable of coming together into units, squads, or teams that sometimes behave with military precision, the police organisation is flexible while it remains fundamentally oriented around the police métier. At minimum, the typical multifunctional police agency will have the capacity to deploy officers on uniform patrol (depicted in the top left of the diagram and split into three functions: PRUs, community response units (CRUs) and

Table 1. The police division of labour

\begin{tabular}{|c|c|c|c|c|}
\hline \multicolumn{4}{|c|}{ UNIFORM PATROL } & ADMINISTRATION \& MANAGEMENT \\
\hline $\begin{array}{c}\text { TYPE } \\
\text { Responsibilities }\end{array}$ & $\begin{array}{ll} & \text { PRUs } \\
\text { - } & \text { Incident } \\
\text { response } \\
\text { - } & \text { Directed } \\
\text { patrol } \\
\text { - } & \text { Proactive } \\
& \text { patrol }\end{array}$ & $\begin{array}{l}\text { CRUs } \\
\text { - Neighbourhood } \\
\text { liaison } \\
\text { - Incident follow-up } \\
\text { - Youth \& School } \\
\text { liaison } \\
\text { - Community } \\
\text { partnership }\end{array}$ & $\begin{array}{ll} & \text { TRAFFIC } \\
\text { - } & \text { Traffic } \\
& \text { enforcement } \\
- & \text { Directed Patrol } \\
- & \text { Impaired Driving } \\
& \text { Check-stop }\end{array}$ & 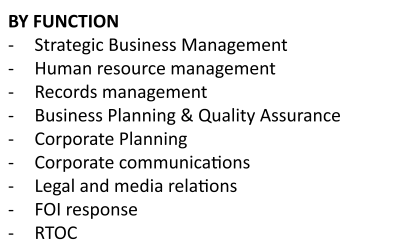 \\
\hline
\end{tabular}

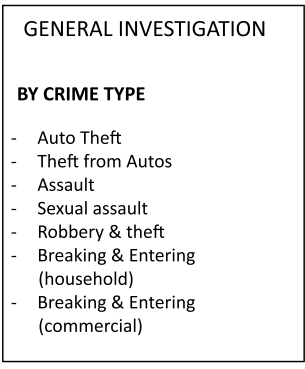

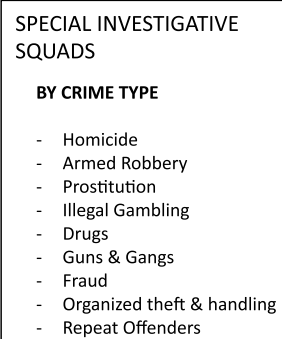

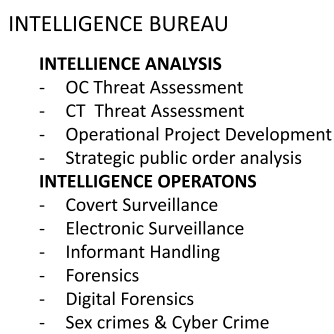

OPERATIONAL SUPPORT

BY FUNCTION

Canine handlers

Horse Mounted

Marine Unit

Aerial Surveillance Unit

VIP Close Protection

ETF (SWAT)

Public Order, Riot Squad \& Special Patrol Group 
traffic patrol) and will likely have the capacity to undertake investigations into 'high volume' crime (depicted on the bottom left). Central administrative functions, such as managing human resources and other administrative records are depicted at the top right-hand side of the diagram. Most, if not all, North American and British police services have a mixture of specialist detective squads (Hobbs 2013, p. 29) depicted in the bottom centre-left. Increasingly these police agencies are creating centralised intelligence centres or bureaus which is depicted in the bottom centre right. In this table, within the intelligence bureau a distinction is drawn between intelligence analysis and intelligence operations. Lastly, in most medium to large-scale multi-functional police services there are an array of operational support units - K9 unit, aerial reconnaissance, SWAT, etc. - and these specialist operational support units are depicted in the lower right-hand quadrant of the diagram. Such units are expensive to maintain and are, in a sense, a luxury. They are, however, redolent of the police métier. Percolating through the police division-of-labour is a myriad of knowledge, facts, information and intelligence that can be described, again in ideal-typical terms, as the seven intelligence foci of police knowledge work.

\section{Seven foci of police intelligence}

Echoing Delpeuch and Ross (2016), there are a plurality of intelligence foci that are put to use in the police organisation. Different kinds of knowledge, facts and information are considered relevant and in different ways depending on where particular actors are located within the police division-oflabour. In ideal-typical terms, there seven foci of police intelligence and chief among them are those having to do with criminal intelligence and public order intelligence (de Lint 2009; McCue 2014). These foci of intelligence are obviously closely aligned with the police métier. Using these lenses, police organisations amass information from a variety of sources about known and suspected criminals, troublesome persons and locations. Analysing these data, police organise to identify occurrences that can be translated into incidents and on that basis pursue an organisational response. In intelligence terms, responses can be reactive, that is intended to support the investigation of past occurrences for translation into criminal incidents pursuable as cases. A key terminological boundary here is the distinction between 'criminal intelligence' and 'criminal evidence'. The former has a projected 'internal career', the latter a projected 'external career' (Travers and Manzo 1997). Police insiders aim to keep criminal intelligence within the purview of a very narrow audience, whereas evidence is a matter of public record. Criminal intelligence can also be used as the basis of proactive policing. Proactive policing occurs when police resources are deployed on the basis of crime analysis (e.g. geo-temporal crime pattern analysis) with the intention of affecting some future situation (Manning 2008). Another two intelligence foci are serious organised crime and counter-terrorism. These lenses also have proactive and reactive aspects and are also closely oriented to the police métier. They are different for the degree of seriousness accorded to them and the consequently greater emphasis on proactive intelligence thinking. Whereas criminal intelligence forms a pool of information which is primarily a source for reactive investigation of crime and occasionally for more proactive planning, intelligence about serious organised crime and terrorism is thought of primarily in terms of proactive enforcement, opportunity reduction, disruption and prevention (Innes and Sheptycki 2004; McCulloch and Wilson 2016; Tilley 2016). Organised crime and terrorism intelligence are obviously similar in that both involve a high degree of presumed violence, threat and danger, but these foci differ from each other because the primary locus of the former concerns illicit market activity and the latter concerns politically motivated activity. Consequently the lens used to scope these activities is different in significant respects.

These four foci of police intelligence - criminal intelligence, public order intelligence, serious and organised crime intelligence and counter-terrorism intelligence - are closely oriented to the police métier which, as already discussed, is defined as a professional line involving specialist abilities in the orchestration of surveillance and coercive power in the governance of crime, disorder and insecurity. The other three intelligence foci designated here operate at different degrees of variance in 
orientation to the police métier. So-called 'community intelligence' is based on a wide variety of informational sources and is not necessarily related only to the occurrence of crime and instances or locations of public disorder. Thinking within the police métier, community intelligence can provide useful clues, for example, if focused through the lenses of serious and organised crime or counterterrorism analysis (Bayer 2010, p. 21-22, Delpeuch and Ross 2016). On the other hand, community and problem oriented policing prescribes a social crime prevention focus on community intelligence that aims to alter the circumstances productive of crime and disorder in the first instance (Ekblom 2003; Mouhanna 2008; Punch et al. 2008; Bullock 2013, 2014; Leighton 2016). Community intelligence can be focused on community capacity building, but doing so is tangential to the police métier (Skogan 2016). External audiences can regard the gathering of community intelligence in a variable light - ranging from demanding of service, grudging acceptance of presence, to not-so-welcome resentment to out-right hostile reception (Edwards and Hughes 2005; Hughes and Rowe 2007). Because community intelligence may be pursued in tandem with other intelligence foci and because some preoccupations of this lens do not necessarily clearly focus the police métier an aura of ambivalence surrounds it and this is true for both internal and external actors.

Multi-agency co-ordination intelligence is another foci which features a certain degree of variance with the police métier. In some contexts, multiple agencies from the police sector may be involved in joint operations or task forces. In other contexts multi-agency co-ordination intelligence involves working with non-police agencies. In either instance, multi-agency intelligence co-ordination can involve both private and public agencies. In all instances, when the multi-agency co-ordination intelligence lens is in use there are trust issues around information sharing between actors internal and external to the police métier (Aden 2016). Intrinsically, all constituent units in a given police organisation will have some concern with the ability to co-ordinate with other units (Giacomantonio 2015). Therefore multi-agency co-ordination intelligence is integral to police organisation but vacillating in orientation to the police métier.

The seventh and final foci concerns managerial and business intelligence which is at variance with the police métier because, although it aims at the strategic and, to a lesser extent, tactical management of police resources, the language of management draws heavily on the métier of the Business School and of new public sector management. In principle aimed at the efficient and effective management of police capacity, there can be discrepancies between the optimal view focused as managerial and business intelligence and other intelligence foci. For example, internal police threat assessments regarding the relative harm posed by different identifiable groups participating in illicit economic activity can be at variance with efficiency and effectiveness criteria used to evaluate the deployment of police resources. As a consequence proactive operational projects can end up focusing on the easy targets rather than the more difficult to get at but more socially harmful activities of other groups. Another example might be community intelligence gathering, where the efficacy of using information and police knowledge to contribute to community capacity building is undermined by quantitative metrics that measure street level enforcement activity. Yet another example could be management metrics for traffic policing that focus on issuing traffic citations and thereby obscure thinking about affecting road safety through environmental design.

These seven foci of police intelligence are different cognitive lenses that define police 'knowledge work' and make sense of the division of expert knowledge that comprises the police intelligence division-of-labour (cf. Haggerty and Ericson 2000; Ericson 1994). These lenses are affected by positioning within the police division-of-labour and the use of different intelligence foci are analytically distinct but may be practically intertwined. For example, general investigators who are normally interested in criminal intelligence having to do with volume crimes like assault, theft and robbery, may co-ordinate with a CRU in a multi-agency project affecting instances of vandalism in a particular area. In such an instance, investigative intelligence, community intelligence and multi-agency co-ordination intelligence foci may all be deployed in different positions within the police division-of-labour in the orchestration of operations. Observations about information boundaries and connections between 
and across units that constitute the typical urban police service are revealed as plural and complex and yet they attain coherence relative to the police métier.

\section{Location and function of intelligence foci in the police division-of-labour}

Table 2 classifies the police intelligence division-of-labour according to an analytical grid formed by the intersection of various roles within the police division-of-labour with the variety of intelligence foci. Institutionally speaking in an abstract sense there are four relevant activities: the acquisition (q) of intelligence or information; the analysis (an) of information in the production of intelligence; tasking and co-ordination (ta/co) on the basis of intelligence 'product'; or being operationally tasked (op/ta) on that same basis (Ratcliffe and Sheptycki 2009). These four activities are largely oriented with respect to the underlying logic of the police métier. There are different ways which the acquisition of intelligence can be undertaken, depending on position and role. For example, traffic enforcement units acquire intelligence through high volume license plate checks and special patrol units do the same by using street identity checks. On the other hand special investigations units and the intelligence bureau may, between them, compete over (and thereby confound) the acquisition of investigative intelligence and thereby distort the strategic intelligence analysis. Analysis is supposed to form the basis of decision-making in the operational tasking of units. Since PRUs are considered the 'backbone' of the archetypal urban police service, it is especially interesting to see how this role is configured by the demands of intelligence-led policing.

Scanning across the top row of the table shows the 'front line' PRUs. These units are often very busy answering to calls for service dispatched centrally. In this respect, such units are operationally tasked through intelligence and information processes. During down time, when not involved in primary response such units may be tasked with responsibility to acquire information suitable for entry on to police databases that could be put to other uses, for example identity checks and vehicle license checks may be subject to geo-temporal analysis useful in operationally tasking operational support units such as a special patrol group (SPG). When it comes to public order intelligence, PRUs are more often tasked by system information demands than they are involved in information

Table 2. Grid analysis of the police intelligence division-of-labour.

\begin{tabular}{|c|c|c|c|c|c|c|c|}
\hline & $\begin{array}{l}\text { Criminal } \\
\text { Intelligence }\end{array}$ & $\begin{array}{l}\text { Public Order } \\
\text { Intelligence }\end{array}$ & $\begin{array}{l}\text { Serious \& } \\
\text { Organized } \\
\text { Crime } \\
\text { Intelligence }\end{array}$ & $\begin{array}{l}\text { Counter- } \\
\text { Terrorism \& } \\
\text { Political } \\
\text { Crime } \\
\text { Intelligence }\end{array}$ & $\begin{array}{l}\text { Community } \\
\text { Security \& } \\
\text { Safety } \\
\text { Intelligence }\end{array}$ & $\begin{array}{l}\text { Multi-Agency } \\
\text { Co- } \\
\text { ordination } \\
\text { Intelligence }\end{array}$ & $\begin{array}{l}\text { Managerial \& } \\
\text { Business } \\
\text { Intelligence }\end{array}$ \\
\hline $\begin{array}{l}\text { Primary } \\
\text { Response Units } \\
\end{array}$ & $\mathrm{q} ; \mathrm{op} / \mathrm{ta}$ & $\mathrm{q} ; \mathrm{op} / \mathrm{ta}$ & $\mathrm{op} / \mathrm{ta}$ & $\mathrm{op} / \mathrm{ta}$ & op/ta & op/ta & $\mathrm{op} / \mathrm{ta}$ \\
\hline $\begin{array}{l}\text { Community \& } \\
\text { Neighbourhood } \\
\text { Patrol Units } \\
\end{array}$ & $\mathrm{op} / \mathrm{ta}, \mathrm{q}$ & $\mathrm{op} / \mathrm{ta}, \mathrm{q}$ & $\mathrm{op} / \mathrm{ta}, \mathrm{q}$ & $\mathrm{op} / \mathrm{ta}, \mathrm{q}$ & $\begin{array}{l}\text { q, an, ta/co, } \\
\text { op/ta }\end{array}$ & $\begin{array}{l}\mathrm{q}, \text { an, ta/co, } \\
\text { op/ta }\end{array}$ & $\mathrm{op} / \mathrm{ta}$ \\
\hline $\begin{array}{l}\text { Traffic Patrol } \\
\text { Units }\end{array}$ & $\mathrm{q}$ & $\mathrm{op} / \mathrm{ta}$ & $\mathrm{q}, \mathrm{op} / \mathrm{ta}$ & $\mathrm{q}, \mathrm{op} / \mathrm{ta}$ & $\mathrm{q}$, an, op/ta, & $\mathrm{op} / \mathrm{ta}$ & $\mathrm{op} / \mathrm{ta}$ \\
\hline $\begin{array}{l}\text { General } \\
\text { Investigative } \\
\text { Units } \\
\end{array}$ & $\mathrm{q}$; an & q; an & $\mathrm{op} / \mathrm{ta}$ & - & - & op/ta & op/ta \\
\hline $\begin{array}{l}\text { Specialist } \\
\text { investigation } \\
\text { units }\end{array}$ & q; an & $\mathrm{q} ; \mathrm{an} ; \mathrm{ta} / \mathrm{co}$ & $\begin{array}{l}\mathrm{q} ; \mathrm{an} ; \mathrm{ta} / \mathrm{co} \\
\mathrm{op} / \mathrm{ta}\end{array}$ & $\begin{array}{l}\text { q; an; ta/co; } \\
\text { op/ta }\end{array}$ & $\mathrm{q} ; \mathrm{an} ; \mathrm{ta} / \mathrm{co}$ & $\mathrm{q} ; \mathrm{an} ; \mathrm{ta} / \mathrm{co}$ & $\mathrm{op} / \mathrm{ta}$ \\
\hline $\begin{array}{l}\text { Intelligence } \\
\text { Bureau }\end{array}$ & $\mathrm{q} ; \mathrm{an} ; \mathrm{ta} / \mathrm{co}$ & $\mathrm{q} ; \mathrm{an} ; \mathrm{ta} / \mathrm{co}$ & $\mathrm{q} ; \mathrm{an} ; \mathrm{ta} / \mathrm{co}$ & $\mathrm{q} ; \mathrm{an} ; \mathrm{ta} / \mathrm{co}$ & $\mathrm{q} ; \mathrm{an} ; \mathrm{ta} / \mathrm{co}$ & q; an; ta/co & $\mathrm{op} / \mathrm{ta}$ \\
\hline $\begin{array}{l}\text { Operational } \\
\text { Support Units }\end{array}$ & $\mathrm{op} / \mathrm{ta}$ & $\mathrm{op} / \mathrm{ta}$ & $\mathrm{op} / \mathrm{ta}$ & $\mathrm{op} / \mathrm{ta}$ & $\mathrm{op} / \mathrm{ta}$ & $\mathrm{op} / \mathrm{ta}$ & $\mathrm{op} / \mathrm{ta}$ \\
\hline $\begin{array}{l}\text { Central } \\
\text { Management \& } \\
\text { Administration } \\
\end{array}$ & - & - & - & - & $\mathrm{q}$ & $\mathrm{q} ; \mathrm{an} ; \mathrm{ta} / \mathrm{co}$ & $\mathrm{q} ;$ an; ta/co \\
\hline
\end{tabular}

Notes: q: acquisition of intelligence/information; ta/co: tasking \& co-ordination;

an: analysis; op/ta: operationally tasked with intelligence. 
acquisition. Nonetheless, such units may be involved in gathering public order intelligence and, with the variety of technological aids to hand increasingly relay important information 'in real time'. PRUs may be operationally tasked on the basis of intelligence analysis involving serious and organised crime, counter-terrorism and community safety intelligence, but are rarely involved in intelligence acquisition focused specifically along these lines. Similarly, these units may be tasked on the basis of multi-agency co-ordination intelligence, but are not primarily involved in its production and are not considered useful repositories of such knowledge themselves. In terms of managerial and business intelligence, these units are managed on the basis of a number of key performance indicators, based on the expectations of the police métier; that is to say having to do with enforcement outcomes. Response times and occurrence resolutions are all subject to recording rules for the purposes of management. Studies of front-line police patrol reveal PRUs to be subject to the vagaries of computer-aided command-and-control systems and, apart from easing behaviour, there is very little discretion (Mastrofski 2005; Sanders and Hannem 2012).

Urban police agencies may differ in the organisational capacity put into primary response to citizen calls for service. Scanning across the second row of Table 2, in some police services, policework can take the form of community and neighbourhood teams (Edwards and Hughes 2005; Hughes and Rowe 2007; Gauthier 2016; Leighton 2016). In some versions the primary raison d'être of community officers is the acquisition, analysis, and tasking and co-ordination of multi-agency responses involving health (including mental health), education, social welfare and public housing all on the basis of community safety intelligence (Cockbain and Knutson 2013; Tilley 2013; Skogan 2016). In this event the convergent intersection of the $\mathrm{CRU}$ with a comprehensive community intelligence and multi-agency co-ordination intelligence foci could produce a self-tasking local area police and community safety partnership or a community security hub (Edwards and Hughes 2005; Bullock 2014). There are dangers. The external sharing of police information about crime and community safety can have perceived negative effects, for example, undermining property values (Barker 2016). In practice, the modus operandi of community policing is at variance with the police métier and, in any case, these capacities are being increasingly absorbed into counter-terrorism and serious organised crime intelligence acquisition (Murphy 2007; Klausen 2009). CRUs can be tasked with acquiring information and intelligence for other purposes, for example, in helping to acquire criminal investigative or public order intelligence, or organised crime and counter-terrorism intelligence. This position in the police division-of-labour involves multi-agency co-ordination intelligence work and boundary maintenance, because it often concerns work with non-police agencies. Officers in these positions act as conduits of information into the policing information environment and may selectively share police information with outside partners. Relevant managerial and business intelligence concerning the activities of those positioned in this part of the police division-of-labour is often project based. Community officers develop project plans, execute and evaluate them providing data for management purposes. Since community safety is reflected in the absence of indicators of crime and public disorder, it is often difficult for officers in these positions to produce management intelligence in direct concurrence with the police métier. Their greatest utility, from the point of view of police organisation, is the ability to acquire a broad range of information from different outside organisations, institutions and groups in the police task environment.

A typical multi-functional police agency will often undertake road traffic safety enforcement. In agencies of sufficient size this function can be consigned to specialists in the division-of-labour. Road traffic enforcement can be an end in itself but it can also be a pretext for intelligence acquisition in relation to other matters (Ingram 2007). Impaired driving stop checks deter drunk driving and associated license plate check data can be geo-temporally coded and put to other uses. The public order intelligence focus comes to bear when traffic units are tasked on a strategic basis in order to manage road congestion during parades, demonstrations and other large-scale events. When it comes to serious and organised crime intelligence and counter-terrorism intelligence foci, traffic units can have some peripheral involvement. For example, the rules of the road can provide pretexts for stopping vehicles and this can be useful in terms of acquiring relevant intelligence or 
information, or non-traffic enforcement outcomes (such as arrest for possession of narcotics) can occur. Seen through the lens of managerial and business intelligence, these units are primarily subject to key performance indicators relating to traffic citations for example: driving without a license or while impaired, speeding or distracted driving. Traffic policing could contribute to significantly to community safety if its allied intelligence processes for acquisition and analysis produced tasking requirements for the enhancement of road safety through environmental design; instead of which this role is harnessed to metrics that emphasise operational tasking for enforcement alone.

Investigative units are considered fundamental to the police division-of-labour. Traditionally, this role has been concerned with 'high volume' crime such as assault, theft and robbery. In matters related to criminal intelligence, investigative detectives both acquire and analyse information and they do so primarily in order to make cases and undertake arrests. A focus on public order intelligence analysis can operationally task investigative operations, for example concerning open-air drug and prostitution markets which impact community quality of life matters. Generalist investigative work is usually institutionally separate from serious and organised crime or counter-terrorism intelligence as well as the work of special units such as the 'vice squad', 'drug squad', 'hold-up squad'. The focus of the managerial and business intelligence lens on this aspect of the police division-of-labour reveals a central concern with clearing cases regarding relatively minor occurrences of theft, damage to property and violence. Measures of effectiveness are understood in terms of the rise and fall of criminal incidents in relation to numbers of arrests.

For a variety of historical reasons, most police agencies retain cadres of specialist detectives formed into squads which are a major source of idiosyncrasy in the organisation of policing (Manning 1980, 1997, 2016). Homicide, armed robbery, guns and gangs, drugs and vice, and now 'cybercrime' offer some of the major pretexts for the formation and retention of specialist investigative units. These positions are covalent with the police métier and consequently high status within the occupation. Such units are distinguished by their active and systematic approach to intelligence gathering marked by a specific investigative focus. In the case of specialist homicide and armed robbery units, the work is reactive: occurrences are translated by detectives into criminal incidents upon which they then try to build into cases. In the case of specialist anti-gang and drug units, work is often proactive: through the intensive use of surveillance teams, these squads gather information on particular individuals and groups for the purposes of criminal prosecution, frequently using organised crime and criminal conspiracy laws to do so. Such units are notorious hoarders of intelligence, because monopoly knowledge protects institutional turf. In some jurisdictions police services have created specialist units in response to political crime. For example, the development of Special Branch in the UK in the late nineteenth and early twentieth century was a response to the socalled Irish question. A focus on multi-agency co-ordination intelligence reveals tensions around this role, where external security agencies compete with nascent or existing specialist political crime units for operational tasking responsibility in relation to counter-terrorism. Special squads may also seek to acquire intelligence from and about the community or communities in their task environment so as to analyse and plan for tasking in operations and projects. Especially when it involves information sharing for proactive covert surveillance, multi-agency co-ordination intelligence work is highly circumscribed and is less about information sharing than it is intelligence acquisition. Managerial and business intelligence concerning the operation of special squads is concerned with project costs (e.g. measured in over-time pay) as against the value of making high-profile cases or achieving other markers of success. Sufficiently oriented to specialist investigative functions regarded as essential to the police métier, these high status units exhibit a relatively high degree of discretionary activity (Manning 1980, 1997; Hobbs 1988; Marx and Fijnaut 1995; Billingsley et al. 2001). This self-tasking and specialisation is at odds with some theories of intelligence-led policing which stress centralisation of strategic intelligence for the purposes of tasking and co-ordination (James 2013).

Intelligence bureaus, acting as general repositories for system-wide analytical capability, are seen to be increasingly important in the orchestration of the police intelligence division-of-labour. These 
are places where all manner of acquired information can be collated, filed and formatted - in short analysed - forming the basis for co-ordinated strategic and tactical operational tasking. As indicated in Table 1, a distinction between operational and analytical intelligence can be drawn. The former is concerned with different modes of intelligence acquisition. This includes mobile surveillance teams, electronic and cyber surveillance, informant handling and covert police operations. There is a significant overlap with the intelligence acquisition work of some special squads (Dunnighan and Norris 1999; Billingsley et al. 2001; James 2013; Manning 2016). In new and innovative areas of police work - for example, with regard to sexual offences with an 'on-line' or 'cyber' element, human trafficking for the purposes of sexual exploitation, or counter-terrorism and political crime - sometimes intelligence bureaus have taken responsibility, preempting the formation of new special squads or absorbing existing ones. A difficulty is that such bureaus often do not have the operational capacity to undertake enforcement operations and affect arrests and therefore must task and co-ordinate other units in order to do so. Scanning across the relevant row in Table 2, it can be seen that the ideal-typical Intelligence Bureau works to acquire and analyse relevant data, information and knowledge across six of the seven foci and on that basis aim to task and co-ordinate the work of other units. The practical limits of data warehousing are mitigated by the ambit of the police métier and the habits of specific organisations. Operational role differences are revealed in the varied orientations to the intelligence division-of-labour and sometimes organisational rivalries are observed (Manning 2016). Intelligence bureaus normally work with information that is intelligence. Special squads traditionally work with information that may become evidence. Moreover, special squads have the ability to mount enforcement operations, whereas the Intelligence Bureau typically does not. Disruption techniques are based on intelligence (Innes and Sheptycki 2004; Tilley 2016) and inter- and intraorganisational multi-agency collaboration intelligence may involve the production of evidence so there is a constant need to manage the evidence-intelligence boundary. Intelligence bureaus produce threat assessments and a variety of intelligence products for tasking and co-ordination of other units. Threat assessments with a projected internal career guide resource allocation decisions in operational planning. Threat assessments with a projected external career are intended to affect the perceptions of outside audiences. Risk assessments consider possible negative consequences for the organisation in the event of project failure. Intelligence Bureaus can potentially monopolise intelligence operations and analysis and, through tasking and co-ordination routines, thereby seek to exercise control of other units. If intelligence bureaus also have direct control of operational enforcement means they could be fuly self-tasking and in that event are potentially a 'firm within a firm'. Seen through the lens of managerial and business intelligence, the routine work of such centres is unquantifiable. Management evaluation is based on project outcomes and as long as there are no misadventures, such units are largely inviolable. It is now difficult to imagine a multi-functional police organisation that did not have facilities for managing large police databases, undertaking analytical work, formulating threat and risk assessments and recommending alternative operational plans.

There are a variety of operational support units in different police services. Common examples are K9 and mounted units, marine and aerial units, emergency response teams (i.e. 'SWAT' units), SPGs and riot squads. In virtually all instances, operational support teams are tasked on the basis of intelligence filtered through one or another of the intelligence foci. For example, mounted units can be deployed in the context of community policing or public order operations. Dog handlers and aerial reconnaissance units can be tasked to gather either evidence or intelligence. Where they exist, marine units serve multiple functions inclusive of primary response, traffic control and police community patrol on rivers, lakes and waterways and have similar relations to the police intelligence division-of-labour as does land-based front-line policing. Operational support units - the SPG (which are hand-picked units of uniformed patrol officers trained to undertake intensive field operations), the riot squad (trained to for large-scale public order events) and the emergency task force (ETF who are trained in special weapons and tactics), or specialists in VIP 'close protection' and bomb disposal - all offer gradations in orientation to the police métier. Often important symbols of 
police organisational potency, units like the mounted section (which reflect tradition and, hence, legitimacy) and the aerial surveillance unit (ensuring order with 'eyes in the sky') are difficult to subject to managerial and business intelligence solutions. Officers who deploy in many of these specialist units, often only do so on a part-time, 'as need' basis and normally fulfil work commitments in other roles.

The managerial and business intelligence lens is the last line of consideration in the police division-of-labour. As can be seen in Table 2, in ideal-typical terms, managerial and business intelligence does not intake information using any of the intelligence foci already enumerated. Managerial intelligence analysis is divorced from criminal intelligence and public order intelligence analyses, as it is from the details of serious and organised crime, counter-terrorism and community policing. Business analytics operate at a distance from the police métier. The metrics for business and managerial intelligence analysis do not concern the 'dirty details' of operational police information. For example, it is possible to know the fuel bills and over-time costs for mobile covert surveillance in a given context without knowing the operational details subsequent to the legal warrant authorising the operation. Business and managerial intelligence units have access to organisational systems data for the purposes of analysis and assessment of agency efficiency, effectiveness and economy. Strategic decisions about organisational tasking, co-ordination and resource allocation are made on the basis of business intelligence analysis. Occasionally, management units may undertake community surveys gathering information on community issues for the purposes of gauging police legitimacy, but these are not usually considered to be sources of operationally useful community intelligence. Administration in police organisations tends also to assume responsibility for a number of ancillary intelligence roles, in addition to things like archiving records concerning human resource allocation, quality assurance business and corporate planning - for example: corporate communications, legal and media relations and facilitation of freedom of information requests. In some of the larger police organisations, a 'real time operations centre' (RTOC) exists and is co-located within the administration offices. In the future these intelligence hubs will commonly operate on the basis of streams of data focused through the complete panoply of intelligence foci in 'real time' potentially enabling full spectrum direct strategic and tactical supervision of front-line uniformed patrol and detectives. Managerial intelligence can distort the police intelligence division-of-labour because economic criteria systematically misrepresent organisational goals pursued through other intelligence foci and are therefore a poor source of information to support the democratic governance of the urban police organisation.

\section{Discussion and conclusion}

It is seldom the case that researchers find themselves doing research inside a police organisation that is not in the midst of 'transformational change'. Every police organisation I have ever studied is either in the midst of an operational review, about to undertake a re-organisation based on one, or reorganisation has recently taken place. As the ancient Greek philosopher Heraclitus said, 'evernewer waters flow on those who step into the same rivers' (Warner 1958, p. 26). The question is, how to picture the river? The previous discussion is the result of an attempt to derive, by the processes of analytical induction, a theoretical picture of the endlessly transforming police intelligence division-of-labour of the typical contemporary urban police service. Accordingly analytical distinctions concerning the police division-of-labour and a variety of intelligence foci provide an analytical grid for describing the police intelligence division-of-labour. The analysis argued further that this picture gains organisational coherence relative to the police métier. The model should be broadly reflective of the situation in Europe, North America and the UK and is useful for comparative purposes and for understanding the interconnections that make up discrete roles that comprise the police organisation as a whole. However, it is an abstraction and its usefulness is chiefly that it provokes future research and thinking. The need for insight is especially acute in matters regarding democratic oversight of police and security governance. 
Table 2 reveals that some positions in the police intelligence division-of-labour exhibit wide discretion while others exhibit relatively narrow discretion. This adds substantial complexity to the classic picture of police organisations as being characterised by high discretion afforded by the increasing 'low visibility of decision-making' as one moves 'down the hierarchy' (Goldstein 1960; Skolnick 1967; Wilson 1968). In this model there is no hierarchy. Instead, the (often unspoken) logic of the police métier is operationalised by performing a variety of specifiable roles within a complex division-of-labour rationalised according to the concurrent preoccupations of several different intelligence lenses and it is in this sense that the archetypal municipal police service can be said to be organised. A key feature of the police intelligence division-of-labour appears to be the management of the boundary between internally circulated information and intelligence, and evidence. The later has a projected external career. The boundary between internal and external knowledge is in continual negotiation with respect to the multi-agency co-ordination intelligence focus, but certain positions within the division-of-labour are expressly concerned with such boundaries, albeit in different ways. Investigative units think differently about the boundaries between internally circulated intelligence and externally released evidence than does the CRU or the media relations department. CRUs and PRUs are more or less oriented to pole star of the police métier and the former inevitably play a complicated game with respect to acquiring community intelligence and disseminating police information to the outside world. This complex picture of the police intelligence division-of-labour raises interesting challenges for democratic governance and adds nuance to our understanding of the politics of police surveillance and visibility (Ericson and Haggerty 2005).

The analytical grid used here to describe the police intelligence division-of-labour reveals the informational dissociation of managerial and business intelligence from all other intelligence foci. Organisational information 'stove-piping' is usually thought of negatively in relation to the hoarding of intelligence by special squads, or by specific operational intelligence focus (say to do with 'organised crime' or 'terrorism'), but with managerial intelligence the stove pipe effect is system wide. The entire police division-of-labour is subject to comprehensive surveillance in the service of acquiring management knowledge by which to strategically task and co-ordinate the organisation according to a business logic disaffiliated from the police métier. This view of the police intelligence divisionof-labour adds complexity to the long ago observed gap between 'street cops' and 'management cops' (Reuss-lanni 1983; Chan 2001). These structural conditions help to explain the persistent problems of governing policing by numbers and targets (Young 1991; Perrin 1998; Maguire 2000; Fassin 2011; de Maillard and Mouhanna 2016) and partly explain the importunate organisational pathologies that plague police intelligence systems (Sheptycki 2004). Existing research suggests that the development of RTOCs will likely reinforce organisational pretensions to the rationality of organisational 'chain of command' (Weisburd et al. 2003; Mastrofski 2005, 2007; McCue 2014). The organisational domination of managerial and business intelligence over the police division-of-labour focuses on the improvement of artificial metrics of police accountability and again raises complex questions about democratic police governance, especially in a period where the economics of policing are dominated by neo-liberal thinking (Sanders and Sheptycki 2016).

This theoretical picture of the police intelligence division-of-labour is not a machine model. It is a schema for understanding the positioning of people in relation to the police métier, which is here defined broadly with reference to the professional craft knowledge concerning the means of surveillance and coercion in making crime, reproducing order and governing insecurity. Within this schema individual people occupy identifiable positions and adjust their work routines, recipes, rituals and roles with regard to the inter-organisational uses that different kinds of information and intelligence propose. Those individual adjustments are based on rationally self-interested calculations and personal considerations that are shaped by situationally conditioned perceptions within the intelligence division-of-labour oriented to the police métier. The police intelligence division-of-labour is designed to limit and facilitate access to information on a 'need to know' basis, but different positions in the schema give greater or lesser strategic access to different kinds of information and individual discretion is thereby shaped and limited in different ways. The structure of these informational relations, 
both formal and informal, is the seedbed of human organisational politics the irrationality of which is one of the primary reasons why police institutions are not simple bureaucratic machines (Sheptycki 2017).

This analysis suggests how to begin to explore the ways in which 'the police' configure in broader networks of security governance. The police métier encourages the conservation and strictly limited application of police power to undertake surveillance and utilise coercive power and all organisational resources are bent to the task of facilitating this. There are a striking number of one-way intelligence channels by which police organisations filter selected knowledge to outside audiences. Intelligence and information acquisition similarly goes on through multiple channels. Information sharing straddles boundaries within the division-of-labour and generally the outcome of analysis is a reflection of the police métier. Police-to-police intra-agency sharing of information is different that sharing with non-police agencies because of fundamental differences in orientation to the police métier as either 'insiders' or 'outsiders'. Multi-agency co-ordination intelligence processes facilitate knowledge about, and exchange with, security network partners. Any resulting selective interpellation of the police métier into institutionalised collaborations of security governance is an ideological move by police agents that imbues governance with the stamp of authority.

\section{Notes}

1. Due to limitations of word length, fieldwork methods cannot be discussed more fully here. For a general discussion of the use of analytic induction and grounded theory see Glaser and Strauss (2009). For a focused discussion of fieldwork policework see Manning (1997) and Manning (2006). Methodological considerations underpinning this particular analysis can be found in: Innes and Sheptycki (2004), Sheptycki (1996, 1998, 2001, 2003, 2004, 2016, 2017).

2. The term 'interpellation' is familiar in French political theory and is etymological derived from the Latin interpellatio, meaning to arrest or interrupt. Interpellation infers the act of control by means of the power of arrest and it also gestures at the image of a judicial demand to do or say something. In French political theory the term has sometimes been used to indicate an ideological and practical process by which people are subject to police power (Rancière et al. 2001).

\section{Acknowledgements}

The author would like to thank Christian Mouhanna, Karine Coté-Boucher, Christopher Giacomantonio, Jacqueline Ross and the two anonymous reviewers of a previous draft. Their insights, questions and encouragement helped considerably in clarifying the analysis. Any shortcomings remain my own.

\section{Disclosure statement}

No potential conflict of interest was reported by the authors.

\section{Funding}

This work was supported by Social Science and Humanities Research Council of Canada [Grant number Insight Grant No. 435-2013-1283].

\section{References}

Aden, H., 2016. The role of trust in the exchange of police information in the European multi-level system. In: T. Delpeuch and J.E. Ross, eds. Comparing the democratic governance of police intelligence. Northampton, MA: Edward Elgar, 322346.

Bacon, M., 2016. Taking care of business; police detectives, drug law enforcement and proactive investigation. Oxford: Clarendon.

Barker, A., 2016. Information as a form of democratic participation in policing: some critical reflections on the role and use of online crime maps in the United Kingdom. In: T. Delpeuch and J.E. Ross, eds. Comparing the democratic governance of police intelligence. Northampton, MA: Edward Elgar, 86-115. 
Bayer, M.D., 2010. The blue planet: informal international police networks and national intelligence. Wasington, DC: US Gov't Printing Office; Center for Strategic Intelligence Research.

Billingsley, R., Nemitz, T., and Bean, P., 2001. Informers; policing, policy and practice. Cullompton: Willan.

Bittner, E., 1970. The functions of police in modern society. Chevy Chase, MD: National Institute of Mental Health.

Boussard, Valérie, Loriol, Marc, and Caroly, Sandrine, 2006. Catégorisation des usagers et rhétorique professionnelle: Le cas des policiers sur la voie publique. Sociologie du Travail, 48 (2), 209-225.

Brodeur, Jean-Paul., 2007. An encounter with Egon Bittner. Crime, law and social change, 48 (3), 105-132.

Brodeur, Jean-Paul., 2010. The policing web. Oxford: Oxford University Press.

Bullock, K., 2013. Community, intelligence-led policing and crime control. Policing and society, 23 (2), 125-144.

Bullock, K., 2014. Citizens, community and crime control. Basingstoke: Palgrave Macmillan.

Chan, J., 2001. E-policing; the impact of information technology on policing. Queensland: Criminal Justice Commission.

Chan, J., 2003. Fair cop; learning the art of policing. Toronto: University of Toronto Press.

Cockbain, Ella and Knutson, Johannes, eds., 2013. Applied police research: challenges and opportunities. London: Routledge.

Delpeuch, T. and Ross, J.E., 2016. Comparing the democratic governance of police intelligence. Northampton, MA: Edward Elgar.

Dunnighan, C. and Norris, C., 1999. The detective, the snout and the audit commission: the real costs of using informants. The howard journal of criminal justice, 38 (1), 67-86.

Edwards, A. and Hughes, G., 2005. Comparing safety in Europe: a geo-historical approach. Theoretical criminology, 9 (3), 345-363.

Ekblom, P., 2003. Organized crime and the conjunction of criminal opportunity framework. In: A. Edwards and P. Gills, eds. Transnational organized crime; perspectives on global security. London: Routledge, 241-263.

Ericson, R.V., 1981. Making crime; a study of police detective work. Toronto: Butterworths.

Ericson, R.V., 1982. Reproducing order, a study of police patrol work. Toronto: Toronto University Press.

Ericson, R.V., 1994. The division of expert knowledge in policing and security. British journal of sociology, 45 (2), 149-175.

Ericson, R.V., 2007. Crime in an insecure world. Cambridge: Polity.

Ericson, R.V. and Haggerty, K.D., 1997. Policing the risk society. Oxford: Clarendon.

Ericson, R.V. and Haggerty, K.D., eds., 2005. The new politics of surveillance and visibility. Toronto: University of Toronto Press.

Fassin, D., 2011. Enforcing order; an ethnography of urban policing. Cambridge: Polity Press.

Gauthier, Jérémie, 2016. Cultural profiling? Police prevention and minorities in Berlin. In: T. Delpeuch and J.E. Ross, eds. Comparing the democratic governance of police intelligence. Northampton, MA: Edward Elgar, 253-272.

Giacomantonio, C., 2014. A typology of police organizational boundaries. Policing and society, 24 (5), 545-565.

Giacomantonio, C., 2015. Policing integration; the sociology of police co-ordination work. London: Palgrave Macmillan.

Gill, P., 1998. Making sense of police intelligence? The use of a cybernetic model in analysis information and power in police intelligence processes. Policing and society, 8, 289-314.

Glaser, B.G. and Strauss, A.L., 2009. The discovery of grounded theory: strategies for qualitative research, (reprint). New Brunswick: Transaction.

Goldstein, J., 1960. Police discretion not to invoke the criminal process: law visibility decisions in the administration of justice. Yale law journal, 69 (4), 543-594.

Haggerty, K.D. and Ericson, R.V., 2000. The surveillant assemblage. The British journal of sociology, 51 (4), $605-622$.

Hobbs, D., 1986. Review of police and people in London. British journal of criminology, 26 (1), 197-198.

Hobbs, D., 1988. Doing the business; entrepreneurship, the working class and detectives in the East end of London. Oxford: Clarendon.

Hobbs, D., 2013. Lush life; constructing organized crime in the UK. Oxford: Clarendon.

Hughes, G. and Rowe, M., 2007. Neighbourhood policing and community safety; researching instabilities of the local governance of crime, disorder and security in the contemporary UK. Criminology and criminal justice, 7 (4), $317-346$.

Ingram, J.R., 2007. The effect of neighborhood characteristics on traffic citation practices of the police. Police quarterly, 10 (4), 371-393.

Innes, M., 2003. Investigating murder; detective work and the police response to criminal homicide. Oxford: Clarendon.

Innes, M. and Sheptycki, J., 2004. From detection to disruption; intelligence and the changing logic of police crime control in the United Kingdom. International criminal justice review, 14, 1-24.

James, A., 2003. Advance of intelligence-led policing strategies: the Emperor's new clothes. Police journal, 76 (1), $45-59$. James, Adrian. 2013. Examining intelligence-led policing; developments in research, policy and practice. London: Palgrave Macmillan.

Jefferson, T., 1990. The case against paramilitary policing. Milton Keynes: Open University Press.

Jobard, F. and de Maillard, J., 2015. Sociologie de la police. Paris: Armand Colin.

Johnston, L. and Shearing, C., 2003. Governing security. London: Routledge.

Jones, T., Newburn . T., and Smith, D., 1996. Policing and the idea of democracy. British journal of criminology, 36 (2), $182-$ 198. 
Klausen, Jytte. 2009. British counter-terrorism after 7/7: adapting community policing to the fight against domestic terrorism. Journal of ethnic and migration studies, 35 (3), 403-420.

Leighton, B.N., 2016. Community policing in Canada: the broad blue line. In: Julian Roberts and M.G. Grossman, eds. Criminal justice in Canada; a reader. Toronto: Nelson, 128-140.

de Lint, W., 2009. Intelligent control; developments in public order policing in Canada. Toronto: University of Toronto Press. van Maanen, J., 1974. Working the street: a developmental view of police behavior. In H. Jacob, ed. The potential for reform of criminal justice. Beverly Hills, CA: Sage, 83-130.

Maguire, M., 2000. Policing by risks and targets: some dimensions and implications of intelligence-led crime control. Policing and society, 9 (4), 315-336.

Maguire, E.R., 2010. Police organizations and the iron cage of rationality. In: M.D. Reisig and R.E. Kane, eds. The Oxford handbook of police and policing. Oxford: Oxford University Press, 68-98.

Maguire, E.R. and Uchida, C.D., 2015. Explaining police organizations. In: E.R. Maguire and D.E. Duffe, eds. Criminal justice theory: explaining the nature and behavior of criminal justice. 2nd ed. London: Routledge, 81-115.

Manning, Peter K., 1980. The Narc's game: organizational and informational limits of drug law enforcement. Cambridge: MIT Press.

Manning, Peter K., 1992. Information technologies and the police. In: Michael Tonry, ed. Crime and justice Vol. 15 modern policing. Chicago: Chicago University Press, 349-398.

Manning, Peter K., 1997. Police work; the social organization of policing. 2nd ed. Prospect Heights, ILL: Waveland Press.

Manning, Peter K., 2006. Fieldwork in transition. In: D. Hobbs and R. Wright, eds. The sage handbook of fieldwork. London: Sage, 361-376.

Manning, Peter K., 2008. The technology of policing: crime mapping, information technology, and the rationality of crime control. New York: New York University Press.

Manning, Peter K., 2010. Democratic policing in a changing world. Boulder: Paradigm.

Manning, Peter K., 2016. Democratic policing; case working and intelligence. In: Thierry Delpeuch and Jacqueline E. Ross, eds. Comparing the democratic governance of policing intelligence. Cheltenham: Edward Elgar, 180-202.

Manning, Peter K., and van Maanen, John, 1978. Policing a view from the street. Santa Monica, CA: Goodyear.

Marks, M. and Sklansky, D., 2013. Police reform from the bottom up. Abingdon, Oxon: Routledge.

Marx, G. and Fijnaut, C., eds., 1995. Undercover: police surveillance in comparative perspective. The Hague: Kluwer.

Mastrofski, S.D., 2005. Making sense of COMPSTAT: how popular police reform works and doesn't work. In: D. Weisbburd, and A. Braga, eds. Prospects and problems in an era of police innovation; contrasting perspectives. Cambridge: Cambridge University Press, 133-154.

Mastrofski, S.D., 2007. Police organization and management issues for the next decade. Washington, DC: Bureau of Justice Assistance.

McCue, C., 2014. Data mining and predictive analysis; intelligence gathering and crime analysis. 2nd ed. Amsterdam: Elsevier.

McCulloch, J. and Wilson, D., 2016. Precrime; pre-emption, precaution and the future. London: Routledge.

de Maillard, Jacques and Mouhanna, Christian, 2016. Governing the police by numbers; the French experience. In: T. Delpeuch and J.E. Ross, eds. Comparing the democratic governance of police intelligence. Northampton, MA: Edward Elgar, 273-300.

Monjardet, D., 1985. A la recherché du travail policier. Sociologie du Travail, 27 (4), 391-407.

Monjardet, D., 1996. Ce que fait la police. Sociologie de la force publique. Paris: Le Découverte.

Moskos, P., 2008. Cop in the hood: my year policing Baltimore's Eastern district. Princeton: Princeton University Press.

Mouhanna, C., 2008. The failure of 'ilotage' and 'police de proximite' systems to withstand 'law and order': rhetoric in contemporary France. In: Tom Williamson, ed. The handbook of knowledge based policing: current conceptions and future directions. Chichester, Sussex: Wiley, 95-116.

Mouhanna, C., 2009. The French centralized model of policing; control of citizens. In D. Wisler and I.D. Onwudiwe, eds. Community policing; international patterns and comparative perspectives. London: CRC Press/Taylor and Francis, 103124.

Murphy, C., 2007. 'Securitizing' Canadian Policing: A New Policing Paradigm for the Post 9/11 Security State? . 'Securitizing' Cana dian Policing: A New Policing Paradigm for the Post 9/11 Security State? , 32 (4), 451-477.

Perrin, B., 1998. Effective use and misuse of performance measurement. American journal of evaluation, 19 (3), $367-379$.

Peterson, Marilyn, 2005. Intelligence-led policing: the new intelligence architecture. Washington, DC: National Institute of Justice, NIJ 210681.

Punch, M., 2011. Police corruption; deviance, accountability and reform in policing. London: Routledge.

Punch, M., Hoogenboom, B., and van der Vijver, K., 2008. Community policing in the Netherlands: Four generations of redefinition. In: Tom Williamson, ed. The handbook of knowledge based policing: current conceptions and future directions. Chichester, Sussex: Wiley, 59-78.

Rancière, Jacques, Panagia, Davide, and Bowlby, Rachel., 2001. Ten theses on politics, theory and event. Project MUSE, 5 (3). doi:10.1353/tae.2001.0028.

Ratcliffe, J.H., 2016. Intelligence-led policing. Cullhompton: Willan. 
Ratcliffe, J.H. and Sheptycki, J., 2009. Setting the strategic agenda. In: J. Ratcliffe, ed. Strategic thinking in criminal intelligence. Annadale, NSW: The Federation Press, 2004, 194-210.

Reiner, R., 2010. The politics of the police, 4, 4th ed. Oxford: Oxford University Press.

Reuss-lanni, E., 1983. The two cultures of policing; street cops and management cops. New Brunswick, NJ: Transaction Books.

Sanders, Carrie B. and Hannem, S., 2012. Policing 'the risky': technology and surveillance in everyday policework. The Canadian review of sociology/Revue Canadienne de sociologie, 49 (4), 389-410.

Sanders, Carrie B. and Henderson, Samantha, 2013. Police 'empires' and information technologies; uncovering material and organizational barriers to information sharing in Canadian police services. Policing and society, 23 (2), $243-260$.

Sanders, Carrie B. and Sheptycki, J., 2016. Policing, crime and 'big data'; towards a critique of the moral economy of stochastic governance. Crime, law and social change. doi:10.1007/s10611-016-9678-7.

Shearing, C. and Marks, M., 2011. Being a new police in the liquid $21^{\text {st }}$ century. Policing, 5 (3), 210-218.

Sheptycki, J., 1996. Law enforcement, justice and democracy in the transnational arena. International journal of the sociology of law, 24 (1), 61-75.

Sheptycki, J., 1998. Police co-operation in the English channel region 1968-1996. European journal of crime, criminal law and criminal justice, 6 (3), 216-235.

Sheptycki, J., 2001. Patrolling the new European (in)security field; organisational dilemmas and operational solutions for policing the internal borders of Europe. European journal of crime, criminal law and criminal justice, 10(2), $144-158$.

Sheptycki, J., 2003. The governance of organised crime in Canada. The Canadian journal of sociology, 28 (3), $489-517$.

Sheptycki, J., 2004. Organizational pathologies in police intelligence systems; some contributions to the lexicon of intelligence-led policing. The European journal of criminology, 1 (3), 307-332.

Sheptycki, J., 2016. In there like a dirty shirt; reflections on fieldwork in the Police Organization. In: George A. Antonopoulos, ed. Illegal entrepreneurship, organized crime and social control; Vol. 14 of the series studies of organized crime. New York, NY: Springer International, 343-357.

Sheptycki, J., 2017. Liquid modernity and the police métier; thinking about information flows in police organisation. Global Crime. doi:10.1080/17440572.2017.1313734.

Sklansky, D.A., 2011. The persistent pull of police professionalism. Boston, MA: New Perspectives in Policing Series, Harvard Kennedy School of Governement.

Skogan, W.G., 2016. Beat meetings, responsiveness to community and police effectiveness in Chicago. In: T. Delpeuch and J.E. Ross, eds. Comparing the democratic governance of police intelligence. Northampton, MA: Edward Elgar, 27-42.

Skolnick, J., 1967. Justice without trial. New York: Wiley.

Smith, D.J. and Gray, J., 1985. Police and people in London. London: Policy Studies Institute.

Stenning, P., 2009. Governance and accountability in a plural policing environment - he story so far. Policing, 3 (1), $22-33$.

Tilley, N., 2013. Handbook of crime prevention and community safety. London: Routledge.

Tilley, N., 2016. Intelligence-led policing and the disruption of organized crime: motifs, methods and morals. In: T. Delpeuch, and J.E. Ross, ed. Comparing the democratic governance of police intelligence. Northampton, MA: Edward Elgar, 153-179.

Travers, M. and Manzo, John F., 1997. Law in action: ethnomethodological and conversation analytic approaches to law. Aldershot: Ashgage/Dartmouth.

Warner, Rex. 1958. The Greek philosophers. New York: Mentor Books.

Weisburd, D., et al., 2003. Reforming to perserve: COMPSTAT and strategic problem solving in American policing. Criminology and public policy, 2 (3), 421-456.

Wilson, J.Q., 1968. Varieties of police behavior. Cambridge, MA: Harvard University Press.

Young, M., 1991. An inside job. Oxford: Clarendon. 


\title{
Boundary crossing: networked policing and emergent 'communities of practice' in safeguarding children
}

\author{
Adam Crawford and Xavier L'Hoiry
}

\begin{abstract}
Child safeguarding has come to the forefront of public debate in the UK in the aftermath of a series of highly publicised incidents of child sexual exploitation and abuse. These have exposed the inadequacies and failings of inter-organisational relations between police and key partners. While the discourse of policing partnerships is now accepted wisdom, progress has been distinctly hesitant. This paper contributes to understanding both the challenges and opportunities presented through working across organisational boundaries in the context of safeguarding children. It draws on a study of relations within one of the largest Safeguarding Children partnerships in England, developing insights from Etienne Wenger regarding the potential of 'communities of practice' that innovate on the basis of everyday learning through 'boundary work'. We demonstrate how such networked approaches expose the differential power relations and sites of conflict between organisations but also provide possibilities to challenge introspective cultures and foster organisational learning. We argue that crucial in cultivating effective 'communities of practice' are: shared commitment and purpose; relations of trust; balanced exchange of information and resources; mutual respect for difference; and an open and mature dialogue over possible conflicts. Boundary crossing can open opportunities to foster increased reflexivity among policing professionals, prompting critical self-reflection on values, ongoing reassessment of assumptions and questioning of terminology. Yet, there is an inherent tension in that the learning and innovative potential afforded by emergent 'communities of practice' derives from the coexistence and interplay between both the depth of knowledge within practices and active boundaries across practices.
\end{abstract}

\section{Introduction}

Risks to children and young people posed by adults have multiple, often inter-related, causes, while conceptions of the nature of child maltreatment are themselves historically relative and subject to the shifts across time, place and culture. In recent years, child protection has become increasingly politicised, notably in England (Parton 2014), often as a proxy for a range of debates about the efficacy of health, welfare and policing professionals; their expertise, specialisation and interdependent relations. Safeguarding children against contemporary risks and harms cuts across the responsibilities, competencies and expertise of diverse organisations. It involves the police working closely with partner agencies - in health, education, social care and youth services inter alia - with

This is an Open Access article distributed under the terms of the Creative Commons Attribution License (http://creativecommons.org/licenses/by/4.0/), which permits unrestricted use, distribution, and reproduction in any medium, provided the original work is properly cited. 
contrasting cultures, priorities and practices. Safeguarding children constitutes an exemplary 'wicked problem' as formulated by Rittel and Webber (1973) to highlight social or cultural issues that are difficult or impossible to solve due to incomplete or contradictory knowledge, have innumerable causes, do not necessarily have a right answer and are the subject of fragmentation under the contemporary division of professional labour. They elaborate: 'The information needed to understand the problem depends upon one's idea for solving it ... to describe a wicked problem in sufficient detail, one has to develop an exhaustive inventory of all conceivable solutions ahead of time' (Rittel and Webber 1973, p. 161, emphasis in original). Yet, the contemporary 'conceivable solutions' are themselves all refracted through differing professional and organisational lenses; they tend to be bureaucracy-premised rather than problem-oriented - myopic and differentiated rather than holistic and joined up (Crawford 2001). Fragmentation suggests a condition in which those people and organisations involved see themselves as more separate than united, and in which information and knowledge are chaotic and scattered. The complex institutional division of labour that surrounds safeguarding children and young people exhibits diverse disciplinary perspectives, epistemologies and methodologies, as well as organisational and cultural barriers. The challenge for contemporary organisations when addressing such 'wicked' issues is how to combine effectively the contributions of different knowledgeable and competent actors towards a clear understanding of the problems and generate professional confidence in delivering appropriate interventions.

This paper contributes to understanding both the barriers and opportunities presented through working across organisational boundaries for contemporary policing through a study of relations within one of the largest Safeguarding Children partnerships in the UK; with a reputation for constructive partnership relations in a challenging national context. It develops insights from Wenger (1998) regarding 'communities of practice' that innovate on the basis of everyday learning and advances a concept of 'boundary work'. We demonstrate how such networked approaches at the confluence of organisations expose the differential power relations and sites of conflict between organisations but also provide possibilities to foster organisational learning and challenge introspective cultures. We argue that crucial in cultivating emergent trans-disciplinary 'communities of practice' are five features: shared commitment and purpose; trust relations; balanced exchange of information and resources; mutual respect for difference; and an open and mature dialogue over possible conflicts. Each of these is considered, in turn, and illustrated through fieldwork examples. We explore the ways in which 'boundary work' can open up opportunities to foster increased reflexivity among policing professionals, prompting critical self-reflection on values, ongoing reassessment of assumptions and questioning of terminology. As such, the paper seeks to prompt new explorations of the possibilities for organisational learning and innovation that arise among 'communities of practice' through boundary work at the interface between distinct professionals with very different cultural assumptions and practices.

The paper proceeds first by highlighting the centrality of partnerships in contemporary policing and the challenges of police organisational culture therein, before going on to sketch the conceptual contours of 'communities of practice' as a framework for analysing what we call 'boundary work'. By way of context, we then outline key recent developments in child protection in the UK that have prompted a 'politics of outrage' (Parton 2014). We go on to explore insights from the research case study regarding boundary crossing and working relations between professionals delivering child safeguarding. These are organised around five core features of communities of practice that emerged from the empirical findings. We conclude with some reflections on the future and the implications for creative trans-professional practices.

\section{Police organisational change}

Given the complex and interdependent causes of crime and disorder, by necessity contemporary policing is embedded in a constellation of inter-agency partnerships. Hence, various commentators have highlighted the need to open up policing and crime control through inter-institutional and inter-disciplinary collaborations with other public, private and third sector providers to encompass 
holistic approaches to 'security governance' (Johnston and Shearing 2003) through networks, alliances and partnerships (Fleming 2006, Bratton and Tumin 2012). These novel approaches recognise that the levers and causes of crime lie far from the traditional reach of the police, let alone the criminal justice system. Crucially, there is no single agency solution to crime, given the multi-faceted nature of its causes and effects. Analogous notions of 'plural policing' (Crawford et al. 2005) and 'nodal governance' (Wood and Shearing 2007) allude to the multi-dimensional and cross-cutting competencies and capabilities of diverse actors in responding to crime-related harms and their prevention. Central to all is the challenge of effectively harnessing the diverse contributions of different actors and agencies in ways that contribute to desirable community safety outcomes.

While the discourse of policing partnerships is now generally accepted wisdom, and institutional frameworks exist to coordinate collective responses and pursue collaborative delivery, nevertheless, progress has been hesitant, uneven and constrained (Crawford and Cunningham 2015). Despite several decades of innovations in practice and research into partnership in community safety, many of the obstacles highlighted in the early years (Sampson et al. 1988, Crawford 1994, 1997) remain stubbornly persistent today. Consequently, much research analysis has centred on the barriers to effective partnership working and the causes of 'collaborative inertia' which, for Vangen and Huxham (2003, p. 62), 'relates to the often-pertaining actual outcome, in which the collaboration makes only hard fought or negligible progress'. Less attention has been given to the creative opportunities for organisational innovation and learning that collaborative working afford. Similarly, less regard has been given to the importance of practitioners' self-identity, commitment, values and motivation in fostering (or resisting) change and the role of boundary crossing therein.

Policing scholars have highlighted the stubbornness of police culture in the face of intentional organisational transformations (see Reiner 2010). Some time ago, Chan noted how change in policing is frequently resisted if it

challenges existing definitions of the problems, if it makes officers feel more vulnerable and their work less predictable, if it deviates from the accepted methods of how their work is to be accomplished, if it does not accord with 'commonsense', if it violates their collective values.(1997, p. 235)

Here, culture is understood as the everyday collective mentalities and sensibilities through which experiences, expectations and behaviour are interpreted and given meaning and by means of which people 'communicate, perpetuate, and develop their knowledge about and their attitudes toward life' (Geertz 1973, p. 89). This translates into 'how officers learn the craft of the job, use their time and interact with different people' (Loftus 2010, p. 1). As a dynamic force, this comes close to an understanding of culture as a product of social learning (Wenger 1998). Forged in everyday interactions, police culture can take different forms and expressions among discrete units and sub-groups within the organisation engaged in distinct activities, external relationships and encounters with the public. Regardless, anchoring change in frontline organisational culture, demands working with the intrinsic motivations, values, commitments, beliefs and everyday social practices of those charged with delivering change on the ground. Evidently, organisational cultures can serve both as impediments to, and facilitators of, strategic change, particularly when located at the interface of differing organisations.

However, police culture is often understood as both overly homogenous (with less attention to differences between hierarchies and specialist sub-teams within the organisation) and in a negative light as constraining innovations and change. While culture can be a conservative force of tradition, it can also be a vibrant source of everyday coping and learning (Loftus 2010). Similarly, insufficient attention has been given to aspects of organisational cultures that unite practitioners working in different professions. There are, of course, important common cultural characteristics that cut across occupational boundaries (Nash and Walker 2009). Charman (2013) usefully highlights the role of humour and banter by police and ambulance staff as a means of making sense of what can be unpleasant, unpredictable and stressful situations. She shows the ways in which: 'The humour of exclusion and the humour of superiority are used to good effect to create shared cultural 
understandings, reinforce group values and strengthen the bonds between organisations' (2013, p. 162). These bonds of solidarity and camaraderie are borne of a shared environment, common street-work and common exposure to difficult emergency situations.

As such, it is instructive to consider partnership working not simply from the viewpoint of institutional fault-lines and structural dynamics - as important as these are - but also from the perspective of professional practices, especially where these are situated in novel inter-institutional spaces at the edges of organisations and in emergent configurations. Hence, in this paper, we draw attention to the everyday experiences, activities and expectations of those engaged in what we term 'boundary work', notably where this involves co-location; those who negotiate and creatively seek to manage the problems they encounter within the wider structural and institutional constraints that frame their work across organisational boundaries. Through an understanding those engaged in everyday 'boundary crossing' and their practices, we can gain insights into the transformative potential, as well as knowledge and learning that such work generates. An approach that explores situated learning in a context in which it is shaped by and in turn shapes everyday practices offers particular relevance for policing; where the prevalence of an occupational culture rooted in 'craft', practitioner intuition and on-the-job tacit knowledge is foundational in making sense of police work (Manning 1977).

\section{Communities of practice}

Etienne Wenger and colleagues - working in the field of education - have provided some useful lines of enquiry with regard to the potential for developing 'communities of practice'. To this end, Lave and Wenger (1991) distinguish learning from intentional instruction (i.e. formal education and training). They argue that learning is necessarily situated, a process of participation in communities of practice. In ways that closely echo long-standing sociological insights into police learning of skills 'on-the-job' (Bayley and Bittner 1984), Lave and Wenger argue that newcomers join such communities via a process of 'legitimate peripheral participation'; namely learning by immersion in the new community and absorbing its modes of action and meaning as a part of the process of becoming a community member. The mastery of knowledge requires newcomers to move towards full participation in the socio-cultural practices of a community, in ways that resemble police knowledge as a 'craft'. Thus, conceived learning is social and comes largely from experiences of participating in daily life alongside others engaged in similar practices. Communities of practice are 'groups of people who share a concern or a passion for something they do and learn how to do it better as they interact regularly' (Wenger and Wenger-Trayner 2015, p. 1). They can exist within an institution or stretch across organisational boundaries that develop in mutual engagement on a joint enterprise.

These insights have implications for practitioners working in diverse fields, especially where interorganisational partnerships of practice are concerned, such as community safety (Henry 2012). Communities of practice are as diverse as the situations that give rise to them. Some communities of practice are deliberately designed (Wenger 1998, p. 244) - they are institutionally intended - while others have an emergent quality, forged through interaction and negotiation. For Wenger et al. (2002, pp. 23-41), despite taking various forms, all 'communities of practice' share a basic structure that includes three interlocking and mutually constitutive elements of: domain, community and practice. The domain is the shared enterprise that a community is engaged in; it denotes the topic that the community focuses on and is committed to and hence the community's identity. As such, membership implies a commitment to the domain, and a shared competence that distinguishes members from other people. The community refers to those who are engaged in the shared enterprise articulated by the domain. Members engage in joint activities and build relationships that enable them to learn from and help each other. Finally, the practice is a shared repertoire of resources;'a set of frameworks, ideas, tools, information, styles' (Wenger et al. 2002, p. 29) and ways of addressing recurring problems. It constitutes the specific knowledge - through language, stories and documents - that the members share. It is by developing these three elements in parallel that a community of practice is cultivated. 
Within communities of practice, learning is viewed as a reflexive engagement through dialogue in an attempt to make sense of, and create meaning from, experience. It is at the interface between professions that new learning resources can flourish. Hence, communities of practice exhibit distinct network-like qualities. For Wenger (2010, p. 191), communities and networks are two types of structuring processes whereby the former emphasises identity and the latter stresses connectivity. Consequently, networks and bureaucracies have very different mechanisms of governance and logics of accountability (Fleming and Rhodes 2005). The intra-organisational focus of bureaucracies affords scant regard to the more complex process of negotiating shared purposes, particularly where there is no hierarchy of control. As such, communities of practice cannot be 'managed' in the traditional control-oriented manner but need to be cultivated though more arms-length processes that accord greater sway to interdependencies.

Inter-organisational teams, clusters and networks may constitute emergent communities of practice in the sense that they are fluid and dynamic over time, involve greater uncertainty, rely more evidently on informal relations and, hence, are often harder to control than more stable or fixed groupings (Juriado and Gustafsson 2007). Wenger recognises not only that boundaries exist between communities of practice, as an unavoidable outcome of any depth of knowledge particularly as these become more highly specialised, but also that 'boundaries are interesting places' as a source of learning in that the 'meetings of perspectives can be rich in new insights and radical innovations' (Wenger 2010, p. 183). So too, boundaries can become 'places of potential misunderstanding arising from different enterprises, commitments, values, repertoires, and perspectives' (Wenger 2010, p. 183). Consequently, it is at the intersections and boundaries between communities of practice that productive dynamics can be forged, as innovations and ideas produced in one domain are translated and feed into others. It is here that 'knowledge brokers' (Wenger et al. 2002, p. 154), with membership in multiple communities, can act as 'translators' between communities, combining knowledge. As such, they have an important role in spurring innovation. But there is a profound paradox at the heart of learning within a 'system of practices' that constitute a field or domain - such as safeguarding children - namely, the learning and innovative potential of the whole system derives from the coexistence and interplay between depth of knowledge within practices and active boundaries across practices.

For Wenger, the concept of 'community of practice' also implies an ethic with regard to how practitioners invest and utilise their identities as they travel through the landscape of boundaries and practice-based communities. This prompts ethical questions about how practitioners contribute to learning as 'brokers' using multi-membership as a bridge across practices and how they exploit their unique position 'to see the need for a community with the legitimacy to call it into being and becoming conveners' (Wenger 2010, p. 197). This ethic infers that practitioners utilise their position as 'learning citizens' to challenge misunderstandings, innovate and disrupt unreflexive assumptions entrenched in historic practices.

\section{Safeguarding children in the UK}

It has long been recognised that the challenges in delivering effective safeguarding services for children and young people demand cross-agency working and robust inter-organisational partnerships. In the recommendations of her Report of the inquiry into child abuse in Cleveland 1987, Butler-Sloss (1988, pp. 248-251) prominently highlighted the need for improved inter-agency coordination in dealing with child abuse cases of the future. Whilst much has changed in the subsequent 30 years to facilitate and embed partnership working, the obstacles to delivering genuinely joined-up and effective responses to child abuse and sexual exploitation remain stubborn. The Children Act 1989, introduced soon after the Cleveland inquiry, gave every child the right to protection from abuse and exploitation. Under section 47 of the 1989 Act, the police, working with partner agencies - children's Social Care, Health and Education services - are responsible for making enquiries to safeguard the welfare of any child in the area who is suffering (or likely to suffer) significant harm. The police are 
under a duty to refer to the local authority those 'children in need' and the local authority is under a general duty to safeguard and promote the welfare of children who are believed to be in need (s. 17 of the 1989 Act). The intervening years, however, have seen a series of high profile cases that have exposed deep faults in safeguarding children services, much of the blame for which has been placed at the door of inadequate communications between intervening organisations.

While each successive safeguarding scandal has prompted wide-ranging reviews, lengthy inquiries, profound public debate and policy responses, there have been significant similarities in the failings of key public services. The Laming Report (2003) into the death of Victoria Climbié in early 2000 found that health, police and social services missed 12 opportunities to prevent Victoria's death from severe child abuse and neglect. The Report prompted the 2004 Children's Act which mandated that each local authority appointed a Children's Director and that statutory Local Safeguarding Children Boards (LSCBs) replaced erstwhile Area Child Protection Committees. LSCBs assumed responsibility for overseeing and coordinating a multi-agency response to child sexual abuse and exploitation and to ensure their effectiveness in safeguarding and promoting the welfare of children in its area. Government guidance entitled Working Together (first published in 1999) sets out how organisations and individuals should work together to safeguard and promote the welfare of children and young people in accordance with the Children Acts 1989 and 2004. It includes the advice that 'every LSCB should play a strong role in supporting information sharing between and within organisations and addressing any barriers to information sharing' which 'should include ensuring that a culture of information sharing is developed' (HM Government 2015, p. 71).

Nonetheless, tragic cases have continued to expose the fault-lines. Notably, 'Baby P', a 17-monthold boy (Peter Connelly) who died in August 2007 at home in north London, after months of abuse having suffered more than 50 injuries, and having been visited some 60 times by the authorities in the 8 months before his death. A serious case review revealed extensive incompetence on the part of social workers, doctors, lawyers and police (Jones 2010). Similar issues have come to the fore following a number of highly publicised incidents of child sexual exploitation (CSE) in which the police and local authorities failed to protect vulnerable children. In November 2010, five men were convicted of sexual offences against under-aged girls in Rotherham. A subsequent independent inquiry into the handling of the cases claimed that, as a 'conservative estimate', some 1400 children had been abused in and around Rotherham during the period between 1997 and 2013 (Jay 2014, p. 1). The report was highly critical of the local authority and the police's role in handling child sexual abuse investigations, accusing them of blatant collective failures. Further allegations have arisen in which similar patterns of sexual abuse against under-aged girls have been reported in as many other towns and cities in the UK.

Added to this, historic child sex abuse offences by a string of well-known public figures in the UK have emerged since the launch of the Metropolitan Police's Operation Yewtree in October 2012. The investigation explored allegations made by over 200 complainants spread across 14 police force areas spanning a period of four decades. The investigation was described by one Police Commander as 'a watershed moment for child abuse investigations' (Dodd 2012). Given the tide of scandals, a currently ongoing Independent Inquiry into Child Sexual Abuse was established and placed on a statutory footing in early 2015 . Scheduled for completion by 2020 , its terms of reference are to 'consider the extent to which state and non-state institutions have failed in their duty of care to protect children from sexual abuse and exploitation'. While plagued by controversies - the first three Chairs (Lady Butler-Sloss, Dame Fiona Woolf and Dame Lowell Goddard) all resigned - the scale and duration of the inquiry are unprecedented.

Meanwhile, in a letter to the Chief Inspector of Constabulary in 2016, the head of Ofsted (the Office for Standards in Education, Children's Services and Skills which inspects and regulates services that care for children and young people in the UK) criticised police forces for failing to take child protection matters seriously. He referred to the fact that more than half of Ofsted's 42 inspections of local authority children's services in the previous year had identified serious weaknesses in the police's contribution to safeguarding children. Inspectors had found that police forces were failing to share 
information about domestic abuse cases in a timely way and were not notifying social workers quickly enough when children went missing.

Evidently, the problem of child sexual abuse and the inadequate organisational responses to it have become something of a national trauma in the UK. This has resulted in what Parton (2014, p. 11) refers to as a growing 'politics of outrage', directed not solely at the perpetrators of crime but also at the professionals responsible for the various cases of institutional failure and the operation of the child protection system itself. Undoubtedly, this reflects not only the nature of the harm caused, its apparent widespread pervasiveness and institutional failures to recognise or address the vulnerabilities to which children have been (and are) exposed, but also the unquestionable 'wickedness' of the problem itself - in the sense that Rittel and Webber (1973) deploy the term - in that it exhibits both social complexity and institutional fragmentation.

\section{Leeds safeguarding children}

Against this bleak national backdrop, safeguarding children services in the city of Leeds have drawn considerable praise and recognition in recent years (Ofsted 2015). Services are coordinated by the LSCB which provides leadership, management and governance to partnerships delivering child protection. They sit nested within a wider commitment by Leeds City Council to bring organisations, businesses and individuals together to make Leeds a 'child-friendly city' across all services, sectors and fields of social life. The LSCB consists of senior representatives for the principal agencies involved in delivering and promoting the welfare of children in the city. Their task is to co-ordinate the actions of agencies represented on the Safeguarding Board and to ensure their effectiveness in safeguarding and promoting the welfare of children in its area. The LSCB provides oversight of the Children's Trust Board which consists of key multi-agency stakeholders from health, schools, children's services, youth justice and police. The Children's Social Work department assesses and supports children and young people. The council's Integrated Safeguarding Unit brings together a variety of services including education and healthcare to deal with child safeguarding matters in collaboration with partner agencies, including the police.

At an operational level, the focal point in Leeds is the 'front door' Safeguarding Hub; an integrated and co-located unit that brings together partners from a range of organisations, including police, children's social work, probation, local authority anti-social behaviour team, housing, education, health and youth offending services. The 'front door' provides early and targeted services to families, children and young people in relation to safeguarding concerns and domestic violence incidents involving children. It provides opportunities to gather, share and exploit information and intelligence. Within the 'front door', the police have embedded a dedicated Partnership Vulnerability Unit which seeks to enable early assessment and information sharing, as well as operational decisionmaking. The 'front door' is supported by the restructuring of social work services into a locality model based around 25 multi-agency 'clusters' across the city. Each cluster is coordinated by a Targeted Services Leader and brings together a range of locally based agencies including (but not limited to) schools, social workers, healthcare workers, youth justice, housing, police and third sector organisations. Alongside the dedicated Partnership Vulnerability Unit, West Yorkshire Police have a number of specialist units within their safeguarding structure whose remit includes child protection, notably a CSE and Missing Persons Unit and a Public Protection Unit, both of which operate out of police headquarters in Leeds.

Daily partnership meetings focus on high-risk cases, allowing information sharing and the development of action plans relating to victims, perpetrators and children. The purpose is to enable the management of risk, facilitate the coordination of support and reduce duplication and multiple contacts with victims. In recent years, there has been an investment in, and commitment to, early intervention and the use of 'restorative practices' - notably family group conferencing - in line with the ambition for Leeds to become a 'Restorative City' (Leeds City Council 2015). Significant funding from the UK Government's Innovation Programme has enabled professional staff across multiple agencies 
(such as the health service, police, schools, voluntary and community organisations) and Leeds City Council to receive training in restorative approaches. The subsequent Ofsted inspection report found 'clear evidence of continuous strengthening of partnerships between schools, police, health and the voluntary sector, supported by the children's social work service' $\left(2015\right.$, p. 15 , para 38)..$^{1}$ This is reflected in a general commitment to engage in a 'professional conversation' between agencies to explore concerns about child protection and safeguarding 'wherever and whenever' these arise. According to Ofsted, this openness and 'assured professional response ... enhances the confidence of these agencies in working with families significantly reducing any barriers between professional boundaries' (2015, p. 15, para 42).

While the Ofsted inspection report in 2015 provided a favourable review of safeguarding services in Leeds, an earlier inspection by Her Majesty's Inspectorate of Constabulary (HMIC) of West Yorkshire Police's engagement with child protection found that: 'some multi-agency teams were less developed, for example in Leeds, and this led to inconsistencies in practices across the force area' (HMIC 2015, p. 11). It also raised concerns about 'how little the police were involved in longerterm plans for children who were most at risk'. Police attendance at case conferences where there may have been a need for a child protection plan was found to be both limited and uneven. The HMIC concluded that the police did not always fulfil its responsibilities under the statutory guidance to attend initial case conferences when required to do so thus highlighting potential areas for improvement in partnership relations and boundary working.

\section{Research study}

The independent study sought to explore the views of actors engaged across the spectrum of delivering safeguarding children services in Leeds. Specifically, it was designed to capture the reflections of both individuals with managerial and strategic responsibilities as well as 'frontline' staff delivering services and seeing the practical implications of partnership working or lack thereof. Two principal elements of data collection were undertaken. First, face-to-face interviews were carried out with six senior managers working within the partnership framework of child safeguarding in Leeds. Second, 9 focus groups were conducted with a total of 50 frontline staff drawn from key organisations involved in child safeguarding activities in Leeds (see Table 1). These organisations were: social work (20), the police (15), health (7), youth services (5) and third sector organisations (3). The three social work focus groups were drawn from across the three different districts that make up Leeds. The three police focus groups included one comprising specialist staff in the Police's Adult and Child Safeguarding Unit, one from the Partnership Vulnerability Unit and one drawn from specialist officers focusing specifically upon CSE and Missing Persons. Table 1 provides a breakdown of participants in each focus

Table 1. FG participants.

\begin{tabular}{|c|c|c|c|}
\hline FG No. & FG & $\begin{array}{l}\text { No. of } \\
\text { participants }\end{array}$ & Participants \\
\hline 1 & Social work & 7 & Social work managers $(\times 3)$ and social workers $(\times 4)$ \\
\hline 2 & Social work & 7 & Social workers $(\times 7)$ \\
\hline 3 & Social work & 6 & Social work manager and social workers $(\times 5)$ \\
\hline 4 & $\begin{array}{l}\text { Police (adult \& child } \\
\text { safeguarding unit) }\end{array}$ & 6 & Detective sergeants $(\times 2)$, constables $(\times 3)$ and trainee investigator \\
\hline 5 & $\begin{array}{l}\text { Police (CSE \& missing } \\
\text { persons unit) }\end{array}$ & 5 & Detective sergeant, constables $(\times 3)$ and trainee investigator \\
\hline 6 & $\begin{array}{l}\text { Police (partnership } \\
\text { vulnerability unit) }\end{array}$ & 4 & Detective sergeants $(\times 2)$ and constables $(\times 2)$ \\
\hline 7 & Youth service & 5 & Youth service team leaders $(x 2)$, youth workers $(\times 3)$ \\
\hline 8 & Health care & 7 & $\begin{array}{l}\text { Safeguarding nurses (hospital-based) }(\times 2) \text {, school nurses }(\times 2) \text {, specialist } \\
\text { nurse for looked after young people and health visitors }(\times 2)\end{array}$ \\
\hline 9 & Third sector & 3 & $\begin{array}{l}\text { Family intervention service team leader, families first team leader and } \\
\text { housing support worker }\end{array}$ \\
\hline
\end{tabular}


group $(\mathrm{FG})$, their professional expertise and their roles within the framework of safeguarding children services.

Fieldwork was conducted between May and August 2015. Interviews and focus groups all lasted between 60 and 90 minutes and were audio recorded and transcribed with each participant assigned an anonymous unique identifier. ${ }^{2}$ As the second largest Children's Safeguarding Board in England with a considerable caseload, Leeds provides an interesting case study in which to explore both the prospects for and challenges of delivering inter-organisational policing partnerships in the context of child protection. The relatively recent organisational changes enabled possibilities for boundary work to establish itself in innovative ways, but there also exist familiar stubborn interorganisational obstacles that have stymied progress.

\section{Boundary work}

In what follows, we explore the empirical findings organised around key attributes of safeguarding partnerships that our research suggests foster and help cultivate forms of creative boundary crossing. In so doing, we draw upon insights from conceptions of 'communities of practice' and highlight the evident possibilities of 'boundary work' for organisational learning, critical reflexivity and innovations in practice.

\section{Shared commitment and purpose}

A shared sense of commitment and purpose is a prerequisite for effective partnership working across organisational boundaries. Fleming and Rhodes (2005, p. 195) note: 'Shared values and norms and an appreciation of divergent organisational cultures are the glue which holds the complex set of relationships together'. This necessitates crafting a mutual understanding about the problem and collective commitment to possible solutions. Practitioners in the focus groups felt that much progress had been made over the preceding years - despite the fluctuating national backdrop and distinctly different organisational priorities - in fostering shared commitment and purpose across agency boundaries. Strong leadership was noted as a major factor in driving this improvement by providing strategic direction that professionals felt a mutual commitment towards. In interview, a Social Care manager, reflecting the views of others, commented:

We've got senior police officers now who are up for it as well. It's senior management in the police who see that,
actually, we can't do this alone ... so that's the big difference. They can't work in isolation anymore, they've done
it in the past but the only way that it can work now is [if] we all work together. (Social Care Manager \#1)

This was reiterated in the focus groups:

It's coming from the top and that's been one of the priorities to link in with senior management in the police and it's working... There's a clear vision and obviously that's so embedded now and we see the benefits. (Social Worker FG1\#1)

This was also perceived to be apparent not just at management levels within the participating organisations but also by those working at the frontline:

[The strategic direction] filters down nicely. Sometimes [in the past] you could have people at the top having a different vision but it's not filtering down to the bottom. But [now] it does, it comes down and works for us [at the frontline]. (Third Sector FG9\#3)

Nonetheless, there was little evidence of a consistent or unproblematic cascading of the operation of partnership relations from managerial to frontline staff. In essence, managerial and frontline staff experience partnership relations differently. So too, the cultural barriers between managers of different organisations are less evident as they share similar lived experiences of managing (large) public sector organisations and workforce. As a consequence, relationships between partners tend to be more easily established and consistent at managerial levels. However, shared experiences by frontline 
personnel of imposed organisational change and managerial reform (notably in the light of austerity measures) provided interesting sites of shared appreciation and empathy.

Equally, however, within the broad strategic vision, divergences in ways of achieving a common purpose inevitably act as inhibitors to productive boundary work. Professionals from partner agencies have differing, and sometimes incompatible, tacit assumptions about the problem and ways of working. The destination may be shared but the means of getting to it frequently diverge. Each group of professionals often believes that their understandings are complete and shared by (or should be shared by) all others. In particular, the emphasis on evidence gathering and prosecutorial zeal of the police were perceived by many participants from across all non-police agencies to sit at odds with the processes and values of partner agencies:

The agenda is always going to be different. So they [police] are always going to be looking for a criminal investigation. We always have to manage what's happened within the family. So as long as you've got two different outcomes, potentially there'll always be issues in how you work together because the agenda at the beginning is different. (Social Worker FG3\#6)

Likewise, this was also recognised from a police perspective:

You'd like to think that we're all working to the same aim, to protect children and vulnerable people that need safeguarding. But from a police point of view we're very much focused on 'has a criminal offence occurred?' (Police FG4\#4)

In interview, an education manager articulated much the same tension regarding the place of criminal prosecutions within the wider problem of safeguarding and securing the protection of children:

There's a huge world of safeguarding outside that legislative process that the police would not be involved in. And it is around prevention, it's around investigation, it's about children building up that resilience, it's about understanding, it's about working with families. (Education Manager \#2)

Highlighted here are the ways in which organisational priorities and structural conflicts that arise from the different functions performed by diverse professionals - reflected in distinct cultural norms and social practices - express themselves in and through routinised social action and the everyday practices to which they give rise.

In safeguarding children, these structural tensions often express themselves in what is seen as a clash between the police's perceived narrow focus on crime and criminalisation and other agencies' longer-term goals, as the following healthcare professional articulated:

I think the police are just concentrating on 'is there a crime? Is there evidence?' We appreciate that but, from a school nursing point of view, there's a big emotional health thing, so we're very much about that. (Healthcare FG8\#4)

Building a case to establish whether a crime has been committed or not can result in prioritising certain responses over and above others, as a police officer acknowledged:

In child protection, you may be investigating a crime so our outcome is the investigation of that crime, to detect it. That can be to find information that assists the prosecution but also undermines it, which can sometimes mean questioning people, and asking difficult questions about information and what people have said. Whereas Social Care can be frustrated by that [approach]. (Police FG5\#1)

These tensions can play out in interactions with members of the public, as the following social worker explained:

I think it's hard when you're going [to do a joint visit] with other professionals because you're looking for different things. So you're asking different questions and it can become a bit confusing [for the family] what the nature or the purpose of the visit is. (Social Worker FG2\#5)

In some cases, differing priorities and approaches can lead professionals to be reluctant to get the police involved in the first place, particularly where the involvement of the criminal process is 
perceived to be counter-productive. Echoing the views of other FG participants, one-third sector worker suggested in relation to a recent case with a problematic young person:

The last thing we had in our minds was to make the police phone call because we didn't want to criminalise the young person. I was thinking why are we making a police call when in theory that could be dealt with via the social work system or mental health for young people? (Third Sector FG9\#3)

Some professionals saw this tension as, in part, a temporal clash between the more immediate shortterm needs for protection and longer-term demands of safeguarding through engagement, prevention, education and relationship building. Given demands on police time, it was frequently suggested that if the police see no obvious criminal prosecution then the justification for their continued involvement in the case fades.

For the police the law is very black and white and they've got to work within that legal framework and if they can't make a conviction then they'll just pull out and that's their involvement ended. Obviously, we have to carry on and things are a bit more grey for us, we've got to look at other factors and not just what's within the law. We've got to look at how that affects the child as well. (Social Worker FG2\#2)

Hence, police involvement can be seen as intermittent and primarily prosecution-focused, which may not serve the long-term aims of safeguarding. Furthermore, relations between partners, at times, can be undermined by perceived imbalances in authority and power. There was also noted a perception on behalf of members of the public that the police are the key decision-makers, which can impact adversely on the work of others:

Families view the police as the more powerful agency. So if the police don't take further action, it makes a mockery of what we're doing - like our work has to stop because the police work has. (Social Worker FG2\#2)

These 'latent' structural differences in organisational role and authority present real challenges for professionals seeking to develop new 'communities of practice' and are particularly acute in the context (and shadow) of the criminal justice process (Sampson et al. 1988, Crawford 1997). As Rutherford noted, some time ago, this leaves criminal justice personnel and partners faced by a perennial challenge of 'how to work creatively with the inherent tensions, affording legitimacy to both independence and interdependence' (1993, p. 126).

\section{Relations of trust: relative stability and co-location}

Whilst the vertical chains within and between departments and agencies in any one field are strong, the horizontal links tend to be weak or non-existent. Emergent 'communities of practice', therefore, require movement away from working in and through hierarchies - the traditional structure of bureaucracies (most evident in 'command and control' type organisations like the police) - to working through networks (Wenger et al. 2002). These networks are characterised by diplomacy, trust and reciprocity rather than the hierarchical authority and rules of bureaucracies (Fleming and Rhodes 2005). One way in which inter-agency tensions express themselves is in 'distrust' and mutual suspicion between personnel from differing organisations. Mary Douglas (1986) correctly noted how 'writing about co-operation and solidarity means writing at the same time about rejection and mistrust' (1986, p. 1). Developing trust across organisational and cultural boundaries is hugely difficult, particularly where there is a history of mistrust or misunderstanding. One police officer noted: 'When we work with other agencies, I think it's a [lack of] understanding of what each other's role is - I think that's what makes us at loggerheads' (FG5\#3).

Hence, overcoming misunderstanding about the role, aims, values and limitations of other professionals through building meaningful and sustainable relations of trust are vital:

When we first started working in the [Safeguarding] Team, we didn't know those [police] officers ... at the start I think the police were quite paranoid ... But now, and it's to do with relationships, we have very open discussions and we are open with them and they are open with us. It's that trust, building that trust and having those relationships over a period of time that counts. (Social Worker FG1\#1) 
Trust is facilitated by the relative stability in interpersonal relations between partners which fosters greater mutual understanding and reciprocity. The following police officer echoed the views of the majority of other professionals:

It's more or less the same people [that we work with every day] ... and that's good because we build up a relationship with them and an understanding of how we work - coming from different angles ... You know who to go to, you know who to contact and you know how they work ... You know you're expectations as well ... It's understanding each other's process and procedures ... We all have difficult jobs for different reasons ... So it's about the realisation of the strengths and weaknesses of both your roles. (Police FG6\#1)

Maintaining stable relationships, however, is subject to a range of practical obstacles, notably different patterns of working, particularly around weekends. This difficulty was highlighted by a number of non-police professionals:

When [police] work different shifts to us as well that can be difficult. I had one a few weeks ago and they said;'well he's not on until the weekend' and I don't work a weekend. (Social Worker FG2\#7)

From a police perspective, this prompts complaints that other partners 'go home at weekends' and that 'child abuse doesn't happen Monday to Friday, 9 till 5 and that's frustrating for us' (Police FG4\#3). Another police officer elaborated:

You could go three or four weeks without having a chance to speak to a social worker because of your shifts, rest days, working lates and nights. So you can't go on joint visits, you can't speak to schools, you can't do any of that ... It also means that those officers can't attend strategy meetings, they can't attend professionals' meetings because if you start work at 4 or $5 \mathrm{pm}$ in the afternoon, then all the other [partners'] officers have gone home. (Police FG5\#5)

In addition, the turnover of key staff out of particular teams or localities severely disrupts relationships that have built up over time. This was especially evident within the police as one social care manager commented reiterating the frustrations of many others:

One of the challenges with police is that they move people around. I understand the reason for doing that but in my career I feel like I've so often built a relationship with somebody - it's taken me several years - and then they move on and it feels like you're starting again. (Social Care manager \#2)

This 'churn' of personnel was also recognised by police as particularly problematic in term of the loss of human capital through expertise and skills that are built up in safeguarding as a specialism.

We don't always help ourselves with moving people around: 'You've already done so long so you can go somewhere else and get some expertise'. [Safeguarding children] is a specialism that requires an in-depth knowledge of how it works and what everybody's doing from the other agencies, the third sector and everybody else. (Police FG5\#1)

Bringing multi-agency teams together in the same physical location - often jointly managed - serves as a means of forging emergent communities of practice. Whilst co-location is not essential for effective boundary crossing and partnership working, co-located teams helps to foster dynamics in which 'communities of practice' can flourish. Sometimes this is met with an initial reluctance on the part of the affected staff which can be overcome by the practical benefits of day-to-day interactions (Crawford and Cunningham 2015). Co-location and cluster working was identified by staff working in safeguarding as a key mechanism of building interpersonal trust relations between colleagues from different agencies.

The big difference in our role in the [Safeguarding] Team and social work teams in the area is that we are so fortunate that we have police at hand and they have us at hand as well, so it works both ways. It's changed our job significantly for the better that we've got that two way process and constant dialogue and constant discussion with police officers, and they're there [in the same office] and they're very accessible. (Social Worker FG1\#1)

Correspondingly, a police manager identified the importance of the multi-agency safeguarding 'front door' for building collaborative relations on mutual understanding at the outset of cases: 
Having been involved now for a few years, the earliest point when you can have a discussion with a partner is vital ... In the past, we have shared emails and shared conversations and reports with Children's Social Care and other partners, and they have not been as beneficial as that initial face-to-face conversation. (Police Manager \#1)

Conversely, a police officer working outside of the co-located clusters commented on the different experience of cross-boundary working for those not co-located.

Down at the Partnership Vulnerability Unit they've got good relations because they work in the same office and they know who to go to if it's a particular area they need to speak to somebody in. With us, it's a different social worker depending on where the child lives so we don't necessarily build up those relationships unless it's a long enquiry that we're dealing with together. (Police FG4\#5)

The majority of participants agreed that getting to know people can help forge collective team identities and erode stereotypical (mis)perceptions. The following is illustrative of many:

I think the clusters are brilliant ... Because you are in your own little bubble, you do get to know everybody ... So even if you don't know directly who you're going to go to, you'll know how to get to somebody who will know. (Social Worker FG2\#3)

Furthermore, close-knit teams foster relationships that enable members to learn from each other about ways of addressing recurring problems. They provide shared knowledge - through shared stories and documents.

Barriers have been broken because we go in in the morning and sit there and we leave at night and we leave together. So it's about personal relationships as well and because of that we have banter with them, we have a joke with them and we go out for a drink with them and that actually really helps to break down those barriers and form relationships. So it's easy to challenge [each other] isn't it? If you can work with somebody then you can challenge them and say;'well, actually I don't agree with that, why can't you do a joint visit?' It is a lot about those face-to-face relationships and we are very fortunate. Other teams ... won't have that luxury. (Social Worker FG1\#2)

As such, close working relations can foster changes in attitudes and behaviours. Reflecting the views of many, one youth worker acknowledged: 'The clusters have been a major [force of] cultural change' (Youth Service FG7\#3). In part, this arises as interpersonal connections afford rich social capital via the norms of reciprocity and trustworthiness that arise from them (Putnam 2000). In many cases of boundary work, these will constitute 'weak ties' serving instrumental goals that do not rely to the same extent on shared values. Here, they constitute a form of social lubricant that allows people to get along, without feeling the need to share too much in terms of identity, interdependency or shared commitment. Where trans-organisational team identity is more developed and resilient, however, these relations may constitute 'strong ties' that exhibit a greater normative sway through dense networks of reciprocal social relations, a common purpose and joint commitment, enabling frontline workers to go beyond their traditional roles and forge new communities of practice. Here, interpersonal trust relations and the norms that accompany them constitute the social glue that binds people together in a shared sense of belonging and identity.

\section{Exchange of information and resources}

A key dimension of reciprocity in partnership working around safeguarding is the balanced exchange of information and resources. Among professionals working closely together in multi-disciplinary safeguarding teams the flow and exchange of information and resources was seen as pivotal to ensure good working relations, as the following police officer attested reflecting a view shared by many:

We are pretty good at sharing information because we can't moan about we're supposed to work together but then not do it ourselves. So within the guidelines of data protection, we are quite free in what kind of information we give which is relevant. (Police FG4\#1) 
Again, trust plays a crucial role both as a precursor for information exchange and as a product of its exchange. Trust circulates in and accelerates norms of reciprocity in potentially virtuous cycles: 'I think as trust builds up between partners and agencies, that information sharing gets better' (Youth Service FG7\#1). Trust becomes reinforced as information flows improve and reciprocal relations become denser. The following interviewee expressed the commonly held view that information exchange had deepened as relations had become more embedded and mature:

Information sharing has improved massively with the clusters coming along ... For me it's about trust, credibility, worth and value for agencies of them sharing information. Where we've made progress over the last couple of years is we've shown other agencies the value of them sharing information with us and we've built that trust. (Youth Service FG7\#4)

While information exchange through interpersonal relations, fluid team exchanges and informal working practices can provide a valuable basis for communication and negotiation, so too, it can provide opportunities that endanger important confidentialities and might sometimes constitute threats to privacy or civil liberties. Hence, balanced information exchange also demands mutual understanding of the limits and legal constraints. There are also implications for professionals' relations with children, young people and their families.

I think Social Care are getting better [at sharing information with the police]. There's a little bit of a fear with Social Care and partner agencies that work with children. Sometimes they don't want to share particular disclosures with us because then the child is aware that they've disclosed something to us and that can break down a relationship. They could have spent months working with somebody, building trust, this child discloses something, then they tell us and bang, it's gone. So I can completely understand the mind-set that they're coming from. (Police FG5\#3)

Consequently, learning is not always an inevitable by-product of partnerships as information exchange itself can be a source of conflict particularly in the context of crime control where information sharing is governed by complex rules and laws relating to sensitive data and privacy, as well as the non-interoperability of much data across different organisational systems for data management. Similarly, learning may be hindered by risks associated with disclosing too much information to partners. Nonetheless, a balanced exchange of information and resources that flows in reciprocal circuits within emergent communities of practice can constitute the basis to contribute to new forms of knowledge production that are genuinely 'trans-disciplinary' (Nowotny 2015), in that they are forged at the intersections between professional boundaries. Boundary workers thus also constitute 'knowledge brokers' (Wenger et al. 2002, p. 154) that can serve as 'translators' between different organisation, combining knowledge and generating new insights. These can be assets with which to challenge introspective cultures, foster organisational learning and prompt critical reflexivity.

\section{Mutual respect for difference}

The existence of latent structural tensions and power differentials places great emphasis upon the manner in which these are managed in routine social practices. A crucial element in this is making partners aware of roles and responsibilities as well as the limitations of their own and other organisations' contribution, so that they neither try to 'do it all' (something that the police are particularly prone to do), nor do they have unrealistic expectations of what others can deliver.

Integration is key, but it's also key that your roles are clearly defined and so nobody is under any misconception: the police are here for a reason, to detect crime. Social Care are there for a different reason and it's about how different relationships intertwine and support each other. (Police FG6\#1)

Fundamentally, though, there is a need for mutual respect for different types of contributions. Shared understanding does not mean that all the partners necessarily agree on the problem or hold the same view of it. Rather, it demands that the partners understand each other's positions well enough to have meaningful dialogue about the different interpretations of the problem, and to exercise collective intelligence about how best to seek to resolve it. 
It's about being open and honest about your role. We have policies and procedures that we have to follow, it's not a choice. As part of our assessment for child safeguarding matters we take into consideration the child's voice, what does the child want and this is all fed into the decision-making on whether it's in the public interest to prosecute the family members because a lot of the stuff we deal with is intra-familial. So it's about that open, honest and transparent - 'cards on the table' - discussion with your partners about what you see these pathways it can go down. (Police FG6\#2)

This acknowledgement and celebration of difference, in terms of the skills and expertise it contributes to a more holistic approach was also recognised by most participants:

I think it's good to be different. That's why other agencies are involved because you're drawing on other people's expertise and backgrounds and they'll see things differently. Just because I see things differently to you, as long as you communicate that then you can see things differently and you're going to get the same outcome. You learn from others. (Third Sector FG9\#2)

Hence, boundary work not only provides different insights but can challenge taken-for-granted assumptions and cultural practices in ways that can offer opportunities for organisational learning. It is, here, at the intersections and nexus between organisations that productive spaces for learning and change can be forged. Through 'boundary work' new ideas and practices can be generated and translated from one context to another.

\section{Conflict management}

The constructive management of conflict was identified by almost all participants as a hallmark of a mature child safeguarding partnership. In Leeds, this was reflected in the explicit commitment to what was referred to as a 'professional conversation' whereby practitioners at all levels are encouraged to discuss difficult issues through frank and open dialogue between partners as a means to resolving problems. In interview, a social care manager explained what this means in practice and its implications:

The common thread is that we have shared behaviour which is if there are issues we talk about them. We find solutions. We don't blame each other; we work together. We have 'good' rows - and I mean that positively because actually tough complex things sometimes need tough complex discussions. Where we're unhappy with each other, we tell each other. We're very good at sharing responsibility for those things. (Social Care Manager \#1)

Moreover, there was some evidence that a mature inter-organisational dialogue between partners can also encourage greater intra-organisational communication, 'voice' and organisational justice, as managers listen to and engage with concerns of frontline staff. For example, a police manager highlighted the ways in which challenges from external partners can constructively improve the ways in which supervisors and frontline staff seek to assess and solve problems.

We've got to a place now where challenge is accepted and quite often there's regular strong discussions taking place between professionals and the police and professionals within partners to look at plans. I've been delighted with the response from people at my level in the partnership who will go back [to their own staff] and challenge the assessments and say: I'm not happy with that plan, you need to look at that'. It's more robust and manages the risk. (Police Manager \#1)

This trans-professional sharing of learning can prompt an ongoing reassessment of assumptions, critical self-reflection on values and questioning of terminology. So too, the individuals engaged in such boundary work practices can become 'knowledge brokers' as they move between communities of practice. As Wenger (2010, p. 183) notes 'boundaries are interesting places' that generate new learning, insights and innovations in practice. Disagreement and challenge as a reflexive engagement through dialogue can form the basis for learning within 'communities of practice' that filters outwards, downwards and upwards. In an organisation like the police, where introspective cultures of defensiveness, suspicion of outsiders and a hierarchical 'command and control' model of decisionmaking apply, the opportunities for organisational learning are simultaneously most challenging but also possibly most rewarding. 
Such practices of boundary work, nevertheless, raise vexed questions about responsibility and accountability, given the complex interdependencies in decision-making and multiple layers of authority that are entailed. Joint and negotiated decisions frequently tie the various parties into outcomes but can fail to identify lines of responsibility. As authority is 'shared', it becomes difficult to disentangle. Hence, clarifying lines of responsibility in this complex context becomes crucial.

Because of the professionalism that's involved nowadays, I don't think [partners] hold grudges. Those in Social Care that we work with closely, we might disagree but that's it, and you put it down to 'your priorities are different to ours'. As long as you can understand that - and don't get me wrong, there are other officers who get quite upset about some of the decisions - but actually, you have to put it in that box of: 'whose responsibility is this to make that decision?' You might not agree with it but ... you understand that it's their responsibility. I've said at meetings: 'I understand it's your responsibility but please make a note in the minutes that I don't agree with that'. (Police FG5\#4)

In some instances of boundary work, institutional complexity can serve to obscure further who is accountable to whom and for what. This gives rise to what Rhodes (1996, p. 663) identified as, "the problem of many hands", where so many people contribute that no one contribution can be identified'. This returns us to the challenges for working within the creative tensions between independence and interdependence in boundary work.

\section{Future challenges}

The current period of austerity in public sector funding in the UK has resulted in unprecedented reductions in police budgets and police officer numbers as well as severe cuts to local authority resource. This presents critical challenges for the future of inter-organisational networks and emergent 'communities of practice'. The ways in which public sector organisations have and are responding to these fiscal challenges can have ambiguous implications for cross-boundary working. On the one hand, organisations (including the police) might retreat increasingly into their own professional 'silos'; retracting from inter-organisational collaborations and commitments, while redrawing their boundaries to focus on core objectives off-loading responsibilities to others, wherever possible. Short-term cost savings may be prioritised at the expense of partnership commitments, particularly where key individuals, posts or teams are lost to early retirements or workforce reorganisations. Similarly, the pressures on workloads - given reductions in staff numbers - can leave little time for boundary work as practitioners withdraw from engagement to focus on core tasks. There is growing evidence that this scenario is playing itself out across community safety partnerships (Crawford and Evans 2017). It was also reflected in the safeguarding context:

Because they're cutting some of the funding for the cluster services, they're looking at social workers to do the work. I see our job, unfortunately, now as a case manager. We don't actually do any practical work, well, we don't do as much as needs to be done. So in any meetings where we have with other professionals, especially family support workers, if we say;'yes, we're becoming involved and we're putting the children on a plan', they say;'oh, well there's no need for us anymore'. And they pull out ... [Consequently] we set these families unrealistic expectations with no actual help. (Social Worker FG2\#5)

Similar views were expressed by other frontline professionals under analogous pressures of fiscal constraint.

On the other hand, austerity has also posed some quite fundamental questions about organisational purpose, expertise, responsiveness and effective service delivery. Such radical rethinking can (and does) prompt public sector managers to look for collaborative advantages that might be gained through partnership working, as a means of attaining longer-term cost efficiencies.

Partnership working has improved because there has been a need to work together because of limited resourcing ... It has improved because you've got to draw on other resources from other agencies because everyone is getting cut somewhere. (Third Sector FG9\#1) 
The possibility for such collaborative advantage rests largely on drawing synergy from the differences - in resources and expertise - between organisations.

I think also the economic situation has helped. It's very interesting because we are all feeling the effects of cuts and lack of money but what it has done is actually help to think of new ways of working across partnerships, because the police have been cut as well. So instead of saying;'we're struggling and they're struggling', people have come together to think;'how can we work together in a better way within the current economic climate?' (Social Worker FG1\#4)

Such quests for collaborative advantages can also prompt investments in 'up-stream' preventive solutions to crime problems; away from the traditional reactive fire-fighting approach to much criminal prosecution. However, the extent to which either, or a combination of both, of these consequences prevails; only time will tell. The reality is that successful inter-organisational partnerships do not arise spontaneously. They need to be forged, nurtured and supported at all levels by people committed to realising the benefits of collaborative working and exploiting the opportunities for innovation that boundary crossing provides. How these tensions play out in the future will depend on the extent to which commitments to long-term benefits that derive from inter-agency teams are protected and secured. Inevitably, therefore, boundary work of the type outlined here remains highly precarious.

\section{Conclusion}

As we have shown, the cluster model, co-located 'front door' and mature networked relations of trust and open conflict management on which safeguarding children in Leeds is grounded have all played important roles in engendering opportunities for critical reflection on practices and possibilities for cultural transformation to effect change. They have helped cultivate and enabled spaces for creative 'boundary work' rooted in shared experiences of participating in daily life alongside others from different professional backgrounds with divergent cultural assumptions engaged in similar practices at the interface between organisations. The research reveals the manner in which boundary crossing can open opportunities to foster increased reflexivity within policing and to develop more systematic organisational cultures of learning as knowledge reservoirs that facilitate the transfer of good practice. Boundary crossing can be both an essential and dynamic element within networked approaches to safeguarding children; prompting ongoing reassessment of assumptions, critical self-reflection on values and questioning of terminology. The study of 'boundary work', we content, should prompt novel explorations of the possibilities for organisational learning, reflexivity and innovation that arise among 'communities of practice' and their implications for trans-disciplinary knowledge creation and its application.

However, these networks rest precariously on an inherent tension in that the productive capacities of boundary crossing, in large part, derive from the existence and depth of the specialist knowledge, expertise and professional organisational frames that constitute the very boundaries across which the 'knowledge brokers' of emergent communities of practice must operate. Consequently, practitioners walk a learning tightrope, striking a delicate balance between, on the one hand, interacting with perspectives beyond their boundaries as a rich source of self-reflection and innovation, and on the other hand, respecting the history, values, practice and accepted organisational wisdom from within the professions to which they belong. The extent to which such knowledge brokers are themselves able to rise to the ethical challenge to utilise their unique positions to contest inter-organisational misunderstandings, build resources, innovate and disrupt unreflexive assumptions rooted in traditional ways of working, however, remains largely untapped and uncharted.

\section{Notes}

1. Ofsted rated the 'leadership, management and governance' of Leeds Children's Services as 'outstanding' - the highest rating possible - and the work of the LSCB as 'good'. 
2. Focus groups contributors are identified by profession, FG number and reference number within the group (i.e. Police FG4\#2).

\section{Acknowledgements}

We would like to acknowledge the invaluable contribution of Matthew Radburn, Clare Johnson, Andy Lloyd, Jim Hopkinson, Gail Faulkner, Andrew Staniforth, Sam Millar and Mark Griffin to facilitating the research and informing the findings on which the paper draws. We would also like to thank Anna Barker, Benoit Dupont, Kate Morris, Clive Norris and the anonymous reviewers for comments on an earlier draft.

\section{Disclosure statement}

No potential conflict of interest was reported by the authors.

\section{Funding}

This work was supported by Economic and Social Research Council [grant number ES/M006123/1].

\section{References}

Bayley, D.H. and Bittner, E., 1984. Learning the skills of policing. Law and contemporary problems, 47, 35-59.

Bratton, W. and Tumin, Z., 2012. Collaborate or Perish: reaching across boundaries in a networked world. New York: Crown Business.

Butler-Sloss, E., 1988. Report of the inquiry into child abuse in Cleveland 1987. London: HMSO.

Chan, J., 1997. Changing police culture. Cambridge: Cambridge University Press.

Charman, S., 2013. Sharing a laugh: the role of humour in relationships between police officers and ambulance staff. International journal of sociology and social policy, 33 (3/4), 152-166.

Crawford, A., 1994. The partnership approach to community crime prevention: corporatism at the local level?. Social \& legal studies, 3 (4), 497-519.

Crawford, A., 1997. The local governance of crime. Oxford: Clarendon Press.

Crawford, A., 2001. Joined-up but fragmented. In: R. Matthews, and J. Pitts, ed. Crime, disorder and community safety. London: Routledge, 54-80.

Crawford, A., et al., 2005. Plural policing. Bristol: Policy Press.

Crawford, A. and Cunningham, M., 2015. Working in partnership: the challenges of working across organisational boundaries, cultures and practices. In: J. Fleming, ed. Police leadership - rising to the Top. Oxford: Oxford University Press, 71-94.

Crawford, A. and Evans, K., 2017. Crime prevention and community safety. In: A. Liebling, S. Maruna, and L. McAra, eds. The Oxford handbook of criminology. 6th ed. Oxford: Oxford University Press, 797-824.

Dodd, V., 2012. Jimmy Savile: How the police investigation grew. The Guardian, 28 October [online]. Available from: https://www.theguardian.com/uk/2012/oct/28/jimmy-savile-police-investigation-grew [Accessed 11 April 2017].

Douglas, M, 1986. How institutions think, Syracuse, NY.

Fleming, J., 2006. Working through networks. In: J. Fleming and J. Wood, eds. Fighting crime together: the challenges of policing and security networks. Sydney: University of New South Wales Press, 60-86.

Fleming, J. and Rhodes, R.A.W., 2005. Bureaucracy, contracts and networks: the Unholy Trinity and the police. Australian and New Zealand journal of criminology, 38 (2), 192-215.

Geertz, C., 1973. The interpretation of cultures. New York: Basic Books.

Henry, A., 2012. Situating community safety: emergent professional identities in communities of practice. Criminology and criminal justice, 12 (4), 413-431.

Her Majesty's Inspectorate of Constabulary, 2015. National child protection inspections: West Yorkshire police, 15-29 August 2014. London: HMIC.

HM Government, 2015. Working together to safeguard children. London: HM Government.

Jay, A., 2014. Independent inquiry into child sexual exploitation in Rotherham 1997-2013. Rotherham: Rotherham Metropolitan Borough Council.

Johnston, L. and Shearing, C., 2003. Governing security. London: Routledge.

Jones, A., 2010. Serious case review 'Child A': March 2009. Haringey Local Safeguarding Children Board. London: Department for Education.

Juriado, R. and Gustafsson, N., 2007. Emergent communities of practice in temporary inter-organisational partnerships. The learning organization, 14 (1), 50-61. 
Laming, W.H., 2003. The Victoria Climbié inquiry: Report. Cm 5730. London: The Stationery Office.

Lave, J. and Wenger, E., 1991. Situated learning: legitimate peripheral participation. Cambridge: Cambridge University Press.

Leeds City Council, 2015. Leeds children and young people's plan 2015-19 [online]. Available from: http://democracy.leeds. gov.uk/documents/s132827/94\%20App\%203\%20cyppfinaleb2406.pdf [Accessed 11 April 2017].

Loftus, B., 2010. Police occupational culture: classic themes, altered times. Policing and society, 20 (1), 1-20.

Manning, P.K., 1977. Police work. Cambridge, MA: MIT Press.

Nash, M. and Walker, L., 2009. Mappa - is closer collaboration really the key to effectiveness? Policing, 3 (2), $172-180$.

Nowotny, H., 2015. The cunning of uncertainty. Cambridge: Polity Press.

Ofsted, 2015. Inspection of services for children in need of help and protection, children looked after and care leavers and review of the effectiveness of the local safeguarding children board. Manchester: Office for Standards in Education.

Parton, N., 2014. The politics of child protection. Houndmills: Palgrave Macmillan.

Putnam, R., 2000. Bowling alone: the collapse and revival of American community. New York: Simon and Schuster.

Reiner, R., 2010. The politics of the police. 4th ed. Oxford: Oxford University Press.

Rhodes, R.A.W., 1996. The new governance: governing without government. Political studies, 44, 652-667.

Rittel, H.W.J. and Webber, M.J., 1973. Dilemmas in a general theory of planning. Policy sciences 4, 155-169.

Rutherford, A., 1993. Criminal justice and the pursuit of decency. Oxford: Oxford University Press.

Sampson, A., et al., 1988. Crime, localities and the multi-agency approach. The British journal of criminology, 28, 478-493.

Vangen, S. and Huxham, C., 2003. Enacting leadership for collaborative advantage: dilemmas of ideology and pragmatism in the activities of partnership managers. British journal of management, 14, S61-S76.

Wenger, E., 1998. Communities of practice: learning, meaning, and identity. Cambridge: Cambridge University Press.

Wenger, E., 2010. Communities of practice and social learning systems: the career of a concept. In: C. Blackmore, ed. Social learning systems and communities of practice. London: Springer-Verlag, 179-198.

Wenger, E., McDermott, R., and Snyder, W.M., 2002. Cultivating communities of practice. Boston, MA: Harvard Business School Press.

Wenger, E. and Wenger-Trayner, B., 2015. Communities of practice: a brief introduction [online]. Wenger-Trayner. Available from: http://wenger-trayner.com/wp-content/uploads/2015/04/07-Brief-introduction-to-communities-of-practice.pdf [Accessed 11 April 2017].

Wood, J. and Shearing, C., 2007. Imagining security. Cullompton: Willan. 


\title{
'It's about using the full sanction catalogue': on boundary negotiations in a multi-agency organised crime investigation
}

\author{
Heidi Fischer Bjelland and Annette Vestby $\mathbb{D}$
}

\begin{abstract}
Inter-organisational and inter-disciplinary investigations are increasingly deployed against criminal networks and cross-jurisdictional crimes. This study provides a unique empirical window into an inter-organisational investigation against a large organised crime network in Norway. Building on interview data from the participants in the multi-agency investigation team that was summoned for this case, the article discusses co-ordination issues that arise when organisations with different goals and interests collaborate to reach a common goal. The article studies co-ordination from inside of the investigation team and discusses the interchangeable use of criminal and administrative law. While bridging organisational boundaries enable agencies to pool powers, co-ordination across organisations may challenge the protection of sometimes conflicting aims and interests.
\end{abstract}

\section{Introduction}

Oslo area, September 2014: After a period of comprehensive communication surveillance and covert investigation, 280 officers from the police, the Tax Administration (henceforth 'TA'), and the Labour and Welfare Administration ('Labour \& Welfare') carried out a raid on 20 shops in the 'Lime' grocery chain. The grocery chain was established and operated by an organised criminal network that was previously known to the police. The shops were profitable to the network who allegedly utilised human trafficking for forced labour, illicit work, money laundering, benefit fraud, tax evasion, violations of immigration law, employment offences, identity theft and credit card fraud. ${ }^{1}$ The raid marked the beginning of a prolonged multi-agency investigation, covering a variety of criminal and administrative violations. The investigation was structured as a multi-agency project, which meant that investigators from all participating agencies (police, TA, Labour \& Welfare) were removed from their daily tasks, co-localised in a shared, rented office space and co-ordinated by the Lime project's chief investigator.

Pluralisation characterises contemporary policing, and partnerships as well as networked security governance between state and non-state actors have been examined empirically (Gundhus et al.2008, Nøkleberg 2016, Søgaard et al.2016). This study explores the co-ordination of state powers in the multi-agency Lime project. While the literature on the pluralisation of policing and nodal governance of security (Johnston and Shearing 2003, Shearing and Wood 2003) emphasises the role of non-state agents in the provision of security, this study delves into the heterogeneity of powers and interests in state sector governmental nodes. Partnership working and information sharing among public agencies intensifies 'the state gaze' [...] in a way which is valued for its ability to make the daily work of the various state agents easier' (O'Neill and Loftus 2013, p. 451). 
This study contributes to the existing literature in two ways: empirically, through studying the internal operations of a pragmatically assembled multi-agency security network whose operations spanned the jurisdictions of a wide range of agencies, and theoretically, by analysing how instrumental practices of co-ordination may challenge accountability and the institutional integrity of deliberately separated public agencies.

While we view the agencies involved in the Lime investigation as 'nodes' in a security network, they also exist as discrete, formal organisations. While the agencies agreed to pool their legal resources and expertise in a joint effort against the allegedly criminal network, accomplishing shared objectives required negotiation of the boundaries drawn around their organisations. In the past, each agency had had some knowledge about parts of the total criminal enterprise. Their knowledge of the criminal network and coercive powers were dispersed due to their separate jurisdictions and information sources. Prior to the establishment of the project, Labour \& Welfare had some administrative law cases regarding illicit work circulating in the courts, and TA had previously been involved in a short-lived collaboration with a police unit targeting the network's businesses. The police's national intelligence database was rife with entries from all over the country. For the project participants, access to shared information was a key incentive to participate in the co-ordinated projected, as well as a perceived necessity to put an end to the criminal enterprise.

Co-ordinating the work and resources of nodes in security networks necessitates negotiations over organisational boundaries. Following Giacomantonio's recent work on the sociology of police co-ordination (2015), this article explores negotiations of such boundaries within a multi-agency investigation: How did organisational boundaries shape the internal operations of the Lime project? The study builds on unique empirical data consisting of 23 interviews with investigators and management-level officers from all three agencies in the Lime project.

\section{Multi-agency co-ordination}

Multi-agency co-ordination has been an area of interest in the literature on both organisations (Alexander 1995, Hardy et al.2003) and the police (Crawford 1994, O'Neill and McCarthy 2014, Webster 2015). Faced with multi-jurisdictional criminal activities, police are increasingly participating in multi-agency networks that include regulatory agencies and other non-police agencies (Maguire 2000, Rosenbaum 2002, Willis and Mastrofski 2011, O'Neill and McCarthy 2014, Webster 2015). Although police involvement in such networks is most commonly associated with preventive policing (e.g. Meyer and Mazerolle 2014, Strype et al.2014), the police are now increasingly involved in more reactive efforts, such as in the formation and use of joint investigation teams (Block 2008). A recent example is Operation Wasp Nest, a multi-agency investigation of human trafficking co-ordinated by the Danish police, and the pan-European Operation ETUTU, directed at West African human trafficking networks (Europol 2016). The growth of multi-agency co-ordination is claimed to be part of a broader shift in governance and crime control (Maguire 2000, Mazerolle and Ransley 2006a, 2006b).

Some studies have noted police scepticism regarding partnerships and have pointed out practical issues, cultural challenges, and the potential for conflict in multi-agency networks (see Crawford 1999, Bullock et al.2006). However, research has also demonstrated that multi-agency co-ordination will create greater opportunities to use suitable legal tools in criminal prosecutions (Mazerolle and Ransley 2006b), that it may ease the work load for the police, facilitate for pragmatic approaches and thus result in more effective police work (O'Neill and McCarthy 2014). One of the most prominent arguments in favour of multi-agency co-ordination is the opportunity it provides to facilitate information sharing across organisations, and thereby increase the efficiency of law enforcement (Plecas et al.2011). Previous studies have demonstrated that information sharing between agencies will increase both the quality and usefulness of data, which in turn will lead to better decision-making (Kahn et al.2002). Researchers exploring some of the internal dynamics of multi-agency networks (Whelan 2015) have also identified the importance of interpersonal trust (Beech and Huxham 
2003, Fleming and Rhodes 2005, O'Neill and McCarthy 2014, Cotter 2015, Whelan 2016). Informal communication and personal relationships have been found to particularly affect the access to and sharing of information in networks (LeBeuf 2005, Cotter 2015).

\section{Sharing resources in security networks}

Viewing the co-ordinated agencies in this study as a security network, we consider them a set of organisational nodes that were interconnected and co-ordinated 'in order to authorize and/or provide security [...]' (Dupont 2004, p. 78). The agencies in this study agreed to co-ordinate their resources because of a high degree of consensus around the objectives of the project. In network terms, studying how resources are pooled and used amounts to analysing how 'connections between nodes [...] influence security outcomes by shaping the flow of network assets (that is, information and resources)' (Brewer 2017, p. 453). Coining the term 'ad hoc instrumentalism', Sklansky (2012, p. 161) outlines a perspective of 'legal rules and legal procedures simply as a set of interchangeable tools', where 'officials are encouraged to use whichever tools are most effective against the person or persons causing the problem'. In the Lime project, the legal resources of the co-ordinated agencies were put to use where they were perceived to be most likely to succeed, indicating an instrumentalist view of the legal tools. Renan (2015) terms the creation of toolboxes by coordinating resources that exist across state agencies, 'pooling powers'. Among the security outcomes discussed in this article are both the efficiency of the instrumentalist approach of the project, as well as the significance of pooling the networked agencies' resources for accountability (Mazerolle and Ransley 2006b, Sklansky 2012, Renan 2015, Dowdle 2017).

\section{Power relations}

Previous research on multi-agency partnerships has shown that although a flat structure is often sought in such collaborations, power differentials exist and conflicts between agencies still tend to arise. This can create unexpected or even undesirable outcomes for the partners in the network (Crawford 1999, Gilling et al. 2013). Often, it is the police that end up with the lead position (Crawford 1999, pp. 127-128). In the Lime project, the police was defined as the leading agency already from the outset. Although agreeing on a shared project objective the project was principally defined by the police's understanding of the crime problem, meaning it was the criminal violations rather than the administrative law cases that defined the project. As discussed by Fleming and Rhodes (2005), tensions over objectives and priorities may cause competition between those involved in a network. The importance of initial clarifications of project objectives and lines of accountability within inter-organisational partnerships has also been highlighted by other researchers (Crawford 1999, Bullock et al. 2002, Meyer and Mazerolle 2014). Clarifying responsibilities between the agencies in the Lime project may have reduced 'the level of "latent conflict"' (Crawford 1999, p. 146) that may develop from different objectives and success criteria.

\section{Police co-ordination}

Organisational boundaries are a central phenomenon in the organisational literature (see, e.g Luhmann 1995, Yan and Louis 1999, Hernes 2004, Santos and Eisenhardt 2005), and have been linked to tasks and identity (Hirschhorn and Gilmore 1992), efficiency, power and competence (Santos and Eisenhardt 2005), as well as normative, relational and activity criteria (Scott 2000).

Grounded in the open-systems perspective on formal organisations (see, e.g. Scott 2004) and a broader sociology of organisations, Giacomantonio's typology of police organisational boundaries (2014, 2015) concerns co-ordination and negotiation of organisational boundaries between work units in police organisations. Giacomantonio defines work units as 'teams of people organized for particular work tasks within organizations' (Giacomantonio 2015, p. 18), and organisational 
boundaries as sites where negotiations between these units take place. More specifically, organisational boundaries are 'areas of responsibility that are unclaimed or contested between units' $(2015$, p. 23). As such, 'boundaries' are only analytically meaningful where there is a need for frequent negotiations (2015, p. 104). Negotiations occur over resources such as personnel or equipment (scarcity boundaries), over geographical distance or jurisdictional lines (proximity boundaries) and over issues related to the use of common databases or communication systems (technical/systemic boundaries).

The typology of police organisational boundaries poses a relevant and significant frame of reference for our empirical case. However, building on a fieldwork within a multi-jurisdictional police environment, Giacomantonio's typology does not encompass boundary negotiation that may arise between the police and non-police agencies. The type of co-ordination work explored by Giacomantonio thus differs from the co-ordination that takes place in the inter-organisational Lime project. While intra-organisational co-ordination between work units within the police is aided by police officials' shared purpose of law enforcement, this is not the case for the Lime investigation network which is, with respect to the participants' organisational mandates and corresponding legal authorities, more heterogeneous. Although both TA and Labour \& Welfare officials involved in the Lime project investigated specific areas within the project and can reasonably be seen as doing policing, they are not police. Committed to different rules and mandates, co-ordination - that is, synchronising the work of purposely separate agencies - may contrast with their respective goals and interests.

Because the agencies participating in the Lime project controlled their own personnel and resources, they did not have to negotiate over resources with one another (i.e. negotiations of scarcity boundaries, cf. Giacomantonio 2015). Below, we will therefore focus on how proximity and systemic boundaries shaped the internal operations of the project.

\section{Data and methods}

This study is based on semi-structured interviews with 23 participants from the police, TA and Labour \& Welfare, of whom 17 are investigators and 6 are management-level officers. All three agencies are represented in the study by participants from both levels. Twelve participants hail from various police districts, another six from special police agencies with national mandates, and five participants are from TA and Labour \& Welfare. All participants explicitly and individually gave their free and informed consent to participate in the study.

\section{Sampling}

Upon first meeting with the project group in December 2015, the project management provided a list of 43 people currently involved in the project, including 7 management-level officers. We sampled participants from different agencies and hierarchical levels from the list of active participants (the project was based on secondments, and several investigators joined and left during the investigation). All participants were affiliated with a specialised sub-group within the investigation (e.g. 'Analysis', 'Financial investigation' or 'Victims'), and we sampled to cover these groups, and organisational affiliation. The sampling strategy was not undertaken to secure generalisability, but to achieve maximum variation, with sampling conducted on 'conceptual grounds' (Miles et al.2013). Participants were recruited successively throughout the collection period. Our sampling strategy can thus be characterised as sequential (Miles et al.2013).

The interviews were semi-structured and based on a topic guide concerning interviewees' experiences working on the investigation, covering (a) the participant's entry into the project group and his/ her role and tasks, (b) detection, co-ordination and information sharing during the covert phase of the investigation, (c) experiences with the open investigation, with emphasis on co-ordination, (d) project management and goal setting and (e) agencies' limits and possibilities in relation to a 
complex and changing crime area. Interviews were recorded and lasted on average one hour. Interviews were conducted at the participants' workplaces, either in the project's rented office space or at their regular workplace. Both authors participated in all interviews.

\section{Data analysis}

All interviews were transcribed concurrently with data collection, and our collaborative analysis (Cornish et al.2013) began with transcription and a round of largely inductive and descriptive annotations. After writing up a descriptive account of our case, we found 'co-ordination' to be a key concept by which we decided to 'attempt to theorise the significance of the patterns and their broader meanings' (Braun and Clarke 2006, Bazeley 2009). We developed codes partly deduced from theory (Bowen 2006), and coded the data with terms focused on co-ordination, boundaries, comparisons, negotiations and other expressions of difference and alignment between groups of actors in the project (cf. Giacomantonio 2015).

We analysed our data using thematic analysis, a flexible and widely used 'method for identifying, analysing and reporting patterns (themes) within data' (Braun and Clarke 2006). Using NVivo 10, we coded for manifest expressions of experience with an understanding of boundaries and differences, looking for 'repeated patterns of meaning' (Braun and Clarke 2006). The aim of the analysis was to give a rich description of this particular aspect of the data which in turn could provide a narrow focus suitable for an analysis of boundary negotiations within the multi-agency security network (Braun and Clarke 2006). We co-ordinated our coding practice by reviewing matrices of coded excerpts. Although no further formal test of inter-coder reliability (Cornish et al.2013) was performed, we monitored the consistency of our coding by continuously reviewing coded excerpts.

\section{Findings}

\section{'The full sanction catalogue': bridging the proximity boundary of criminal and administrative law}

Different violations discovered in relation to the grocery chain fell under the criminal and administrative jurisdictions of the three agencies. Human trafficking, credit card fraud and money laundering 'belong' to the police and were part of the criminal case, benefit fraud and illicit work within the purview of Labour \& Welfare, and tax evasion to the TA. The project generated many administrative law cases, and some of these were used to support the criminal charges. Many of the suspects' actions could be targeted using either administrative or criminal law, most notably in the financial investigations of the network. Here, the agencies were functionally proximate. Thus we consider the delineation of jurisdiction between the agencies as proximity boundaries which required negotiation of which agency and corresponding set of legislation would be used to target particular violations (Giacomantonio 2015).

As separate nodes in the security network that relates to the labour market, no one agency was responsible for the totality of offences uncovered in the project. The overarching goal of the project was to stop the criminal activities by seizing the network's assets, and co-ordinating the agencies' legal powers and sanctions could aid in accomplishing it. 'Pooling powers' dispersed among agencies enables legal authority and expertise to be combined (Renan 2015). The pragmatic and goal-oriented multi-agency approach taken in this police-initiated project is congruent with previous research on the fit between the pragmatism of police occupational culture, and partnership working (Reiner 2010, O'Neill and McCarthy 2014).

The administrative agencies have coercive powers suited to fulfil their mandates. These are founded in administrative law, and require a lower threshold of suspicion than the police's enforcement measures. Under their administrative rules, Labour \& Welfare were authorised to ID workers in the grocery chain. They would check whether workers received unemployment or sickness benefits 
while working, proving benefit fraud and preparing the case for a special administrative court. Under similar rules, TA can collect documents, computers and mobile phones from a place of business. If tax evasion can be proved in an administrative law case, the required threshold of proof is lower than for the criminal law route to confiscation. Pragmatic decisions were made with regard to which agency would confiscate and thus whether the administrative or criminal 'track' should be used (Sklansky 2012). A TA informant said:

Isn't it better that we, who can get assets through a lower threshold of proof, take them? And perhaps greater sums, and more easily. Maybe even more quickly. The most important thing is that someone takes their profits, and does it in the most efficient way. [...] So we went with those two parallel tracks. [...] lt's about taking their profits by using - let's call it the full sanction catalogue.

A police officer reflected similarly:

So far, we work in both tracks: Police and TA. We'll see how far that takes us. I think it's the right way to do it, and the most important thing is the goal: Stop the business and take the money.

Both quotes reflect a goal-oriented pragmatism. The legal authority of the participating agencies become if not shared, at least conditionally available, in pursuit of the stated goal. The approach of the Lime project can be analysed through Sklansky's concept 'ad hoc instrumentalism':

[A]d hoc instrumentalism empowers a wider range of front-line officials, including but not limited to prosecutors, to view all substantive laws and all enforcement regimes, criminal and civil, as tools to be employed strategically, as the circumstances demand. $(2012$, p. 201)

From this instrumental perspective, whether violations are pursued using administrative or criminal law is not important in and of itself. The most important thing is that the network's assets are seized. There runs a proximity boundary between the police and the TA in relation to offences that may authorise confiscation, and bridging creates a pool of resources out of which the connected agencies can choose the ones that are most likely to accomplish their goal (Sklansky 2012, Renan 2015). Pooling of resources in pursuit of increased effectiveness and decreased vulnerability is an important aspect to why being connected to a security network is attractive (cf. Fleming and Rhodes 2005, Dupont 2006, p. 168).

The dynamic between the agencies carried the potential of mutual benefit: Unlike TA, the police are allowed to conduct searches and to seize property at private addresses (which TA's regulations do not allow). The police may achieve confiscations more easily by collaborating with TA, and when TA is partnered with the police, they may gain access to information (from the police's searches at private addresses or communication surveillance) that they would not be able to procure themselves. A similar dynamic applied in the relationship between police and Labour \& Welfare. Due to the suspicion of 'aggravated human trafficking' in the criminal case, police were authorised to use communications surveillance. This brought to light possible frauds that Labour \& Welfare were unable to discover through their own methods:

[T]his is perhaps the first time people who have been at no risk of being caught, have actually been caught. [...] We wouldn't have been able to handle these cases with our own means, our legal authority. There had been zero risk, really. (Labour \& Welfare investigator)

Sharing data from the communication surveillance with Labour and Welfare was necessary to optimally pool the agencies' resources. Through explicit negotiation of which suspects were of mutual interest to the agencies and whom their efforts should thus be directed towards, data from the communications surveillance could be transmitted to Labour and Welfare for use in their administrative case:

We run into some challenges with communications surveillance. We can't use it directly in our administrative case. [The administrative law] violations have to be reported to the police for that to happen. We had a number of persons of interest, and so we came to an agreement with the police as to which suspects they would go for. [...] and that we would report to the police. So we and the police selected 18 persons that we [Labour and 
Welfare] would look into from our end, and then we used what was discovered in the police's investigation of those persons.

The outcome of boundary negotiations may be to uphold boundaries, as well as to bridge (Giacomantonio 2015). Striking the balance between maintaining and bridging the boundaries between agencies remained challenging throughout, as illustrated by the example given by a senior police officer:

[W] want Labour \& Welfare to check a shop because we [the police] want to know who's there. But they only record those workers who receive benefits. [...] But they get the names of everyone who's there, right? But the ones receiving benefits are the only ones entered into the system. And they sit there with a piece of paper with the name of everyone that was in the shop. [We] who're investigating human trafficking, we're very interested in the names of the others who were there. In one way, we were the ones who sent them there [Labour \& Welfare to the shop], but they need independent grounds for doing it. We can't deputise them, and there's a reason why that's the case. That we can't just say 'Labour \& Welfare - go there - [...] - If the police were supposed to be able to do that, we would've had that legal authority ourselves. So, we can't deputise them, but we're in the same project. We share a goal. We must be able to say to Labour \& Welfare: 'Check that shop'. And they'll do it, but we need to be able to get the information [...] into the shared project [...].

\section{Power relations}

The participating agencies' combined legal authority and expertise were suited to serve the shared goal of the project. All the while, each agency still had their own agency-specific goals and interests which were furthered by participating in the project. Although many administrative cases were investigated to support the criminal prosecution, some 'satellite' administrative cases were pursued by the agencies due to their own organisational mandates. Even though not every administrative case could be subsumed under the shared umbrella of the overarching goal, the goals of the participating agencies were largely complementary.

While we find that the relationship between the goals of the agencies relative to the shared goal of the project was harmonious, actualising the goals proved more fraught. Signs of this emerged during the raid against the shops in the early stage of the project: Each shop was raided by a multi-agency team in order to use their various authorities to collect evidence, arrest, and interview witnesses, as well as for the agencies to confiscate according to their own needs. Large numbers of (largely patrol) police officers from several districts were seconded to participate in the raid, and with few exceptions these had no relation to the case or subject areas of the regulatory agencies. This created friction between participants whose agency-specific needs were not always met, as described by an informant from the TA:

There was so much chaos that day. [S]everal police officers thought that we should seize as few documents as possible. I think a lot of police officers aren't used to taking so many papers for evidence, but we want to bring all of it with us. [...] But the police had the last word, so in most of the shops a lot of material was left behind.

\section{A Labour \& Welfare investigator relayed similar experiences:}

[...] We had hoped to be able to give more input before the raid. About what sorts of investigative steps we would like for our cases. And I think that's where ... some of that communication, that we hadn't worked together before, that they sort of "Yeah, yeah, benefit fraud. We got it." But we were like, "There are so many exceptions, we'll need this and this documentation." And we don't have it. And now it's too late.

The raid made practical, professional differences between agencies visible. Despite a complementary goal structure, many seconded police officers were not familiar enough with financial investigations or the work of the administrative agencies to support the evidence collection and thus the further investigation of some administrative cases. '[O]nly certain nodes can fully exploit the opportunities this new governance yields' (Dupont 2004, p. 78), and while we found no conflict regarding the goals or fundamental idea of pooling authority and expertise, the project was initiated by the police and structured with criminal prosecution and policing objectives in mind. The police, we 
argue, was 'the most central (and, hence, most powerful)' (Brewer 2017, p. 454), least constrained, and most influential node within the project (Dupont 2006, p. 175). That we found no evidence of overt conflict over objectives does not mean that negotiations over how the work of the agencies should be connected took place in a space void of power relations. The police importantly exercised power 'through the power to define: to set broad agendas [...] and direct resources' which increased their 'relative capacity [...] to achieve desired outcomes' (Crawford 1999, pp. 132-133). Our analysis suggests that every agency was largely satisfied with what they got out of participating. Still, it is likely that their interests would be better and more easily served had their problem definitions and investigative requirements been equally present to the police's in the planning stages of the project.

\section{Connecting the work of similarly specialised sub-groups}

'Police is not just police' one informant from one of the regulatory agencies said, pointing out that expertise and experience is not predictably located within organisations. Financial crime detection and investigation is not generalised knowledge in the police. We found that police and non-police participants alike experienced the difference between investigators with and without financial investigation expertise as significant. Police investigators were either generalist criminal investigators, organised crime investigators, or financial crime investigators:

What it's like to work with the police? It varies, really. I don't feel that we work with 'the police', because we work with some officers that work with financial crimes, and those who work with other cases [...] [T] hey have different platforms. But [...] we've been on a team with the people from [national financial crime unit], and then you're on the same planet, really, if you know what I mean. We understand that things take time, that there is a crazy number of documents and numbers and everything else. (TA investigator)

Both the TA's and Labour and Welfare's investigations related wholly to the financial aspects of the Lime project. The difference between police with and without any expertise in that subject area was thus most keenly felt by the regulatory agencies. The Labour and Welfare investigator who gave the following quote had extensive experience from working with the police on cases involving benefit fraud, but had never previously worked with an organised crime unit:

\footnotetext{
We worked with a new branch of the police this time. We've worked with the specialists in the police districts for a long time. But now - I don't know, they work with organised crime and they're not used to working with other public agencies, I think. The cultures are different. There are keys to investigating benefit fraud that are difficult for a novice to understand. There were some things from the early cooperation, I don't want to call it problematic, but it takes time to speak the same language, understand each other, what's important and how we work.
}

Both quotes illustrate how the informants distinguish between 'police' in general on the one hand, and specialist financial crime investigators on the other. Professionals with expertise in some form of financial investigation can be viewed as a sub-group that was less heterogeneous than the project as a whole with regard to expertise and prior case experiences. Our findings suggest that shared expertise among partners from separate organisations was a beneficial background on which to connect the work of the participating agencies.

\section{Professional secrecy}

Throughout the project, the regulatory agencies contributed information useful to the criminal investigation, while they also used information from the criminal investigation in their administrative cases. However, all participating agencies were bound by separate legislation regarding information exchange with partner agencies. These rules of professional secrecy ran through the project organisation and represented systemic boundaries (cf. Giacomantonio 2015) between participants from different agencies. The purpose of secrecy provisions is to protect data from improper dissemination, and sharing information is thus an exception. Negotiations over access to other agencies' data were 
often explicit, and thus were suitable for studying tensions between network demands and the purposes and obligations of its connected formal organisations.

Each of the agencies whose work was co-ordinated in the project had purchase of parts of the activities of the suspects, and it varied which agency could share what information, at what time, for what purpose, and with whom. As a Labour \& Welfare investigator put it:

[Information sharing] is problematic when you're in a group like this - well, we're released from our confidentiality depending on who else is present. For example, there'll be information that we can give to the Tax authority, but if the Labour Inspection Authority is in the same room, we'll either have to ask them to leave, or - you know.

Due to mutually supporting rules and a formalised procedure, neither TA nor Labour \& Welfare described information sharing between the two as particularly challenging. TA could share more with the police than Labour \& Welfare could. If the minimum sentence for a suspected crime is six months' imprisonment, TA may share 'most of what we have' (TA investigator). The relationship between the police and Labour \& Welfare, on the other hand, was described as challenging:

[Information sharing has been] challenging. That's got mostly to do with Labour \& Welfare, though, in this project. Customs - no problem. TA - more pragmatic about these things, and we have better formal agreements with them. While Labour \& Welfare - they're a bit of a hybrid organisation, they aren't primarily a control agency [...] (Police officer)

The primary aim of Labour \& Welfare is to contribute to social and economic security, and to support (re-)entry into the workforce (Adminstration of Labour and Welfare Act 2006). They can share information with the police to the extent that sharing promotes their own purposes. As the quote from a Labour \& Welfare investigator illustrates, this was challenging in the multi-agency, co-localised environment of the Lime project:

Our legal basis for sharing information is based on whether it serves our purposes to do so. And that's quite a discretionary judgment - when we can say that it is, and when it isn't. You're sitting in a meeting and have to weigh every word in a way that doesn't breach confidentiality. It's a big responsibility [...] and the other thing is that we may well have information that in light of the group's shared goals we should've shared. But we can't necessarily do that.

Labour \& Welfare is allowed to share more with TA than they are permitted to share with the police, and don't have rules governing sharing information related to criminal activity. However, the police have wider access to share information with the partner agencies in the project:

We [the police] can probably get a bit too eager sometimes. We've talked about information sharing all the time. And what we've arrived at is, and I've always meant this, but to get the other agencies to see it - there are purposes behind what we're doing that enables us to share information. (Police officer)

We found that the police viewed themselves as the most able and willing to share information in the project. The police are allowed to share information with public agencies if the purpose is crime prevention. This mandate gives the police wide purchase on a range of social and criminal problems, making their potential reach in security networks less 'confined within distinct subgroups, or clusters' (Brewer 2017, p. 453). Whether an effort is considered 'preventive' is largely a matter of discretion. For instance, if the police pick up information suggesting ongoing benefit fraud during communications surveillance, sharing this with Labour \& Welfare could be considered preventive. Thus, the police are far more able to bridge the systemic boundary of professional secrecy from their side, compared with the partner agencies in this study (Giacomantonio 2015).

\section{Access to shared IT systems}

The lack of shared software for information processing and project management highlighted IT systems as yet another systemic boundary between participants. The project was subdivided into eight functional teams, and every individual participant was assigned to one of the following: analysis, confiscations, communication surveillance, documents, investigation management, victims, 
tactical investigation and financial investigation (Labour \& Welfare and TA participants were members of the tactical and financial investigation teams). In the information infrastructure, communication surveillance, confiscations and analysis occupied central positions. The communications surveillance team recorded e-mails, texts and phone calls in both the covert and the exploratory phase of the criminal investigation. The confiscations group systematised and recorded the extensive materials collected. The analysis group created systems and procedures for data processing that facilitated sharing of the materials collected.

The proprietary software Indicia was the analysis team's primary tool to impose a unitary order and recording practices for information in the project. Indicia is used by Norwegian police for intelligence work and project management. Its separate modules makes it well suited for recording, systematising and linking information, as well as for delegating and following up on tasks. An interview transcript, for instance, can be uploaded to the database with names or places tagged, enabling others who may be interested in those names or places to find them. Additionally, Indicia features free text searches in the database. Ideally, the software could be a one-stop shop for anyone who wanted to know whether someone had recorded information of interest.

All police officers, but only the police, have had access to Indicia. The software is connected to a national intelligence database where most information is visible to every user, but access can be controlled. Entries related to organised crime or ongoing projects are usually hidden from anyone not positively authorised to view them. However, a user cannot be given access only to the project module without access to the national intelligence database at the same time. There was a perceived need for everyone, regardless of agency, to work together in the same information environment:

It's been hell getting the system owners to let the control agencies in - TA and Labour \& Welfare. That's where the job gets done, and we can't have satellites that don't see what we're working on or that we can't delegate tasks to. (Police officer)

The question of access to Indicia highlighted tension between the concern for expediency and communication within the project, and the separation of agencies' data. Everyone was eventually given access, and could search police reports and interview transcripts. The key to bridging this systemic boundary was to define the participants as police personnel. As an investigator from one of the non-police agencies explains: 'We worked in Indicia, but not as [representative from our own agency]. As police.' Once they had access, the investigators from the control agencies had varying experiences with the usefulness of this access:

We've had access to the police systems when we worked in the shared office space, but we received some training in Indicia [...] There's probably a lot there that could have been useful that we only now [in a late stage of the project] feel like we have the time to look up. There are piles and piles of documents. You'd drown.

Another says that:

[Indicia] was very useful. When a case has so many people working on it and there are so many documents, we don't always know who we're looking for. Someone could have discovered something that they didn't know was relevant to us because they didn't know that this person received benefits. And we didn't know that the person worked [while receiving benefits].

Familiarity with the system, adequate training, but also the quality of the entries and how information was indexed for retrieval likely impacted how and to what extent this bridge between the police system and the control agencies was utilised. While the analysis team created a system for information processing, the result was largely determined by how the investigators who added documents to the data base adhered to it.

\section{Connecting disparate areas of expertise}

The material collected in the Lime project was massive: interviews, communication surveillance containing e-mails and text messages in addition to at least 50,000 phone calls, confiscations of paper 
documents from the 20 raided shops and electronic confiscations consisting of hundreds of thousands of files. While giving all agencies access to Indicia helped bridge a systemic boundary, the information flow between participants and teams hinged in part on the ability to recognise data of interest to other participants. While Indicia was a tool for organising information, the interpretation, naming and tagging of the data required manual and deliberate action from whoever handled it. A police officer who worked on communication surveillance reflected on the challenges of serving colleagues in the multi-agency and multi-disciplinary project with relevant information:

[K]nowing what to look for - what should we look for to support the financial investigators? [ ... ] [T] hose of us who work on communication surveillance, who don't have any background in financial crime - what should we look for? Which calls are important? What is required to prove guilt?

The communication surveillance police officer is an expert on this collection method, but is not familiar with every crime type detected in the project. The function of his team was to collect and convey information to investigators from the different agencies as it emerged. Similarly, police officers conducted interviews, and the TA investigators could see from the transcripts that follow-up questions that were obvious to them had not been asked:

It has been challenging, really, that the people who have interviewed and that have listened to the phone calls that don't know about financial crimes - they can hear things and they don't know what to ask that would be relevant for us [TA] to know about. [...] It's been completely impossible for police officers who don't work with financial crimes to recognise that this would be something the TA needs.

Distributing information from the interviews or telephone tap to specialised investigators was challenging. At times, the information flow was hindered by 'gatekeepers' lacking expertise in financial crime in general, or benefit or tax fraud in particular. This challenge was somewhat alleviated by the ability of the agencies to search parts of the collected material themselves in Indicia. However, as a Labour \& Welfare investigator reported, delving into the data in this way was not an entirely satisfactory option:

I know there is a lot of information there, and I know where to find it. It's more a question of finding the time to look for it. Looking through communication surveillance and confiscations is very time consuming.

Despite the challenges described above, working in a shared space appears to have aided investigators in locating specialised knowledge within the project, improving information flow to some extent. Through collegial conversations and overhearing what other teams were working on, investigators became familiar with details and status of other parts of the investigation:

If the police have something we need - say from the telephone tap - and we can use it, they usually have to give it to us in a format that we're allowed to use. We'll say: 'We need this. Can you write us a report?' (TA investigator)

The quote above also refers to how information in a police document, for instance from communication surveillance, was translated into a format that the administrative agencies could use in their own cases. TA could not lawfully use that information in their investigation, but had to receive it in the form of a police report. The information flow from the police to the other agencies was facilitated by informal transmission of snippets of information, as well as through inclusion in the shared ICT environment. Simply sharing the same office space created opportunities to overhear and subsequently ask for the right information report from the police. Information was translated from a police-specific format to a report accessible to TA.

\section{Discussion}

\section{Bridging systemic boundaries of information flow}

Shared knowledge is important because it enables participants to communicate with greater accuracy (Gittell 2011), and increases awareness of how their tasks relate to those of others. Above, we 
argued that professional secrecy and the lack of a common management system were influential systemic boundaries which impacted the information flow within the project, and required negotiation by the participants.

To connect the work of agencies within the project, the project management secured access to the police intelligence database and project management system Indicia for the non-police agencies. This initiative resembles boundary spanning activities discussed by Giacomantonio (2015), in that relevant boundary actors (such as managers) may overcome systemic boundaries by creating new systems or rule frameworks. The non-police agencies' access was the result of intra-organisational negotiation between project managers and system administrators, and was unique in the sense that, as far as we have been able to ascertain, access had never been given to anyone outside the police before. Still, information exchange raises complex issues of confidentiality (Nash and Walker 2009, Harvey et al. 2015), contrasting agency-specific obligations with the shared interest of the project as a whole. Although the use of the intelligence software as a medium for information sharing is striking, basic confidentiality considerations underlay the negotiation (as by default users do not have access to classified intelligence).

Indicia in principle made the police's information readily available, but availability of data does not, as noted by Dupont (2006, p. 169), 'ensure its diffusion and use by all institutional nodes'. Having access to the same information is important because 'the holder of information often fails to recognize the value of it to others' (LeBeuf 2005). Still, unfamiliarity with partners' interests and needs proved to interfere with the project's information flow. Challenges existed both between participants belonging to different agencies, and between participants with expertise in different subject areas. While the projects' police investigators share basic standardised training in criminal investigation, specialisation makes investigators more apt at recognising valuable information for some types of crime rather than others. Examining the negotiation of inter-organisational boundaries between the project participants, we found that the sharing of expertise, such as 'having knowledge about financial investigation', helped participants from different agencies co-operate. Nevertheless, it was a common perception that information flow persisted to be difficult throughout the project.

While some information simply could not be shared due to issues of confidentiality - the administrative agencies notably have less license to share with the police than vice versa - the participants in many cases managed to find pragmatic solutions to co-ordinate their work. Co-localisation in the shared, rented office space appears to have created an organisational context conducive for building familiarity and trust within the project as a work unit. Spending every day in the same space gave ample opportunity for informal meetings, coffee breaks, and accidental encounters between investigators from different agencies. This facilitated what we consider informal pockets of information sharing where inter-agency co-ordination was aided by the personalised trust that participants came to place in each other, giving room for attempts to bridge systemic boundaries of information flow (cf. Giacomantonio 2015). These findings align with previous research, which has found that information sharing also relies on informal activities and personal relationships (Dupont 2004, O'Neill and McCarthy 2014, Cotter 2015, Søgaard et al.2016), and 'that the underlying relational properties of security networks [...][make] it difficult to distinguish between formal and informal ties' (Whelan 2016).

Although we identify informal pockets of information sharing, we do not claim that the codes of confidentiality were dishonoured by the investigators. While all participants were guided by separate codes of secrecy which regulated each agency's information sharing practices, these regulations also enabled them to make discretionary judgment calls based on their abstract knowledge, regarding whether a particular case justified information sharing. Discretion accounts for much of the usefulness of a flexible network approach (Mazerolle and Ransley 2006b, p. 185), and, as we find in this study, the discretionary space is even more flexible in partnerships where interests are strongly interwoven (Hartmann 2014). 


\section{Negotiating jurisdiction: using the whole 'sanction catalogue'}

Partnerships (or other modes of networked practice, such as third party policing) represent pragmatic attempts to solve problems of crime and disorder, in which getting the job done might be more important than questions of whether the problem at hand is crime or an administrative violation (Maguire 2000, cf. Weber 2013). Networked crime control occurs in response to external pressures to disperse the 'responsibility and interest in crime control across a range of regulatory nodes' (Mazerolle and Ransley 2006b). Partnering with other 'regulatory nodes', the police gain access to the 'legal levers' and sanctions of their partners. The police inhabit a role as information brokers in security networks, partly because of the content of their information (Ericson and Haggerty 1997, Crawford 1999).

Co-ordinating resources from three agencies created a potentially wide and varied toolbox for the Lime project, referred to as 'the sanction catalogue' by one participant. As shown, different parts of the Lime case complex fell under the separate jurisdictions of the involved agencies. While many violations firmly and obviously belonged to one particular agency, other violations could be handled by either TA or the police. Working towards a shared project goal, these jurisdictions could be interpreted as proximity boundaries (cf. Giacomantonio 2015) that necessitated negotiation to achieve effective co-ordination. For instance, if hindered by own organisational jurisdictions, the police could propose Labour \& Welfare to do shop controls. These controls were legitimate in light of Labour \& Welfare's jurisdiction, but might not have occurred but for the request of the police. Being able to choose strategically between the most suitable 'tracks' available for the project as a whole, also known as 'ad hoc instrumentalism' (Sklansky 2012), was perceived as an effective strategy for spanning the proximity boundaries and ensuring that useful information was shared in included in the project.

\section{Accountability versus efficiency}

The collaborative strategy and 'pooling powers' made the Lime project's investigations more efficient (Dupont 2006, Mazerolle and Ransley 2006b, Renan 2015): securing confiscation through the TA's authority required a lower threshold of proof compared with the police, and reduced the risk of failure and wasted resources. Further, pooling enabled participants to be effective in the first place: Labour \& Welfare would not be in a position to discover and investigate many of the cases discovered except through the police's communications surveillance. Joining the two tracks of administrative and criminal law in pursuit of a shared objective created a dynamic toolbox which furthered agencies' ability to handle a cross-jurisdictional crime problem. However, whether participation is an effective strategy for individual agencies in achieving their goals will depend in part, as shown in this study, to what extent their interests and particular needs are embedded in the goals and structure of the co-ordinated effort (Mazerolle and Ransley 2006b, p. 181). While agencies agreed on the goals and the general road map for getting there, the police benefited from having had an important hand in defining the project, its 'crimes [and] appropriate solutions' (Crawford 1999, p. 133).

Increased efficiency, though, came bundled with accountability challenges. Even if the instrumental approach demonstrated in this study was conducted according to the letter of the law, such practices border on deputisation of partner agencies by the police. Co-ordinating agencies potentially creates tension between the goal of the joint project and the separate mandates of the agencies and professions involved. Ad hoc instrumentalism challenges traditional expectations of political accountability, meaning 'the desirability of formal, legal constraints on official action' (Sklansky 2012), sought by adherence to 'rationalised and transparent systems of bureaucratic control' (Dowdle 2017, p. 198). Using administrative law for crime control ends and vice versa blurs the boundary between the two tracks, and requires that we find 'ways to bolster accountability at the intersection of the systems [...] by making the system, and its lines of responsibility, more transparent' (Sklansky 2012, p. 219). The tracks exist with different purposes, and the choice between them is 
consequential for those whom interventions are directed at, in terms of rights and the standard of proof required to sanction (Mazerolle and Ransley 2006b, p. 179, cf. Goold 2016). Our findings illustrate the need for further studies on whether close-knit multi-agency constellations strain professionals' primary obligations to the recipients of their services (Grimen 2008).

\section{Concluding remarks}

Multi-agency investigations are increasingly deployed against criminal networks and cross-jurisdictional crimes. This study's unique empirical material from an inter-organisational investigation allows an analysis of the internal dynamics of a security network of co-ordinated state sector governmental nodes. Networks involving multiple state agencies hold great potential power, which warrants further studies into the practices and ideologies of co-ordination.

Despite difficulties presented by organisational boundaries, we find that the participants generally managed to co-ordinate work across agencies. While bridging organisational boundaries enabled agencies to pool their powers, co-ordination across organisations may challenge the protection of sometimes conflicting aims and interests. Although potentially effective against cross-jurisdictional crime, use of the full 'sanction catalogue' also raises important questions about weighing efficiency against the protections offered by formal organisations in terms of accountability. This study thus also contributes to the literature on the interchangeable use of criminal and administrative law, a topic notably explored in 'crimmigration' research (Stumpf 2006, Sklansky 2012, Weber 2013, Gundhus 2017). Tempering efficiency with transparency, we argue, is paramount to preserve the institutional integrity of, and trust in, deliberately separated public agencies as they participate in powerful networked assemblages.

\section{Note}

1. The Oslo District Court is expected to render its decision in the spring of 2017.

\section{Acknowledgements}

We are grateful to Helene O.I. Gundhus and Fredrik Engelstad for valuable feedback, as well as to the three anonymous reviewers for their insightful comments on earlier versions of this paper.

\section{Disclosure statement}

No potential conflict of interest was reported by the authors.

\section{Funding}

This work was supported by Ministry of Justice and Public Security, Norway; Norwegian Police University College; The Research Council of Norway [grant number NFR 238170/F60].

\section{ORCID}

Annette Vestby (D) http://orcid.org/0000-0002-7947-780X

\section{References}

Alexander, E.R., 1995. How organizations act together: interorganizational coordination in theory and practice. Luxembourg: Gordon and Breach.

Bazeley, P., 2009. Analysing qualitative data: more than 'identifying themes'. Malaysian journal of qualitative research, 2 , 6-22. 
Beech, N. and Huxham, C., 2003. Cycles of identity formation in interorganizational collaborations. International studies of management \& organization, 33, 28-52.

Block, L., 2008. Combating organized crime in Europe: practicalities of police cooperation. Policing: an international journal of police strategies \& management, 2, 74-81.

Bowen, G.A., 2006. Grounded theory and sensitizing concepts. International journal of qualitative methods, 5, 12-23.

Braun, V. and Clarke, V., 2006. Using thematic analysis in psychology. Qualitative research in psychology, 3, 77-101.

Brewer, R. et al., 2017. Controlling crime through networks. In: P.E. Drahos, ed. Regulatory theory. Foundations and applications. Canberra: ANU Press, 447-464.

Bullock, K., Erol, R., and Tilley, N., 2006. Problem-oriented policing and partnerships: implementing an evidence-based approach to crime reduction. Abingdon: Taylor \& Francis.

Bullock, K., Farrell, G., and Tilley, N., 2002. Funding and implementing crime reduction projects. London: Home Office.

Cornish, F., Gillespie, A., and Zittoun, T., 2013. Collaborative analysis of qualitative data. In: U. Flick, ed. The SAGE handbook of qualitative data analysis. London: Sage, 79-93.

Cotter, R.S., 2015. Police intelligence: connecting-the-dots in a network society. Policing and society, 1-15. doi:10.1080/ 10439463.2015.1040794.

Crawford, A., 1994. Social values and managerial goals: police and probation officers' experiences and views of interagency co-operation 1. Policing and society: an international journal, 4, 323-339.

Crawford, A., 1999. The local governance of crime: appeals to community and partnerships. Oxford: Oxford University Press.

Dowdle, M.W., 2017. Public accountability: conceptual, historical and epistemic mappings. In: P. Drahos, ed. Public accountability: conceptual, historical and epistemic mappings. Regulatory theory: foundations and applications. Canberra: ANU Press.

Dupont, B., 2004. Security in the age of networks. Policing and society, 14, 76-91.

Dupont, B., 2006. Delivering security through networks: surveying the relational landscape of security managers in an urban setting. Crime, law and social change, 45, 165-184.

Ericson, R.V. and Haggerty, K.D., 1997. Policing the risk society. Toronto: University of Toronto Press.

Europol. 2016. Joint action to tackle West African human trafficking networks [online]. Press Release. Available from: https://www.europol.europa.eu/newsroom/news/joint-action-to-tackle-west-african-human-trafficking-networks-0 [Accessed 2 February 2017].

Fleming, J. and Rhodes, R.A.W., 2005. Bureaucracy, contracts and networks: the unholy trinity and the police. Australian \& New Zealand journal of criminology, 38 (2), 192-215.

Giacomantonio, C., 2014. A typology of police organizational boundaries. Policing and society: an international journal of research and policy, 24, 545-565.

Giacomantonio, C., 2015. Policing integration. The sociology of police coordination work. London: Palgrave Macmillan.

Gilling, D., et al., 2013. Powers, liabilities and expertise in community safety: comparative lessons for 'urban security' from the United Kingdom and the Republic of Ireland. European journal of criminology, 10 (3), 326-340.

Gittell, J.H., 2011. 30 New directions for relational coordination theory. In: K.S. Cameron and G.M. Spreitzer, eds. The Oxford handbook of positive organizational scholarship. New York: Oxford University Press, 400-411.

Goold, B.J., 2016. Policing and human rights. In: B. Bradford, B. Jauregui, I. Loader, and J. Steinberg, eds. The SAGE handbook of global policing. Thousand Oaks, CA: Sage, 226-240.

Grimen, H., 2008. Profesjon og profesjonsmoral. In: A. Molander and L.I. Terum, eds. Profesjonsstudier. Oslo: Universitetsforlaget, 144-160.

Gundhus, H.I. et al., 2008. Modell for forebygging av kriminalitet?: evaluering av Samordning av av Lokale kriminalitetsforebyggende tiltak (SLT). Oslo: Politihøgskolen.

Gundhus, H.O.I., 2017. Discretion as an obstacle: police culture, change, and governance in a Norwegian context. Policing. doi:10.1093/police/pax012.

Hardy, C., Phillips, N., and Lawrence, T.B., 2003. Resources, knowledge and influence: the organizational effects of interorganizational collaboration. Journal of Management Studies, 40, 321-347.

Hartmann, M.R.K. 2014. In the gray zone. With police in making space for creativity (PhD thesis). Copenhagen Business School. Available from: http://openarchive.cbs.dk/bitstream/handle/10398/9043/Mia_Rosa_Koss_Hartmann.pdf? sequence $=1$.

Harvey, J.H., Hornsby, R.A., and Sattar, Z., 2015. Disjointed service: an English case study of multi-agency provision in tackling child trafficking. British Journal of Criminology, 55 (3), 494-513. Available from: https://doi.org/10.1093/bjc/azu115.

Hernes, T., 2004. Studying composite boundaries: a framework of analysis. Human Relations, 57, 9-29.

Hirschhorn, L. and Gilmore, T., 1992. The new boundaries of the "boundaryless" company. Harvard Business Review, 70, 104-115.

Johnston, L. and Shearing, C., 2003. Governing security. Explorations in policing and justice. New York: Routledge.

Kahn, B.K., Strong, D.M., and Wang, R.Y., 2002. Information quality benchmarks: product and service performance. Communications of the ACM, 45, 184-192.

Lebeuf, M.-E., 2005. Information sharing among Canadian police departments: trusting individuals or systems?. The Canadian Review of Policing Research, 1, http://crpr.icaap.org/index.php/crpr/article/view/36/32.

Luhmann, N., 1995. Social systems. Stanford: Stanford University Press. 
Maguire, M., 2000. Policing by risks and targets: some dimensions and implications of intelligence-led crime control. Policing and society, 9, 315-336.

Mazerolle, L. and Ransley, J., 2006a. The case for third-party policing. In: D. Weisburd and A.A. Braga, eds. Police innovation. Contrasting perspectives. New York: Cambridge University Press, 191-206.

Mazerolle, L. and Ransley, J., 2006b. Third party policing. Cambridge: Cambridge University Press.

Meyer, S. and Mazerolle, L., 2014. Police-led partnership responses to high risk youths and their families: challenges associated with forming successful and sustainable partnerships. Policing and society, 24, 242-260.

Miles, M.B., Huberman, A.M., and Saldaña, J., 2013. Qualitative data analysis: a methods sourcebook. Thousand Oaks, CA: Sage.

Nash, M. and Walker, L., 2009. Mappa - Is closer collaboration really the key to effectiveness? Policing, 3 (2), 172-180. doi:10.1093/police/pap007.

Nøkleberg, M., 2016. Security governance - an empirical analysis of the Norwegian context. Nordisk Politiforskning, $3,53-82$.

O'Neill, M. and Loftus, B., 2013. Policing and the surveillance of the marginal: everyday contexts of social control. Theoretical criminology, 17 (4), 437-454.

O'Neill, M. and Mccarthy, D.J., 2014. (Re) negotiating police culture through partnership working: trust, compromise and the 'new' pragmatism. Criminology and criminal justice, 14, 143-159.

Plecas, D., et al., 2011. Evidence-based solution to information sharing between law enforcement agencies. Policing: An International journal of police strategies \& management, 34, 120-134.

Reiner, R., 2010. The politics of the police. Oxford: Oxford University Press.

Renan, D., 2015. Pooling powers. Columbia law review, 115 (2), 211-291.

Rosenbaum, D.P., 2002. Evaluating multi-agency anti-crime partnerships: theory, design, and measurement issues. Crime prevention studies, 14, 171-225.

Santos, F.M. and Eisenhardt, K.M., 2005. Organizational boundaries and theories of organization. Organization science, 16, 491-508.

Scott, W.R., 2000. Institutional change and structuration processes. In: W.R. Scott, M. Ruef, P.J. Mendel, and C.A. Caronna, eds. Institutional change and healthcare organizations: from professional dominance to managed care. Chicago: University of Chicago Press, 340-363.

Scott, W.R., 2004. Reflections on a half-century of organizational sociology. Annual review of sociology, 30, 1-21.

Shearing, C. and Wood, J., 2003. Nodal governance, democracy, and the new 'denizens'. Journal of law and society, 30, 400-419.

Sklansky, D.A., 2012. Crime, immigration, and ad hoc instrumentalism. New criminal law review: in international and interdisciplinary journal, 15 (2), 157-223.

Strype, J. et al., 2014. Perceptions of interprofessional collaboration. Professions and professionalism, 4, 1-16.

Stumpf, J.P., 2006. The crimmigration crisis: immigrants, crime, and sovereign power. American university law review, $56,367-419$.

Søgaard, T.F., Houborg, E., and Tutenges, S., 2016. Nightlife partnership policing-(dis) trust building between bouncers and the police in the war on gangs. Nordisk Politiforskning, 3, 132-153.

The Administration of Labour and Welfare Act., 2006. Act of 1 July 2006.

Weber, L., 2013. Policing non-citizens. London: Routledge.

Webster, J., 2015. Effective third-party policing partnerships or missed opportunities? Policing and society, 25, 97-114.

Whelan, C., 2015. Security networks and occupational culture: understanding culture within and between organisations. Policing and society, 1-23. doi:10.1080/10439463.2015.1020804.

Whelan, C., 2016. Informal social networks within and between organisations: on the properties of interpersonal ties and trust. Policing: an international journal of police strategies \& management, 39, 145-158.

Willis, J.J. and Mastrofski, S.D., 2011. Innovations in policing: meanings, structures, and processes. Annual Review of Law and Social Science, 7, 309-334.

Yan, A. and Louis, M.R., 1999. The migration of organizational functions to the work unit level: buffering, spanning, and bringing up boundaries. Human relations, 52, 25-47. 


\title{
Taking stock of networks across the security field: a review, typology and research agenda
}

\author{
Chad Whelan and Benoît Dupont
}

\begin{abstract}
Security network research has grown considerably in the last decade as it has been increasingly recognised that security is pursued through networks of public, private and hybrid actors or nodes. This research deals with local, institutional, international and virtual security networks and includes techniques such as social network analysis and approaches more familiar to organisational theory and management. However, much of the security network research employs the network concept as a metaphor to suggest a relationship between a set of security nodes, without examining the structural pattern of these relationships or the underlying properties of security networks. Different uses of the network concept have led to confusion about the application of network theory across the security field. This article attempts to address these issues by clarifying the fundamental concepts of a network perspective and revisiting existing typologies of security networks. We review research on the use of network perspectives across the security field, evaluate theoretical and empirical trends, and give directions for future research. We examine the geographical properties of security networks operating at the subnational, national and transnational levels and put forward four types of networks that have the potential to improve security network research: information exchange networks, knowledge generating networks, problem-solving networks and coordination networks. The article concludes by highlighting the importance of networks for understanding and promoting the governance of security.
\end{abstract}

\section{Introduction}

Security is increasingly recognised as being pursued through networks of public, private and hybrid actors or nodes. Following the 'nodal governance' perspective (Johnston and Shearing 2003, Wood and Dupont 2006), scholars have emphasised how mentalities and technologies of security governance have evolved from a more state-centered approach to one involving an array of potential governing nodes. Grabosky (1995) was among the first to highlight the diverse range of mechanisms that can be used to enlist non-governmental commercial and voluntary institutions in the co-production of regulatory compliance. While these regulatory or security nodes may or may not form ties or enter networks, and while the precise nature of these ties is not always the direct focus of advocates of nodal governance, it is important to distinguish between the nodal governance and security network perspectives. The main focus of the nodal governance perspective has been to argue that no particular node - such as the state - should be given priority in networks of security governance. It is perhaps this particular point that attracted most attention, with scholars adopting a normative 
position with regard to the central role of the state in such networks (Loader and Walker 2007). Following a related but at times quite different trajectory, research on security networks and related themes such as partnerships has grown considerably in the last decade. This body of research extends to what one of us calls local, institutional, international and virtual security networks (Dupont 2004) across the field of 'low' to 'high' policing (Brodeur 2010). Security network research now encompasses researchers using techniques such as social network analysis (SNA) (Dupont 2006, Brewer 2014) as well as those calling attention to the organisational dynamics of networked forms of security governance (Whelan 2012). Security network research differs from nodal governance in that it is more focused on networks rather than governance. It is, as such, less concerned with the attributes of individual security nodes than it is the relationship between a given set of nodes and the underlying properties of such relationships.

By expanding its focus of enquiry to capture the diversity of institutions, capacities, linkages and interactions contributing to defining and responding to particular security problems, security network research overcomes one of the major limitations experienced by police scholars attempting to analyse the contribution of police organisations to the delivery of security. That is, they find it exceedingly difficult to accurately assess the impact of a single institution on complex crime and security problems, no matter how powerful that institution proves to be. Some private security scholars who legitimately raise the instrumental features and democratic shortcomings of this specific mode of security delivery face a similar challenge; reducing the contribution of private security providers to commodified exchanges fails to account for the complex web of formal and informal relationships and constraints that shape their operations (Dupont 2014). The security network approach frames security as the cumulative outcome of activities undertaken by a broad and diverse range of interdependent institutions. For example, in the field of counter-terrorism, security network research seeks to move beyond analysing how security agencies address the terrorist threat, evaluating policy or legislation, or focusing on the organisational failures that may have preceded a particular attack. Instead, it focuses on 'structural' properties such as how institutional networks form and adapt in response to perceived threats and what governance mechanisms emerge as a result, and 'relational' dynamics such as how organisational cultures and interpersonal relationships enable and constrain these arrangements (Whelan 2012). The broader scope of this approach makes it more challenging, both theoretically and empirically, but also potentially more rewarding. In light of the considerable growth in network research and diverse methodological approaches, it is time to take stock of the security network literature in the form of a systematic review that provides directions for future research.

This article aims to clarify the fundamental concepts associated with a network perspective and assess the current state of empirical knowledge on security networks. We argue that current security network research has many limitations. For example, different uses of the concept of network have generated confusion about how network theory should be applied across the security field. A large volume of research employs the network concept as a metaphor to suggest a relationship between a set of security nodes but fails to examine the structural pattern of these relationships or the organisational properties of security networks. Much of the literature focuses on partnerships, which we take to include dyads (two actors), whereas our definition of network, commensurate with leading approaches in organisational (Kilduff and Tsai 2003) and public administration research (Provan and Kenis 2008), is based on groups (three or more actors). We suggest that the network concept only ceases to be employed as a metaphor when researchers focus on actual security networks and can identify their structural and relational properties, which requires researchers to adopt an analytical or organisational network perspective. We therefore argue that in order to advance security network research, we need to develop our language and tools with which to analyse and understand security networks.

The article is organised in three sections. First, we outline the context and method of our systematic review of the security network literature, which uses two main categories: network terminology and network form. Our objective is to highlight the different ways in which security networks have 
been studied and to call for greater consistency in these approaches, particularly by drawing on leading network research in other disciplines. The second section uses our assessment of the security network literature to revisit Dupont's (2004) typology of security networks. We review the geographical and functional features of this typology to provide guidance for further research on specific types of security networks, their unique properties and dynamics. Drawing on the inter-organisational network literature (Popp et al. 2014), we call attention to four types of networks that we believe have much relevance across the security field: information exchange networks, knowledge generating networks, problem-solving networks and coordination networks. We present these ideal-types as a heuristic device with which to develop the language of security network research. In particular, we hope that these network types will assist future research move beyond the metaphorical use of the network concept by bringing into focus certain features of different networks. Third, we map out a research agenda that addresses our requirements for more consistent network terminology and approaches as well as specific gaps in knowledge. We focus on both the methodological approaches used to study networks and the types of security networks that have been studied. Due to space constraints, we will not address the specific algorithms and mathematical techniques that can be used to study networks (Borgatti et al. 2013). The article concludes by highlighting the importance of furthering our knowledge of networks in order to better understand the governance of security.

\section{A systematic review of the security networks literature}

\section{Context and methods}

The network mode of organisation, with its promises of a less hierarchical, more empowered, innovative and productive world, has captured the imagination of social theorists, who conceptualised it as the natural by-product of the rise of technical and computer networks (Powell 1990, Castells 1996, 2000, Jones et al. 1997, Castells and Cardoso 2005, Latour 2005, Benkler 2006, Rainie and Wellman 2012). In the criminology and policing literature, this larger narrative is reflected in the growing realisation that the myth of the state's hegemonic control over the authorisation and delivery of security should be replaced by acknowledgment of more diffuse arrangements involving a broad range of private and hybrid organisations undertaking policing functions (Jones and Newburn 1998, 2006, Loader 1999, Bayley and Shearing 2001, Johnston and Shearing 2003, Wood and Dupont 2006, Ayling et al. 2009, Brodeur 2010, Schuilenburg 2015). Although the network terminology had occasionally been used to describe these expanding security arrangements, discussions remained largely metaphorical until the publication of Dupont's (2004) programmatic paper in Policing and Society.

That article, which took note of the recent advances made by social network analysts to understand complex social phenomena (Wasserman and Galaskiewicz 1994, Watts 2003), defined security networks as 'a set of institutional, organisational, communal or individual agents or nodes that are interconnected in order to authorise and/or provide security to the benefit of internal or external stakeholders' (Dupont 2004, p. 78) and then provided a typology of existing security networks (local, institutional, international, informational). Dupont leverages Bourdieu's (1986) seminal notion of five forms of capital to illuminate how security nodes navigate complex sets of relationships to achieve desired individual and collective outcomes. He then calls for the development of a 'common conceptual platform to interpret the complexification of security provision across a whole spectrum of configurations' that could bridge the gap between state-centric and pluralist views of security (Dupont 2004, p. 87). The article argues that two areas of empirical research should be prioritised: generating a pool of case studies that examine the core features of security networks in a broad range of national and local contexts; and assessing the dynamic impact of these configurations on security outcomes. Using the analytical tools usually applied to 'dark' networks (Raab and Milward 2003) - a term that refers to both illicit and covert networks that depend heavily on trust relations to maintain their cohesion but also rely heavily on coercion and physical force for management and conflict resolution - a growing number of policing scholars started to explore security as an interactive process involving a complex web of institutional actors. 
The security network approach has, however, always been more a diffuse sensibility than a hard paradigm. Rather than drawing from a single source of inspiration, Dupont's (2004) article reflected shifting social science and public policy landscapes that facilitated a match between a complex problem (fragmenting security) and new theoretical and methodological tools. More than 10 years after its publication, it seems relevant to assess the literature on security networks and its contribution to our understanding of contemporary policing. In particular, we believe it is important to look at what types of security networks have been studied, whether a consistent terminology been employed, what methods have been used, what types of data have been collected, and which research gaps and opportunities should become the focus of our attention.

To answer these questions as systematically as possible, we conducted an extensive search of three major bibliographic databases (criminal justice abstracts, sociological abstracts and social sciences full text) for articles published in the last 12 years that used the terms 'policing' and/or 'security', 'networks' and/or 'partnerships' or variations in journal titles, abstracts or key words. Our initial search, conducted during the second half of 2015, found over 500 academic articles, which we then categorised manually. First, we excluded articles that focused exclusively on dark networks as well as those that dealt with networks only superficially. A more difficult - and not entirely satisfactory - decision was to set aside a large proportion of the works on partnerships because, although some large partnerships operate as networks and are studied as such, most research on the subject emphasises the nature and quality of bilateral ties (or dyads). We considered only contributions focusing on groups (three or more actors). We also included only a limited number of contributions from the third-party policing literature. This strategy focuses on a vast network of guardian institutions that can be coerced by the police to prevent disorder (Buerger and Green Mazerolle 1998). Even when a more cooperative view of third-party policing is outlined (Mazerolle and Ransley 2006), the analysis is often primarily concerned with the police role and effectiveness in instrumentalising potential partners, laws and regulations and less interested in the underlying structure and dynamics of the thirdparty policing network as a whole.

We ended up with 117 journal articles, books and book chapters that form the basis of this review. Articles were then coded using a template that extracted relevant details across eighteen categories listed in Table 1, which include definition, type and size of network under analysis, geographical scope, security issues addressed, nature of ties, performance assessment and accountability. We concentrate on three key aspects: network terminology, methodological approaches and the forms of networks under analysis. In each of these categories we find considerable disparities among researchers, suggesting that a shared approach would offer significant benefits for security network research.

Table 1. List of categories used to code the 117 articles in our sample.

\begin{tabular}{ll}
\hline Category & \\
\hline Source information & Author(s) \\
& Date of publication (range: 2004-2015) \\
& Title \\
Definition used & Focus: network (56\%); partnership (26\%); other (18\%) \\
& Full text of definition extracted (53 definitions) \\
Theoretical & Prominent author(s) cited \\
framework & Focus on network as goal-directed (35\%); emergent (23\%); metaphor (37\%); other (5\%) \\
Methodology & Source(s) of data \\
& Number of network nodes analysed (range: 3-103) \\
& Type of analysis: quantitative (4\%); qualitative (79\%); mixed methods (16\%) \\
Geography & Country location (24 different countries) \\
& Scope: subnational 61\%; national (21\%); international (14\%); various (4\%) \\
Institutional sectors & Nodes: public (19\%); private (0\%); hybrid (81\%) \\
Security issues & General policing/urban security/terrorism/transport security/cyber-crime/etc. (see Table 2 for details) \\
Nature of ties & Informal (6\%); formal (7\%); both (87\%) \\
Assessment & Effectiveness of security networks (2 studies attempted to quantitatively measure network effectiveness or \\
& impact) \\
& Accountability mechanisms \\
& Recommendations for future studies \\
\hline
\end{tabular}




\section{Network terminology: defining networks, nodes and ties}

Networks consist of nodes and ties. Nodes, or actors, can represent individuals, groups, organisations, or any other entity. Ties, or relationships, are what connect the nodes. These ties can indicate communication between nodes, such as advice and information exchange, but they can also reflect more substantive transactions, such as resource pooling. Relationships may be either formal, based on legal, contractual, or some other kind of organisational arrangement, or informal, depending essentially on the strength of interpersonal trust and relationships. In defining networks and nodes, boundaries play an important role and must be explicitly delimited to avoid endless - and potentially meaningless - webs of connections. Confusing interpretations about the nature of nodes can also result from insufficiently well-defined boundaries. For example, large nodes - such as Interpol or Europol - can become networks in their own right when they reach a certain level of complexity. At the other end of the spectrum, particular individuals can play key roles in institutional networks, especially when these individuals broker relationships across organisational boundaries. There is no perfect solution to this methodological dilemma, but to avoid confusion authors should clearly define nodes and ties in security network research. Although a majority of the literature highlights the horizontal or egalitarian features of networks over their internal, potentially hierarchical tensions, significant variation in node capacity and power imbalances means that there will invariably be unequal relations in certain networks. In some contexts, such as in the organisational and public management literature, the concept of network has a much more precise meaning. For example, in one of the most influential papers in the field, Provan and Kenis (2008, p. 232) define a network as 'groups of three or more legally autonomous organisations that work together to achieve not only their own goals but also a collective goal'.

The network concept is used in three principal ways. The first - and most common - is as a metaphor, where a loose use of network terminology suggests some kind of self-organising relationships between a given set of nodes that operate in fragmented, fluid and complex environments (Knox et al. 2006). The use of the network term moves beyond a metaphor when researchers describe and analyse such factors as which actors comprise the particular network under analysis, the nature of the relationships between actors and how that network operates.

The second use relates to network analysis. SNA is a set of formal analytical tools widely used across the social and behavioural sciences (Wasserman and Faust 1994, Freeman 2004, Borgatti et al. 2013). While network analysis has been used extensively in relation to dark networks (e.g. Morselli 2009, 2014, Bouchard 2015), very few have applied it to 'bright' networks - those that are both licit and apparently more 'visible' - in the field of policing and security (Dupont 2006, Brewer 2014, Nøkleberg 2016). The limited number of empirical studies that apply the SNA toolbox to security issues reflects the methodological challenges associated with this approach. That is, contrary to dark networks, where data sets are more easily collected online or may be obtained from law enforcement or intelligence agencies, and bright networks in other fields such as public administration and management, mapping security networks usually requires high degrees of trust to broker access to respondents and thus significant resources at the data collection stage.

The third use refers to networks as a particular logic of organisation or governance. Such research largely reflects developments in organisation science and public administration (Jones et al. 1997, Provan and Kenis 2008, Popp et al. 2014, Molin and Masella 2016), where the network concept is used to refer to organisational configurations in which organisations constitute nodes and various formal exchange relations constitute ties. Whether a unique form of social organisation or a hybrid between hierarchies and markets (Powell 1990), networks are increasingly being used as platforms for organisations to work together to achieve their own goals and also shared goals. Networks often form as an attempt to address so-called 'wicked problems' (Rittel and Webber 1973), or those problems that cannot be formulated easily or divided into simple pieces that can be allocated to independent organisations, because they rely on often contradictory professional and political judgments for resolution (O'Toole 2007). Network forms of governance have been examined 
across the security field in the context of actual security networks, where case studies have for example been conducted on business improvement districts (Sleiman and Lippert 2010), international police cooperation mechanisms (van Buuren 2012), or national security arrangements (Whelan 2012), to name a few. Very few scholars have drawn on the management literature to raise questions about the organisational properties of security networks (e.g. Whelan 2012, Giacomantonio 2014).

Our findings reveal that the metaphorical use of the term 'network' accounts for a significant share of the literature $-37 \%$ of the contributions we analysed. For example, researchers have drawn on the concept of network to identify security apparatuses where a diversity of actors interact on a regular basis to prevent street crime or fight terrorism (e.g. Brodeur and Dupont 2006, Crawford 2006, Bures 2013). Network, then, is used to suggest that relationships exist between a given set of actors that cooperate to achieve a common end. Researchers have concentrated much less on actual networks and very few have undertaken a comprehensive analysis of a 'whole' network (Provan et al. 2007). Many of these studies make limited use of the broader network literature.

The more empirically oriented papers adopt a goal-directed approach of networks (40\%) or, to a lesser degree, an emergent approach (23\%), a classical distinction in management studies (Kilduff and Tsai 2003). The goal-directed category includes studies on entities that recognise themselves as networks (e.g. Cherney et al. 2006, Palmer and Whelan 2006, Groenendaal and Helsloot 2015), work together to achieve their own goals as well as a broader collective goal, and have boundaries that are already well delimited by members themselves. These networks may employ a core-periphery design (Kilduff and Tsai 2003), where members of the core share an interest in the general goals of a particular network while other members reside on the periphery and come in and out of the core as the need arises in relation to a specific, often temporary, goal. This configuration would, for example, apply to an anti-money-laundering network where the core would consist of key law enforcement, regulatory and intelligence agencies, while the periphery would be made up of banks' internal security units and various private intelligence providers whose expertise would be mobilised in an ad hoc manner for specific cases. The emergent category focuses on communities of actors that often develop serendipitously and can be examined through a network lens but are not necessarily aware that they are embedded in a unified web of ties (e.g. Dupont 2006, Bénit-Gbaffou 2008, Levi and Williams 2013). Research projects on such emergent security networks require significant data collection efforts as researchers must identify relevant organisational actors in various fields of practice and then design methodologies that can capture sprawling relational patterns.

When we broke the terminology down even further, although all the documents comprising our database refer extensively to the network concept, only a little more than half (56\%) actually focus on networks in one of the three specific ways outlined above, while $26 \%$ of the papers are more accurately described as focusing on partnerships - most notably the dynamics of relationships between public and private stakeholders. Contributions that use a partnership lens tend to rely on a more normative approach, examining the benefits and challenges of collaboration or, in some instances, its perils (e.g. Jameson and Strudwick 2009, Desmond and Valdez 2012, Cook 2013). The remainder (18\%) evoke the language of network and/or partnership in the context of broader conceptual frameworks such as community policing (e.g. Baker 2009, Marks et al. 2009), third-party policing (e.g. Ransley and Mazerolle 2009, Drew 2011), governance of security (e.g. Fleming et al. 2006, Friesendorf 2007), plural policing (e.g. McCahill 2008, O'Reilly 2015) and police work (e.g. Cotter 2015).

The prevalence of studies with a goal-directed or metaphoric view of security networks as well as the blurred boundaries between security networks and partnerships or related concepts explain why qualitative methods such as interviews, focus groups, observations, life histories, document analysis and literature reviews dominated the methodological landscape $-80 \%$ of reviewed papers. Studies that relied exclusively on quantitative approaches such as surveys accounted for only $4 \%$ of our sample, while mixed methods were used in $16 \%$ of studies. This result is hardly surprising, as the systematic collection of quantitative data is a time-consuming task that entails much larger costs and efforts than the more focused node-centric approach allowed by qualitative methods. Reviews of 
the management literature have made a similar observation, noting that many studies approach networks from the perspective of one single focal organisation (what network analysis calls an 'ego network') rather than studying the network as a whole (Provan et al. 2007). We suggest mixed methods is a promising compromise for capturing rich and complementary data the node and network levels (Creswell 2014). This approach can enable researchers to both map security networks and their ties as well as more fully appreciate their underlying organisational dynamics.

\section{Network forms}

Beyond a review of epistemic approaches, we were also interested in understanding what types of networks have been studied. We focus on their geographical location and scope, their institutional make-up, the nature of ties under study, and the security issues addressed. The aim was to identify patterns that could suggest whether the network form tends to fit best with specific domains or regions as well as to locate notable clusters or gaps in the literature.

From an operational perspective, the level of diversity is extensive. Research has been conducted on networks delivering security in fields as diverse as, for example, urban security (e.g. Huey 2008), counter-terrorism (e.g. Gill 2006, Palmer and Whelan 2014), general policing (a category that focuses on basic policing tasks rather than on a particular geographical setting; e.g. Roberts and Roberts 2009), cyber-crime (e.g. Nhan and Huey 2008), high policing (e.g. O'Reilly and Ellison 2006), organised crime (e.g. Bruns 2015) and transport security (e.g. Paes-Machado and Nascimento 2014). However, Table 2, which summarises the distribution of papers across security issues, reflects the prominence of two themes that account for more than half of the sample. Urban security probably owes its first place to the more easily observable nature of the web of uniformed security providers, surveillance technologies and crime prevention strategies in modern cities, while counterterrorism has come to be firmly anchored in the isomorphic belief that it takes a network to fight a network (Dupont 2015). Research on natural candidates for security network case studies such as emergency management, transport security, organised crime policing, or cyber-crime policing can be conducted only when researchers have significant resources and privileged access, which likely explains why it remains sporadic.

The institutional makeup of the security networks studied in our sample overwhelmingly favoured hybrid relationships between public, private and community stakeholders (81\%), with a residual $19 \%$ dealing with exclusively public security networks. Not a single contribution studied a security network

Table 2. Distribution of the security issues dealt with by 117 security networks studied.

\begin{tabular}{lcc}
\hline Issue & Number & $\%$ \\
\hline Urban security & 46 & 39.32 \\
Counter-terrorism & 16 & 13.68 \\
General policing & 13 & 11.11 \\
Cyber-crime & 7 & 5.98 \\
High policing & 4 & 3.42 \\
Transport & 4 & 3.42 \\
Organised crime & 4 & 3.42 \\
Mega-event & 4 & 3.42 \\
Drug control & 4 & 3.42 \\
Police socialisation & 2 & 1.71 \\
Campus security & 2 & 1.71 \\
Emergency management & 2 & 1.71 \\
Border security & 2 & 1.71 \\
Human trafficking & 1 & 0.85 \\
Resource extraction & 1 & 0.85 \\
Health & 1 & 0.85 \\
Rural security & 1 & 0.85 \\
Various & 3 & 2.56 \\
Total & 117 & 100 \\
\hline
\end{tabular}


made up of private actors. Even O'Reilly $(2010,2015)$, one of the few to study transnational security consultancies that epitomise the growing capacity of corporate actors to perform high policing tasks outside government, inevitably reminds us of the symbiotic ties these players maintain with state security and intelligence agencies.

A classic way to understand networks is through the distinction between 'formal' and 'informal' ties. Most papers in our sample (87\%) study both formal and informal ties, with $7 \%$ considering only formal and $6 \%$ only informal, but the inter-relationship between these types is rarely clearly identified. While informal ties often underpin formal networks, considerable work remains to be done to unpack the distinction between formal and informal ties and determine what distinguishes them and how they complement each other. For example, ties between two people from separate organisations ('boundary spanners') could have multiple functions - interpersonal and inter-organisational relationships, informal and formal - and it can be quite difficult to determine how one shapes another.

Dupont's (2004) typology devotes considerable attention to the geographical dimension of security networks, differentiating local, national and transnational configurations. Given the importance of the theme of urban security in this literature, it seems logical that subnational networks, which include local and regional groupings, account for $61 \%$ of the papers reviewed. An additional $21 \%$ were dedicated to national security networks and a more modest $14 \%$ focused on international networks. The empirical constraints created by arduous data collection procedures at the national and international levels may partly explain this distribution. In many instances, the categorisation process raised definitional challenges as, for example, when very local community policing networks are supported and funded by international organisations (e.g. Blaustein 2014). Finally, analysis of the countries of origin of the security networks studied (Table 3 ) illustrates that research in this area remains anchored in English-speaking social science communities, with a very strong presence of North American scholars. This situation may result from the fragmentation of security organisations caused by the highly decentralised US and Canadian federal systems and the proliferation of private security providers, which vastly outnumber public police officers in these two countries (Brodeur 2010), as both foster a greater need for networked coordination mechanisms. Other nations making cameo appearances include European countries (Greece and Norway), English-speaking African countries (Kenya, Liberia, Nigeria, Sierra Leone and Soudan), Latin-American countries (Argentina and Brazil) and Asian countries (China, India and Japan). The geographical coverage of this literature is unquestionably uneven and would certainly benefit from a more systematic research programme that would expand and diversify our empirical knowledge base.

\section{A revised typology of security networks}

We begin our review of questions about the dynamics, size and scope of networks by revisiting Dupont's (2004) typology of security networks, which concentrates largely on the geographical

Table 3. Countries of origin for the security networks studied.

\begin{tabular}{lrr}
\hline Country & $N^{\mathrm{a}}$ & \multicolumn{1}{c}{$\%$} \\
\hline US & 48 & 41.03 \\
Canada & 22 & 18.80 \\
UK & 18 & 15.38 \\
Australia & 18 & 15.38 \\
South Africa & 10 & 8.55 \\
The Netherlands & 7 & 5.98 \\
Ireland & 6 & 5.13 \\
France & 3 & 2.56 \\
Other & 30 & 25.64 \\
\hline
\end{tabular}

${ }^{a}$ Certain studies examined networks operating in more than one country. The sum of countries of origin is therefore larger than 117 and percentages are greater than 100 . 
parameters in which networks operate and on membership across public, private and hybrid sectors. Dupont identified four ideal-types of formal security networks: local, institutional, international and virtual. While local and international security networks can clearly be distinguished in geographical scope, they also differ in terms of goals, nature of ties and dynamics. For example, local networks are directed toward local security problems and therefore almost always include public and private actors as well as physical ties. International security networks focus on cross-border security problems, are more likely to be state-based - with only a few including private actors - and to depend more on virtual ties.

The remaining two network types are not necessarily geographically focused but rather are defined more in terms of their functional or operational characteristics. Institutional security networks are referred to as those networks in which the explicit purpose is 'the facilitation of inter-institutional bureaucratic projects or the pooling of resources across government agencies' (Dupont 2004 , p. 80). Such networks are exclusively state-based in terms of membership and are largely national in terms of scope. Examples include crime and security intelligence fusion centres (Monahan and Palmer 2009, Ratcliffe and Walden 2010, Chermak et al. 2013). Dupont initially suggested that institutional networks were mostly designed to maximise efficiency, but it is now recognised that some are intended to increase effectiveness, such as attempting to address complex or wicked problems. Virtual security networks are the technological systems that facilitate the communication and exchange of data and information between security nodes. Examples of these include the various intra- and inter-organisational databases that are designed to process data, information and intelligence between security actors. There are literally thousands of those systems and databases in operation in North America, Europe, Australasia and the rest of the world, across the field of policing and security.

While these four ideal-types are not exclusively geographically focused, they can be combined with our findings from the review of security network literature to create a revised typology, as summarised in Table 4.

Table 4 summarises some of the different features of security networks at the subnational, national and transnational levels. While it was helpful originally to categorise virtual networks as a distinct ideal-type, the prominence of technological systems in security networks at all levels suggests it is more useful to concentrate on the nature of network ties than to see virtual networks as a separate category. Many, if not most, security networks will involve both physical and virtual ties, especially if they are more formal and enduring in nature. Dupont's (2004) institutional security networks are replaced by networks operating at the national level, which provides flexibility for when non-state actors are permitted or required (as the case may be) to enter these particular security networks. Examples of this include telecommunications companies and financial institutions, which are playing increasing roles in combatting organised crime and terrorism (Michaels 2008, Amicelle 2011), and technology firms that are central players in cyber security (Dupont 2016).

We have extended the table to include key questions about network goals, membership, ties and dynamics to emphasise some of the important differences between networks with regard to modus operandi and particular structural and relational dynamics. We have also called attention to different capacities and constraints. For example, information classification requirements are unlikely to come into play at the local level whereas they almost certainly will, to varying degrees, in national and transnational security networks. As such, in order to better appreciate the membership and dynamics of security networks, we also need to consider where each network sits along the low-high policing continuum (Brodeur 2010). It is also important to recognise that leadership within networks may display various tensions.

This brings us to the limitations of a geographical-based typology of security networks. For instance, it was often assumed that a network's mode of exchange moves from the local to the international, through the national. Many local security actors have formed direct networks with their equivalents in other jurisdictions to share capabilities, development and training programmes, for 
Table 4. Networks across the security field.

\begin{tabular}{|c|c|c|c|c|}
\hline $\begin{array}{l}\text { Network } \\
\text { scope }\end{array}$ & Network goals & Network membership & Network ties & Network dynamics \\
\hline Subnational & $\begin{array}{l}\text { Local crime and security } \\
\text { problems within } \\
\text { defined territorial or } \\
\text { jurisdictional } \\
\text { boundaries } \\
\text { Networks are typically } \\
\text { goal-oriented but } \\
\text { these goals may only } \\
\text { be loosely stated }\end{array}$ & $\begin{array}{l}\text { Membership is usually } \\
\text { open to public and } \\
\text { private security nodes } \\
\text { Limited security } \\
\text { classification } \\
\text { constraints restricting } \\
\text { membership }\end{array}$ & $\begin{array}{l}\text { Ties are usually physical as } \\
\text { in structured meetings, } \\
\text { with support of some } \\
\text { virtual systems } \\
\text { Informal ties play a } \\
\text { prominent role due to } \\
\text { physical and } \\
\text { institutional proximity }\end{array}$ & $\begin{array}{l}\text { Leadership can shift } \\
\text { between public and } \\
\text { private actors although } \\
\text { local police will often } \\
\text { adopt central positions } \\
\text { Relationships largely } \\
\text { shaped by individual } \\
\text { members on an } \\
\text { interpersonal basis }\end{array}$ \\
\hline National & $\begin{array}{l}\text { National crime and } \\
\text { security problems, or } \\
\text { those crossing intra- } \\
\text { national borders. } \\
\text { These include (but are } \\
\text { not limited to) } \\
\text { organised crime, drug } \\
\text { trafficking and } \\
\text { terrorism } \\
\text { Networks are largely } \\
\text { goal-oriented with } \\
\text { articulated objectives } \\
\text { and often outcome- } \\
\text { focused }\end{array}$ & $\begin{array}{l}\text { Membership is usually } \\
\text { limited to public } \\
\text { security nodes, with } \\
\text { private actors involved } \\
\text { on the periphery on a } \\
\text { case-by-case basis, } \\
\text { mainly as a source of } \\
\text { intelligence } \\
\text { Medium to high } \\
\text { security classification } \\
\text { constraints restrict } \\
\text { membership and mode } \\
\text { of operations }\end{array}$ & $\begin{array}{l}\text { Ties are both physical and } \\
\text { virtual in nature, } \\
\text { including structured } \\
\text { meetings, liaisons, } \\
\text { fusion centres and } \\
\text { intelligence databases }\end{array}$ & $\begin{array}{l}\text { Leadership can be a source } \\
\text { of tension as security } \\
\text { nodes often consider } \\
\text { themselves to be equals } \\
\text { and wield significant } \\
\text { political influence } \\
\text { Relationships shaped by } \\
\text { inter-organisational and } \\
\text { interpersonal dynamics }\end{array}$ \\
\hline Transnational & $\begin{array}{l}\text { Transnational crime and } \\
\text { security problems or } \\
\text { those crossing national } \\
\text { borders } \\
\text { Networks are goal- } \\
\text { oriented with } \\
\text { articulated objectives } \\
\text { and strict modes of } \\
\text { governance }\end{array}$ & $\begin{array}{l}\text { Membership includes } \\
\text { supranational and } \\
\text { public security nodes } \\
\text { with private actors } \\
\text { involved on the } \\
\text { periphery on a case-by- } \\
\text { case basis, especially } \\
\text { when they display } \\
\text { unique forms of } \\
\text { technical expertise } \\
\text { High security } \\
\text { classification } \\
\text { constraints restrict } \\
\text { membership and mode } \\
\text { of operations }\end{array}$ & $\begin{array}{l}\text { Ties are both physical and } \\
\text { virtual, but more often } \\
\text { facilitated by liaisons } \\
\text { and information and } \\
\text { communication systems }\end{array}$ & $\begin{array}{l}\text { Leadership can vary } \\
\text { between lead-country or } \\
\text { lead-organisation } \\
\text { depending on the nature } \\
\text { of the task and network } \\
\text { Relationships shaped by } \\
\text { international and inter- } \\
\text { organisational dynamics }\end{array}$ \\
\hline
\end{tabular}

instance. Examples include knowledge sharing arrangements between host jurisdictions of megaevents (Boyle 2011) as well as owners and operators of critical infrastructure such as port security (Brewer 2014). More relevant to our objectives in this paper, a geographical typology does not do justice to the myriad of functions that networks may perform. To better acknowledge the complexities of security networks, we propose a functional typology that would allow us to be more flexible and less constrained when dealing with networks that simultaneously operate across various geographical scales. For example, when international organisations fund local security networks to enhance community safety or when national police services pool their resources with multinational corporations to take down an international cyber-crime ring, traditional geographical boundaries are blurred and seem less relevant than the functions that are being fulfilled. Although there are very few attempts to develop typologies of organisational networks, those that do exist are largely based on network goals and functions. In the field of public administration and management, Milward and Provan (2006) distinguish between four main types of networks - those involved with service implementation, information diffusion, problem-solving and community capacity building. Another approach differentiates between outreach, informational, developmental and action networks (McGuire 2006). Other more extensive reviews have identified up to 20 different network types, albeit with considerable overlap between them (Popp et al. 2014). While it must be emphasised 
that all security networks are potentially unique, with their own opportunities and constraints, it is still possible to distinguish some of the main functions performed by different networks.

We argue that four network types have considerable relevance across the security field and provide avenues for future research: information exchange networks, knowledge generating networks, problem-solving networks and coordination networks (see Table 5). Each of these forms can be identified at the subnational, national and transnational levels. Each of these types operates across the security field, with membership, nature of ties and dynamics varying in accordance with each network's specific goals and operational requirements. As with most typologies, there is overlap between the different forms and none is mutually exclusive. It is important to recognise as well that networks can have multiple functions. For example, all networks involve information sharing but in some instances this may be the primary goal in and of itself, while in other instances information is shared in order to achieve a particular purpose, such as generating knowledge, solving problems, or coordinating roles and responsibilities among organisations. A network that starts out as an information exchange may become a problem-solving network. These network types can therefore reasonably be expected to function in different ways and have potentially very different criteria for determining success.

Ultimately, distinguishing between different types of networks is useful only if it helps bring into focus the underlying purpose behind any particular network, which enables researchers and practitioners to better understand and analyse how networks form and function - both in a descriptive and prescriptive capacity. It is in this context that we present this typology here, particularly as a means of potentially sharpening the focus of future research on security networks. At present, much more security network research has concentrated on information sharing networks and, to a lesser extent, coordination networks than knowledge and problem-solving networks. However, as the remainder of this paper will show, we suggest all four types would benefit from further research.

\section{A research agenda on security networks}

Our review highlighted several areas that we believe require further attention by scholars who adopt a security network approach. In putting forward these suggestions we are sensitive to the various critiques of the network perspective in other contexts. For example, Dowding (2001, p. 89), in a paper critical of the policy network framework, expresses his scepticism about some of the findings in this literature, which in his view 'merely demonstrate what most of us would intuitively believe from more casual, nonformal observation'. His aim is not to discard network analysis but to remind the reader that this expensive and time-consuming methodology needs to be used discerningly to demonstrate how particular forms of organisation influence practices and policy outcomes, and to help explicate the nature of governance (Dowding 2001, p. 103). Other critiques in the organisational and management literature have argued that, although there is compelling

Table 5. Security network type and functions.

\begin{tabular}{|c|c|}
\hline Network type & Network function \\
\hline $\begin{array}{l}\text { Information exchange } \\
\text { networks }\end{array}$ & $\begin{array}{l}\text { Facilitate the sharing of information across intra- and inter-organisational boundaries. Examples } \\
\text { include automated police systems and crime intelligence databases }\end{array}$ \\
\hline $\begin{array}{l}\text { Knowledge generating } \\
\text { networks }\end{array}$ & $\begin{array}{l}\text { Generate new knowledge (understood as processed information enabling decision-making) and to } \\
\text { distribute this knowledge between organisations. Examples can best be identified in relation to } \\
\text { organised crime and terrorism threat assessments. Evidence-based policing networks that seek to } \\
\text { identify and disseminate best-practices also belong to this category }\end{array}$ \\
\hline Problem-solving networks & $\begin{array}{l}\text { Develop responses to complex or 'wicked' problems that cannot be addressed by organisations } \\
\text { acting alone. Examples include local security networks focusing on crime prevention initiatives to } \\
\text { reduce gang violence (Boston's Operation Ceasefire, for example) or third-party policing } \\
\text { interventions to improve quality of life }\end{array}$ \\
\hline Coordination networks & $\begin{array}{l}\text { Coordinate joint responses and service delivery across organisational boundaries. Examples can } \\
\text { include joint police taskforces as well as can be identified in the field of disaster and emergency } \\
\text { management }\end{array}$ \\
\hline
\end{tabular}


evidence that networks matter (Brass et al. 2004), researchers need to continue working to advance network theories of organisational behaviour, especially if we are to properly understand their normative aspects (Galaskiewicz 2007). We now aim to provide directions around the use of the network concept and method in the security network literature, and then identify pressing areas for further research on networks across the security field.

Research on security networks would benefit greatly from increased clarity and consistency in the use of the network concept. Much of literature reviewed adopts the network term as simply a metaphor to denote some kind of relationship, or set of relationships, between any given set of security actors. Actors or nodes and the nature of these relationships or ties are rarely explicitly defined. This is not the case in many other disciplines such as organisation and management studies, where a sophisticated literature has developed on various forms of networks. To advance the security network approach, we need to move beyond the metaphorical use of the concept and develop rigorous language to deal with specific types of networks and the ways nodes are networked. Some of the network language from other disciplines has great potential to assist with this task. For example, Kilduff and Tsai's (2003) distinction between goal-directed and emergent or serendipitous networks offers much promise to help distinguish between broad categories of networks and to determine how networks form and function. In defining goal-directed networks, we suggest that security network scholars follow the existing network literature (e.g. Provan and Kenis 2008) by defining networks as groups of three or more actors that work together to achieve independent and shared goals. Emergent networks, by contrast, follow a serendipitous trajectory that capitalises on opportunity and may rapidly change. The types of networks proposed above - information exchange, knowledge generating, problem-solving and coordination - also provide tools for differentiating between network types based largely on their goals and purpose.

To move away from the metaphorical use of the network term and address these research questions, scholars must adopt an appropriate methodological position. SNA clearly holds much promise as it enables researchers to map the relationships between a given set of actors and then apply various mathematical techniques to determine the nature of these relationships for individual actors as well as whole networks (Borgatti et al. 2013). Network analysis can be employed in virtually all circumstances to advance our knowledge of how networks function. With goal-directed networks, especially where membership is relatively stable, methods such as SNA can be used to describe and analyse the structural and relational properties of networks, which can then be juxtaposed against the network's stated goals. This is particularly useful for information sharing networks for example, where SNA is able to identify potential gaps or blockages in the flow of information. Even in serendipitous network types, SNA is useful for explaining how networks form and function at a specified point in time. Such an approach poses many methodological challenges - collecting relational data can be difficult in many security environments (Brodeur and Dupont 2006) and determining a network's boundaries is one of the main challenges with both dark and bright networks (Burcher and Whelan 2015) - but, as mentioned above, there are ways to address problems with data collection and adopting clear boundary specification rules can keep network studies to a workable level. We lack the space in this article to detail the actual methods that may be deployed to apply formal SNA techniques to security networks - and their strengths and limitations - but a growing number of manuals tailored to the particular needs and research questions of various disciplines provide excellent introductions (Wasserman and Faust 1994, Knoke and Yang 2008, Borgatti et al. 2013, Scott 2017).

Another approach is to draw more on the organisational or network governance literature that has flourished in fields such as public administration and management (e.g. Popp et al. 2014, Hu et al. 2015). This literature provides further concepts and tools to examine important network questions, particularly the factors shaping the effectiveness of networks and techniques for promoting their accountability (Kenis and Provan 2009). This approach is ideal for the remaining network types here - particularly knowledge sharing and problem-solving networks - as it is difficult to properly assess how these networks function and to what extent they achieve their goals via methods such 
as SNA alone. Examining such networks requires researchers to 'look inside their operations' (Agranoff 2006, p. 56), which is an invaluable way to improve security network research. As other recent reviews of network research have found (Kapucu et al. 2014), however, mixedmethods research designs are highly likely to have the most potential for advancing security network research. Researchers can leverage the quantitative techniques of network analysis contextualised within a qualitative framework concerning the type of network under analysis, its specific goals and dynamics.

Once issues around terminology and methodology are addressed, there are many research questions worthy of further analysis. Due to space constraints, we limit our focus here to three observations. First, we need more research on specific security networks in various contexts, including countries - the vast majority of the literature is focused on North America - and across the lowhigh policing continuum. Such research is necessary to develop a body of literature that is sufficient for comparative research as well providing a knowledge base that will make it possible to understand and analyse the effects of culture, history and particular institutional configurations on networks (Brass et al. 2004). Second, further research should concentrate on the structural and relational properties of security networks and how these interact. Structural properties include attributes such as the design, size and level of goal consensus between network members (Provan and Kenis 2008). Relational properties refer to the relationships between actors within networks, including the potential for conflict and different levels and kinds of commitment among actors (Meyer and Mazerolle 2014, Whelan 2016, 2017). These properties interact continually, shaping network dynamics and the attributes of individual actors. Understanding these complex dynamics would help us better evaluate the evolution of a security network over time. Third, we need to move beyond purely descriptive accounts and develop more advanced ways of assessing the effectiveness and performance of security networks, using networks as both independent and dependent variables. Researchers should concentrate on what makes security networks effective and what causes them to fail (Yar 2011), not only as independent units of analysis but in relation to community or society expectations of what specific types of networks should and should not do. If we accept that networks are central to security governance, such a task is crucial to promoting security.

\section{Conclusion}

This article has provided a systematic review of the security network literature over the last decade to assess the state of such research since the publication of Dupont's (2004) initial programmatic paper on security networks. We focused on the types of security networks that have been studied, the terminology and methods employed to study them, and opportunities for further research. Noting the inconsistencies in terminology across the security network literature, we have argued strongly for a more exact and meticulous use of the network concept. We hope that limiting the network concept to groups, emphasising the distinction between goal-directed and emergent or serendipitous networks, and taking into account the different network types and functions put forward in this article will assist in this task. While it is unfortunately beyond the scope of this paper to develop this typology any further, we suggest that distinguishing between these four network types provide useful avenues to think about further research on specific security networks. By drawing on the analytical and organisational methodologies, we also hope that research will focus on the precise ways in which security nodes are networked and the structural and relational dynamics of these actual (rather than metaphorical) networks. This task is undoubtedly best achieved using mixed-methods approaches, but we recognise that this is not an easy process for many researchers. It is certainly possible, however, as the wider social and organisational network literature demonstrates. If there is a final conclusion, it is that there is compelling evidence across the security field that networks have become as important as hierarchies and markets. However, much more methodologically rigorous work is needed in a variety of contexts to advance our knowledge of how security networks form and function. 


\section{Acknowledgements}

The authors would like to thank Emily Maddocks for her outstanding research assistance, as well as the participants to the Seventh Annual Illicit Networks Workshop, Peter Manning, James Sheptycki and Jennifer Wood, and the anonymous reviewers, for their helpful feedback on an earlier version of this article.

\section{Disclosure statement}

No potential conflict of interest was reported by the authors.

\section{References}

Agranoff, R., 2006. Inside collaborative networks: ten lessons for public managers. Public administration review, 66 (1), $56-$ 65.

Amicelle, A., 2011. Towards a 'new' political anatomy of financial surveillance. Security dialogue, 42 (2), 161-178.

Ayling, J., Grabosky, P., and Shearing, C., 2009. Lengthening the arm of the law: enhancing police resources in the twenty-first century. Cambridge: Cambridge University Press.

Baker, B., 2009. A policing partnership for post-war Africa? Lessons from Liberia and Souther Soudan. Policing and society, 19 (4), 372-389.

Bayley, D. and Shearing, C., 2001. The new structure of policing: description, conceptualization, and research agenda. Washington, DC: National Institute of Justice.

Benkler, Y., 2006. The wealth of networks: how social production transforms markets and freedom. New Haven, CT: Yale University Press.

Blaustein, J., 2014. The space between: negotiating the contours of nodal security governance through 'Safer Communities' in Bosnia-Herzegovina. Policing and society, 24 (1), 44-62.

Bénit-Gbaffou, C., 2008. Unbundled security services and urban fragmentation in post-apartheid Johannesburg. Geoforum, 39 (6), 1933-1950.

Borgatti, S., Everett, M., and Johnson, J. 2013. Analyzing social networks. London: Sage.

Bouchard, M., ed., 2015. Advances in research on illicit networks. New York: Routledge.

Bourdieu, P., 1986. The forms of capital. In: J. Richardson, ed. Handbook of theory and research for the sociology of education. New York: Greenwood Press, 241-258.

Boyle, P., 2011. Knowledge networks: mega-events and security expertise. In: C. Bennett and K. Haggerty, eds. Security games: surveillance and control at mega-events. Hoboken: Routledge, 169-184.

Brass, D., et al., 2004. Taking stock of networks and organizations: a multilevel perspective. Academy of management journal, 47 (6), 795-817.

Brewer, R., 2014. Policing the waterfront: networks, partnerships and the governance of port security. Oxford: Oxford University Press.

Brodeur, J.-P., 2010. The policing web. Oxford: Oxford University Press.

Brodeur, J.-P. and Dupont, B., 2006. Knowledge workers or "knowledge" workers? Policing and society, 16 (1), 7-26.

Bruns, M. A network approach to organized crime by the Dutch public sector. Police practice and research, 16 (2), $161-174$.

Buerger, M. and Green Mazerolle, L., 1998. Third-party policing: a theoretical analysis of an emerging trend. Justice quarterly, 15 (2), 301-327.

Burcher, M. and Whelan, C., 2015. Social network analysis and small group 'dark' networks: an analysis of the London bombers and the problem of 'fuzzy' boundaries. Global crime, 16 (2), 104-122.

Bures, O., 2013. Public-private partnerships in the fight against terrorism? Crime, law and social change, 60 (4), $429-455$.

Castells, M., 1996. The information age: economy, society and culture, Vol. 1: the rise of the network society. Cambridge: Blackwell.

Castells, M., 2000. Material for an exploratory theory of the network society. British journal of sociology, 51 (1), 5-24.

Castells, M. and Cardoso, G., eds., 2005. The network society: from knowledge to policy. Washington, DC: Johns Hopkins Center for Transatlantic Relations.

Chermak, S., et al., 2013. Law enforcement's information sharing infrastructure: a national assessment. Police quarterly, 16 (2), 211-244.

Cherney, A., O'Reilly, J., and Grabosky, P. 2006. Networks and meta-regulation: strategies aimed at governing illicit synthetic drugs. Policing and society, 16 (4), 370-385.

Cook, l., 2013. Policing, partnerships, and profits: the operations of business improvement districts and town center management schemes in England. Urban geography, 31 (4), 453-478.

Cotter, R., 2015. Police intelligence: connecting-the-dots in a network society. Policing and society, 27 (2), $173-187$.

Crawford, A., 2006. Networked governance and the post-regulatory state? Steering, rowing and anchoring the provision of policing and security. Theoretical criminology, 10 (4), 449-479.

Creswell, J., 2014. Research design: qualitative, quantitative and mixed methods approaches. Thousand Oaks, CA: Sage. 
Desmond, M. and Valdez, N., 2012. Unpolicing the urban poor: consequences of third-party policing for inner-city women. American sociological review, 78 (1), 117-141.

Dowding, K., 2001. There must be end to confusion: policy networks, intellectual fatigue, and the need for political science methods courses in British universities. Political studies, 49 (1), 89-105.

Drew, J., 2011. Police responses to the Methamphetamine problem: an analysis of the organizational and regulatory context. Police quarterly, 14 (2), 99-123.

Dupont, B., 2004. Security in the age of networks. Policing and society, 14 (1), 76-91.

Dupont, B., 2006. Delivering security through networks: surveying the relational landscape of security managers in an urban setting. Crime, law and social change, 45 (3), 165-184.

Dupont, B., 2014. Private security regimes: conceptualizing the forces that shape the private delivery of security. Theoretical criminology, 18 (3), 263-281.

Dupont, B., 2015. Security networks and counter-terrorism: a reflection on the limits of adversarial isomorphism. $\mathrm{In}$ : M. Bouchard, ed. Social networks, terrorism and counter-terrorism. New York: Routledge, 155-174.

Dupont, B., 2016. Bots, cops and corporations: on the limits of enforcements and the promise of polycentric regulation and as way to control large-scale cybercrime. Crime, law and social change, 67 (1), 97-116.

Fleming, J., Marks, M., and Wood, J. 2006. 'Standing on the inside looking out': the significance of police unions in networks of police governance. The Australian and New Zealand journal of criminology, 39 (1), 71-89.

Freeman, L., 2004. The development of social network analysis: a study in the sociology of science. Vancouver: Empirical Press.

Friesendorf, C., 2007. Pathologies of security governance: efforts against human trafficking in Europe. Security dialogue, 38 (3), 379-402.

Galaskiewicz, J., 2007. Has a network theory of organizational behavior lived up to its promises? Management and organization review, 3 (1), 1-18.

Giacomantonio, C., 2014. A typology of police organizational boundaries. Policing and society, 24 (5), 545-565.

Gill, P., 2006. Not just joining the dots but crossing the borders and bridging the voids: constructing security networks after 11 September 2001. Policing and society, 16 (1), 27-49.

Grabosky, P., 1995. Using non-governmental resources to foster regulatory compliance. Governance: an international journal of policy and administration, 8 (4), 527-550.

Groenendaal, J. and Helsloot, I., 2015. Toward more insight into the tension between policy and practice regarding the police network function of community police officers in the Netherlands. Police journal: theory, practice and principles, 88 (1), 34-50.

Hu, Q., Khosa, S., and Kapucu, N., 2015. The intellectual structure of empirical network research in public administration. Journal of public administration research and theory, 26 (4), 593-612.

Huey, L., 2008. When it comes to violence in my place, I am the police!' Exploring the policing functions of service providers in Edinburgh's Cowgate and Grassmarket. Policing and society, 18 (3), 207-224.

Jameson, J. and Strudwick, K., 2009. Tensions in security partnerships: observations of a city CCTV system and its partners on the ground. Crime prevention and community safety, 11 (2), 90-103.

Johnston, L. and Shearing, C., 2003. Governing security: explorations in policing and justice. London: Routledge.

Jones, C., Hesterly, W., and Borgatti, S. 1997. A general theory of network governance: exchange conditions and social mechanisms. The academy of management review, 22 (4), 911-945.

Jones, T. and Newburn, T., 1998. Private security and public policing. Oxford: Clarendon Press.

Jones, T. and Newburn, T., eds., 2006. Plural policing: a comparative perspective. London: Routledge.

Kapucu, N., Hu, Q., and Khosa, S. 2014. The state of network research in public administration. Administration and Society (online first 6 November 2014).

Kenis, P. and Provan, K., 2009. Towards an exogenous theory of public network performance. Public administration, 87 (3), 440-456.

Kilduff, M. and Tsai, W., 2003. Social networks and organizations. London: Sage.

Knoke, D. and Yang, S., 2008. Social network analysis. 2nd ed. Thousand Oaks, CA: Sage.

Knox, H., Savage, M., and Harvey, P. 2006. Social networks and the study of relations: networks as method, metaphor and form. Economy and society, 35 (1), 113-140.

Latour, B., 2005. Reassembling the social: an introduction to actor-network-theory. Oxford: Oxford University Press.

Levi, M. and Williams, M., 2013. Multi-agency partnerships in cybercrime reduction: mapping the UK information assurance network cooperation space. Information management and computer security, 21 (5), 420-443.

Loader, I., 1999. Consumer culture and the commodification of policing and security. Sociology, 33 (2), 373-392.

Loader, I. and Walker, N., 2007. Civilizing security. Cambridge: Cambridge University Press.

Marks, M., Shearing, C., and Wood, J. 2009. Who should the police be? Finding a new narrative for community policing in South Africa. Police practice and research, 10 (2), 145-155.

Mazerolle, L. and Ransley, J., 2006. Third party policing. Cambridge: Cambridge University Press.

McCahill, M., 2008. Plural policing and CCTV surveillance. In: M. Deflem and J. Ulmer, eds. Surveillance and governance: crime control and beyond. Bingley: Emerald Group, 199-209. 
McGuire, M., 2006. Collaborative public management: assessing what we know and how we know it. Public administration review, 66 (1), 33-43.

Meyer, S. and Mazerolle, L., 2014. Police-led partnership responses to high risk youths and their families: challenges associated with forming successful and sustainable partnerships. Policing and society, 24 (2) 242-260.

Michaels, J.D., 2008. All the president's spies: private-public intelligence partnerships in the war on terror. California law review, 96 (4), 901-966.

Milward, H. and Provan, K., 2006. A manager's guide to choosing and using collaborative networks. Washington, DC: IBM Center for The Business of Government.

Molin, M.D. and Masella, C., 2016. From fragmentation to comprehensiveness in network governance. Public organization review, 16 (4), 493-508.

Monahan, T. and Palmer, N.A., 2009. The emerging politics of DHS fusion centers. Security dialogue, 40 (6): $617-636$.

Morselli, C., 2009. Inside criminal networks. New York: Springer.

Morselli, C., ed., 2014. Crime and networks. New York: Routledge.

Nhan, J, and Huey, L., 2008. Policing through nodes, clusters and bandwidth. In: S. Leman-Langlois, ed. Technocrime: Technology, crime and social control. Portland, OR: Willan Publishing, 66-87.

Nøkleberg, M., 2016. Security governance - an empirical analysis of the Norwegian context. Nordisk politiforskning, 3 (1), 53-82.

O'Reilly, C., 2010. The transnational security consultancy industry: a case of state-corporate symbiosis. Theoretical criminology, 14 (2), 183-210.

O'Reilly, C., 2015. The pluralization of high policing: convergence and divergence at the public-private interface. The British journal of criminology, 55 (4), 688-710.

O'Reilly, C. and Ellison, G., 2006. Eye spy private high: Re-conceptualizing high policing theory. British journal of criminology, 46 (4), 641-660.

O'Toole, L., 2007. Treating networks seriously: practical and research-based agendas in public administration. Public administration review, 57 (1), 45-52.

Paes-Machado, E. and Nascimento, A.M. 2014. Conducting danger: practices and nodal networks of security governance among taxi drivers. International journal of comparative \& applied criminal justice, 38 (1), 1-22.

Palmer, D. and Whelan, C., 2006. Counter-terrorism across the policing continuum. Police practice and research, 7 (5), $449-$ 465.

Palmer, D. and Whelan, C., 2014. Policing and networks in the field of counter terrorism. In: D. Das, A. Turk, and D. Lowe, eds. Examining political violence: studies of terrorism, counterterrorism, and internal war. Boca Raton, FL: CRC Press, 145166.

Popp, J., et al., 2014. Inter-organizational networks: a review of the literature to inform practice. Washington, DC: IBM Center for the Business of Government.

Powell, W., 1990. Neither market nor hierarchy: network forms of organization. Research in organizational behavior, 12, 295-336.

Provan, K., Fish, A., and Sydow, J. 2007. Interorganizational networks at the network level: a review of the empirical literature on whole networks. Journal of management, 33 (3), 479-516.

Provan, K. and Kenis, P., 2008. Modes of network governance: structure, management and effectiveness. Journal of public administration research and theory, 18 (2), 229-252.

Raab, J. and Milward, H., 2003. Dark networks as problems. Journal of public administration research and theory, 13 (4), 413-439.

Rainee, L. and Wellman, B., 2012. Networked: the new social operating system. Cambridge: MIT Press.

Ransley, J. and Mazerolle, L., 2009. Policing in an era of uncertainty. Police practice and research, 10 (4), 365-381.

Ratcliffe, J. H. and Walden, K., 2010. State police and the intelligence center: a study of intelligence flow to and from the street. IALEIA journal, 19 (1), 1-19.

Rittel, H. and Webber, M., 1973. Dilemmas in a general theory of planning. Policy sciences, 4 (2), 155-169.

Roberts, A. and Roberts, J. M., Jr., 2009. Impact of network ties on change in police agency practices. Policing, 32 (1), $38-55$.

Schuilenburg, M., 2015. The securitization of society: crime, risk and social order. New York: New York University Press.

Scott, J., 2017. Social network analysis: fourth edition. Thousand Oaks, CA: Sage.

Sleiman, M. and Lippert, R., 2010. Downtown ambassadors, police relations and 'clean and safe' security. Policing and society, 20 (3), 316-335.

van Buuren, J., 2012. Runaway bureaucracy? The European police chiefs task force. Policing: a journal of policing and practice, 6 (3), 281-290.

Wasserman, S. and Faust, K., 1994. Social network analysis: methods and applications. Cambridge: Cambridge University Press.

Wasserman, S. and Galaskiewicz, J., eds., 1994. Advances in social network analysis: research in the social and behavioral sciences. Thousand Oaks, CA: Sage.

Watts, D., 2003. Six degrees: the science of a connected age. New York: W. W. Norton.

Whelan, C., 2012. Networks and national security: dynamics, effectiveness and organisation. London: Routledge. 
Whelan, C., 2016. Informal social networks within and between organisations. Policing: An international journal of police strategies \& management, 39 (1), 145-158.

Whelan, C., 2017. Security networks and occupational culture: understanding culture within and between organisations. Policing and society, 17 (2), 113-135.

Wood ., J. and Dupont, B., eds., 2006. Democracy, society, and the governance of security. Cambridge: Cambridge University Press.

Yar, M., 2011. From the 'governance of security' to 'governance failure': refining the criminological agenda. Internet journal of criminology, 1-19. 


\section{Index}

Note: Page numbers in italics refer to figures Page numbers in bold refer to tables Page numbers followed by ' $n$ ' refer to notes

Abbotsford Police Foundation 26, 27, 29, 32 accountability $2-3,8,23,35,36 \mathrm{n} 11,40,50,59,70$, $75,76,93,101$; versus efficiency $86-7$ actors $1,3,6,40,44,57,74,85,91,94-8,101-2$ ad hoc instrumentalism 2-3, 76, 79, 86 Administration of Labour and Welfare Act (2006) 82 aerial surveillance units 49 austerity 22, 35; in public sector funding 70

behaviour change 2, 6; problem of 7; trying to deliver 14-16

Bittner, Egon 42

Bjelland, Heidi Fischer 2, 74

boundaries 1, 11, 39, 43, 77; between agencies 80; between communities of practice 59 ; crossing 55-72; between CS and police 26-7, 33-4; of information flow, bridging 84-5; information sharing and 51; between internal and external knowledge 50; intra- and inter-organisational 5; negotiations in multi-agency investigation 74-87; network's 101; organisations 23; of police fundraising 31; police reform across 16-18; proximity $78-9,86$; public-private 22,31 ; in safeguarding children context 55-72; spanning 21-35, 97; transgressing 31-4; see also organisational boundaries

boundary work, for organisational learning: conflict management 69-70; information and resources, exchanging $67-8$; mutual respect for difference 68-9; shared commitment and purpose 63-5; trust, relations of $65-7$

Bourdieu, P. 92

'bright' networks 94, 101

bureaucracies, networks and 59, 65

bureaucratic rationality 40

business intelligence see managerial and business intelligence

Butler-Sloss, E. 59, 60

Calgary Police Foundation 27, 29, 32

Canada, police foundations in 21-35
Canada Revenue Agency (CRA) 24

capital, forms of 92

Carriere, K. 25

child sexual exploitation (CSE) 60, 61, 62

children: abuse and neglect of 59-60; Leeds safeguarding 61-2; protection 55-6, 62, 64; safeguarding services for $55-71$; welfare of 60

Children Acts (1989 and 2004) 59, 60

Children's Social Work 61

Children's Trust Board 61

Climbié, Victoria: death of 60

co-location 58, 85; and cluster working 66 ; relative stability and 65-7

co-ordinated agencies 75-6; resources of 76

College of Policing 6, 9, 11

communication surveillance 79,83

communities of practice $56,58-9,65,66,68,69$

community intelligence 44, 45, 46, 49, 50

community response units (CRUs) 42, 44, 46, 50

COMPSTAT 8

confiscations $79,80,82-4,86$

conflict management 69-70, 71

coordination networks 100

counter-terrorism 96; intelligence 43, 45, 46; security network research 91

Crank, J.P. 8,11

Crawford, Adam 55

credit card fraud 78

'Crime is Toast' 26

Crime Stoppers (CS) 2, 22-3, 24-5; donations and expenditures 27-31; maintaining and transgressing boundaries $31-4$; origins and boundaries 26-7; previous research on 25-6; programs, in Canada 28; public funding 31; research procedures 26

criminal and administrative law, proximity boundary of 78-80

criminal evidence 43

criminal intelligence $43,44, \mathbf{4 5}, 47,49$

criminal justice $29,57,65$ 
cyber security 98

cybernetics 40

dark networks 92, 93; and bright networks 94

Delpeuch, T. 43

Delta Police Foundation 27, 29-30

division of labour, of police intelligence 39-51, 56

domain 58-9

donations 22; and expenditures 27-31, 35; and sponsorships 23

Douglas, Mary 65

Dowding, K. 100

Dupont, Benoît 1, 3, 90

Edmonton Police Foundation 27, 29

education $5,46,58,61$

efficiency $11,30,70,76,98$; accountability versus 86-7

'ego network' 96

emergency task force (ETF) 48

England 7, 40, 41, 47, 49; child protection in 55;

Children's Safeguarding Board in 63; Innovation

Programme 61-2; Police College 2; safeguarding children in 59-61; and Wales, stop and search powers by police in 5-6, 9-10, 17

Equality and Human Rights Commission (EHRC) 6, 9, 11,12

Ericson, R. 25

ethics, and communities of practice 59

Europe 40, 49

Europol 94

evidence: criminal 43, 64, 80-1; and intelligence 48, 50 ; in policing research 7

expenditures, donations and: police foundations and CS program 27-31

'fair and effective' searches 10, 13, 14, 16

Fleming, J. 63, 76

freedom of information (FOI): legislation 24; requests 2435

'front door' Safeguarding Hub 61, 66, 71

Frydll, K. 7

fundraising 27-31

'funnelling', problem of $23,33-4$

Giacomantonio, Chris 1-2, 5, 24, 39, 76, 85

Goddard, Dame Lowell 60

governance $22,25,50,61,91,94$; of insecurity 41 , 43 ; network forms of $94-5$; of security $41,51,57$, 74,102

Grabosky, P. 90

health 46, 55, 61, 62; and education services 59

Her Majesty's Inspectorate of Constabulary (HMIC), of West Yorkshire Police 62

Heraclitus 49

human trafficking $48,74,75,78,79$

Huxham, C. 57

implementation fidelity, maintaining 5-18

Indicia software 83,84 information 8, 34, 43, 44, 50, 98; access to 1 ; acquisition of intelligence and $41,45-6,51$; analysis of 41,45 ; about crime $23-5$; exchange networks 100; flow of $30,34,68,84-5$; and resources, exchanging $67-8$; sharing $2,47,51,60$, 61, 74-5, 81-2, 100

Innovation Programme (UK) 61-2

institutional change 8

institutional security networks 98

Integrated Safeguarding Unit 61

intelligence: activities, four aspects of 41,45 ; community 44, 45, 46, 49, 50; counter-terrorism $43,45,46$; criminal 43, 44, 45, 47, 49; database 83; managerial and business 44, 45, 46-9; multi-agency co-ordination $44,45,46,75-6$; organised crime and terrorism 43, 45, 46; and police security networks 40 ; public order 43,45 , 45-6, 47; serious organised crime 43, 45, 46; seven foci, of police knowledge work 43-5; see also police intelligence division-of-labour Intelligence Bureaus 48 inter-organisational policing 1,39, 63 international security networks 98 interpellation $51 \mathrm{n} 2$

Interpol 94

intra-organisational policing 1, 39

investigators 23, 25, 27, 33, 44, 81-5

IT systems $82-3$

Jancsics, D. 23

jurisdictions 47, 75, 78, 99; negotiating 86

Kenis, P. 94

Kilduff, M. 101

knowledge: access to information and 1,56; brokers 59, 68, 69, 71; generating networks 100; mastery of 58 ; sharing 84,99 ; transfer of 18

Labour and Welfare Administration 74, 75, 78-9, 82 Laming Report 60

Lave, J. 58

learning $2,57,69,71$; in communities of practice 58-9; and information sharing 68; objectives 14 , 14-15; see also boundary work, for organisational learning

Leeds $63,69,71$; safeguarding children in 61-2

L'Hoiry, Xavier 55

Lippert, Randy K. 1-2, 21

Litmanovitz, Yael 1-2, 5

local crime 42, 99

Local Safeguarding Children Boards (LSCBs) 60, 61 local security networks 98

London Police Association Charity Fund 36n6 loosely coupled systems 6 ; defining national vision 12-13; implementation fidelity in 5-18; making sense of institutional chain 11-16; national vision to force level 13-14; trying to deliver behaviour change 14-16

MacAleese, Greg 27, 36n5

Maguire, E.R. 11 
managerial and business intelligence 44, 45, 46-9

Manning, Peter K. 1, 8, 40-2

metaphor, network concept as $391,92,94,95,101$, 102

Metropolitan Police: Operation Yewtree 60

Milward, H. 99

Missing Persons Unit, in Leeds 61

money laundering 74, 78, 95

Moskos, Peter 41-2

multi-agency co-ordination intelligence $44,45,46$, 75-6

multi-agency organised crime investigation 74-87

mutual respect, for different types of contributions 68-9

national crime and security problems 99

national vision: defining 12-13; to force level 13-14

navigating organisational boundaries, problem of 7-8

networks: communities and 59; defining 94-6; forms $96-7$; across security field 99 ; types 99-100; see also security networks

New York City Police Foundation 26

nodes 40, 92, 94-6; governance and security network perspectives $90-1$; regulatory 86 ; in security networks 75,76

North America 22, 24, 27, 40, 41, 43, 102

Norway, multi-agency action in 2

Ofsted $60,62,71 \mathrm{n} 1$

Ontario: Police Services Act (1990) 22

Operation Wasp Nest 75

Operation Yewtree 60

O'Reilly, C. 97

organisational boundaries 76-7; in loosely coupled system 11; police reform across 16-18; policing across 1-3; problem of navigating 7-8; shared sense of commitment across 63

organisational cultures $2,57,63,71,91$

organised crime: investigators 81 ; multi-agency investigation 74-87; and terrorism intelligence $43,45,46,49,98$

Oslo District Court 74, 87n1

Ottawa Police Services Board policy 22

Partnership Vulnerability Unit 61

partnerships 21, 31, 56-9, 62-3, 67-8, 70-1, 74, 76, $86,91,93$; security networks and 95

Parton, N. 61

police: challenge for 21-36; co-ordination 75, 76-7; and communities 6 ; culture 8 ; investigators 81 ; organisational change $56-8$; organisations of 1-2, 8, 11; reform 6-9, 16-18; see also Crime Stoppers (CS); specific entries

police foundations $2,22,23-4$; donations and expenditures 27-31; maintaining and transgressing boundaries 31-4; origins and boundaries 26-7; previous research on 25; research procedures 26 ; using corporate model, in Canada 28 police intelligence division-of-labour 39-51; discussion 49-51; four aspects of intelligence activities 45; grid analysis of 45 ; location and function of intelligence foci in 45-9; police divisionof-labour 41-3, 42; seven intelligence foci 43-5

police métier $2,8,40-51$

police organisational boundaries, typology of 76-7

police reform: behaviour change 7; implications, across organisational boundaries 16-18; institutional change 8 ; multiple problematics of 6-9; navigating organisational boundaries, problem of 7-8

Police Services Act (1990) 22

Policing and Society 92

'pooling powers' $76,78,86$

primary response units (PRUs) 41, 42, 45-6, 50

problem-solving networks 100

problem theory 7-8, 12-13, 15-17

professional secrecy $81-2$

programme theory $7-8,13,16$

protection 22, 48, 87; and safeguarding children $55-6,59-62$

Provan, K. 94, 99

proximity boundaries $7,78,79,86$

public order intelligence 43, 45-6, 45, 47

public police 42,97 ; and inter-organisational boundaries 21-36

Public Protection Unit, in Leeds 61

public-private boundaries $22,23,35$; transgressing 31-3

RCMP Foundation $24,36 \mathrm{n} 3$

reciprocity $65,66,67-8$

Reiner, Robert 40

relationships 41, 94-6; between actors/ organisations $6,8,31,57,58,63,65-7,68,76,69$, 82; between security nodes $90-103$

Renan, D. 76

Report of the inquiry into child abuse in Cleveland 1987 (Butler-Sloss) 59

'restorative practices', use of 61

Rhodes, R.A.W. 63, 70, 76

riot squads 48

Rittel, H.W.J. 56, 61

road traffic safety enforcement $46-7$

Ross, J.E. 43

Rutherford, A. 65

'sanction catalogue' 86

Saskatoon Police Service 24, 32-3

security networks $3,40,75,76,82,85,86,87-9$, 90-1, 98; context and methods $92-3$; countries of origin for 97 ; defined 92 ; four ideal-types of networks 98; geographical dimension 97; improving research, type and functions 100; issues 96; network forms 96-7; network terminology 94-6; networks across security field 99; nodes and ties in 75, 94; partnerships and 95; research agenda on 100-2; review of 92-7; revised typology of 97-100; sharing resources in 76 
sexual offences 48; against under-aged girls 60 shared knowledge 67, 84-5, 101

shell corporations, domestic 23, 29

Sheptycki, James 2, 39

Sklansky, D.A. 76

Skogan, W. 7

Social Care, children's 59

social network analysis (SNA) 91, 94, 101

South Peace Crime Prevention Association 36n10

special patrol group (SPG) 45,48

stop and search 5-6, 9-12, 15, 17

Targeted Services Leader, at Leeds City Council 61

Task Force on Policing 9

Tax Administration (TA) 74, 75, 78-9, 82

terrorism 43, 46, 50, 95, 98

ties 90, 93; formal and informal 97; network 99; and

nodes 94-6; physical and virtual 98; weak/strong

67 ; see also relationships

traffic policing 44,47

transnational security consultancies 97

trust $44,65-7,68,75,85,94$

Tsai, W. 101
UK see England

urban security $96-7$

Vancouver Police Foundation 27, 29, 31

Vangen, S. 57

Vestby, Annette 2, 74

virtual security networks 98

Walby, Kevin 1-2, 21

Wales, stop and search powers by police in $5-6$, 9-11, 17

Walters, C. 25, 32

Webber, M.J. 56, 61

Wenger, Etienne 56, 58-9, 69

West Yorkshire Police 61

Whelan, Chad 1, 3, 8, 90

Willis, J.J. 8

Woolf, Dame Fiona 60

work units 76-7, 85

Working Together 60

young people, services for $55-6,59-62$,

65,68 